\title{
Modeling operational forestry problems in central Appalachian hardwood forests
}

\author{
Yaoxiang Li \\ West Virginia University
}

Follow this and additional works at: https://researchrepository.wvu.edu/etd

\section{Recommended Citation}

$\mathrm{Li}$, Yaoxiang, "Modeling operational forestry problems in central Appalachian hardwood forests" (2005). Graduate Theses, Dissertations, and Problem Reports. 4166.

https://researchrepository.wvu.edu/etd/4166

This Dissertation is protected by copyright and/or related rights. It has been brought to you by the The Research Repository @ WVU with permission from the rights-holder(s). You are free to use this Dissertation in any way that is permitted by the copyright and related rights legislation that applies to your use. For other uses you must obtain permission from the rights-holder(s) directly, unless additional rights are indicated by a Creative Commons license in the record and/ or on the work itself. This Dissertation has been accepted for inclusion in WVU Graduate Theses, Dissertations, and Problem Reports collection by an authorized administrator of The Research Repository @ WVU.

For more information, please contact researchrepository@mail.wvu.edu. 


\title{
MODELING OPERATIONAL FORESTRY PROBLEMS IN CENTRAL APPALACHIAN HARDWOOD FORESTS
}

\author{
Yaoxiang Li
}

\begin{abstract}
Dissertation Submitted to the
Davis College of Agriculture, Forestry, and Consumer Sciences at West Virginia University in partial fulfillment of the requirements for the degree of
\end{abstract}

Doctor of Philosophy

in

Forest Resources Science

Jingxin Wang, Ph.D., Chair Joseph McNeel, Ph.D.

Pamela Edwards, Ph.D.

James P. Armstrong, Ph.D.

R. Bruce Anderson, Ph.D.

Division of Forestry

Morgantown, West Virginia

2005

Keywords: Timber harvesting, forest operations, modeling, simulation, stand generation, Appalachia hardwoods, traffic intensity, production analysis. 


\section{ABSTRACT \\ MODELING OPERATIONAL FORESTRY PROBLEMS IN CENTRAL APPALACHIAN HARDWOOD FORESTS}

\section{By Yaoxiang Li}

Because of the species diversity, varied site conditions and growth rates, it is really challenging to manage the central Appalachian hardwoods. Examining the harvesting techniques and interactions among stand, harvest, and machines is becoming a concern to the researchers in the region. A simulation system was developed to aid these efforts by estimating the productivity, cost, and traffic intensity of different harvesting configurations under a variety of harvesting prescriptions and stand conditions.

Stands used in the simulation were generated by using the stand generator that was validated by comparing the generated stands with the actual mapped stands statistically. Results indicated its validity and have shown that it can be used to visualize the stand structure and composition of hardwood stands and perform dynamic analyses of various management prescriptions.

Three harvesting systems of chainsaw (CS) /cable skidder (CD), feller-buncher (FB)/grapple skidder (GD), and harvester (HV)/forwarder (FW) were modeled and simulated on five generated stands of different ages in the study. Five harvest methods of clearcut, shelterwood cut, crop tree release cut, diameter limit cut, and selective cut were examined. Simulation results showed that felling production and cost were primarily affected by tree size removed, removal intensity, distance traveled between harvested trees, and felling machines. The feller-buncher was the most cost-effective and productive machine and harvester was more sensitive to individual tree size. Clearcutting 
always presented the highest productivity while the shelterwood cut was the least productive method. Unit cost of harvester was higher than that of feller-buncher or chainsaw. Extraction operation was sensitive to payload size, average extraction distance, bunch size, extraction pattern, and extraction machine. The forwarder was the most productive machine under the simulated extraction prescriptions. The cable skidder resulted in higher unit cost than that of grapple skidder or forwarder.

System productivity increased from chainsaw/cable skidder system to harvester/forwarder system, and to feller-buncher/grapple skidder system. The fellerbuncher/grapple skidder system could produce $28484 \mathrm{ft}^{3}$ or 177 thousand board feet (MBF) per week with a unit cost of $\$ 27$ per 100 cubit feet (cunit) or $\$ 44 / \mathrm{MBF}$. For chainsaw/cable skidder and harvester/forwarder systems, the weekly production rate was $12146 \mathrm{ft}^{3}$ (76 MBF) and $16714 \mathrm{ft}^{3}$ (104 MBF), with unit cost of $\$ 35 /$ cunit (\$57/MBF) and \$44/cunit (\$70 MBF), respectively.

TI3 and TI4 are the major concerns since they caused the most soil compaction. Harvester/forwarder system was associated with more unaffected areas while fellbuncher/grapple skidder system resulted in more affected areas. TI3 and TI4 level was $20 \%$ of the total area affected with harvester/forwarder, $23 \%$ with chainsaw/cable skidder system, and $44 \%$ with feller-buncher/grapple skidder system. A total of $49 \%$ of extraction site was recorded as TI3 and TI4 level for SP1, which was more than two times higher than that recorded for SP5. 


\section{ACKNOWLEDGEMENT}

I would like to give my heartfelt gratitude to my major professor, Dr. Jingxin Wang, for his unlimited input to this project. Without his valuable advice, great assistance and inspiration, this work can never be done. Deep gratitude and appreciation are expressed to my advisory committee members: Dr. Joseph McNeel, Dr. Pamela Edwards, Dr. James P. Armstrong, and Dr. R. Bruce Anderson for their consistent support and guidance during my three years of study at WVU.

I would like to thank Dr. Gary Miller of the USDA Forest Service for providing the stand data for model validation. I also want to extend my appreciation to Dr. John Brooks who offered much encouraging support throughout my education, and to Dr. Dave McGill for his valuable friendship.

Special thanks go to my husband, Lichun, for his unconditional love and consistent support, endless patience, and to my dearest daughter, Trina, for always being there to give her "Mommy" a big smile for support. 


\section{TABLE OF CONTENTS}

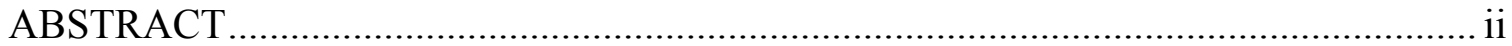

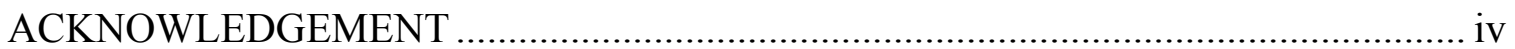

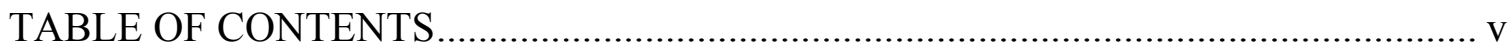

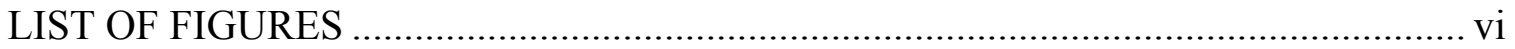

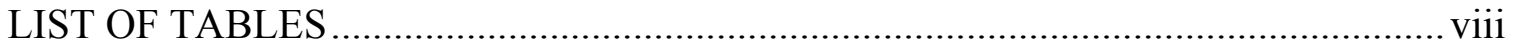

LIST OF SYMBOLS/NOMENCLATURE .............................................................. ix

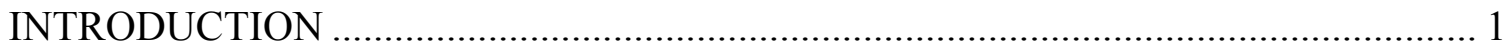

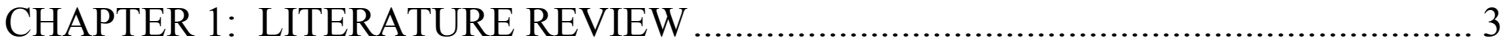

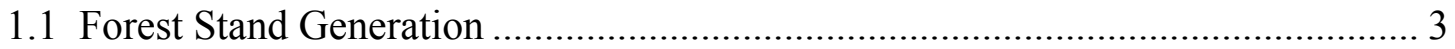

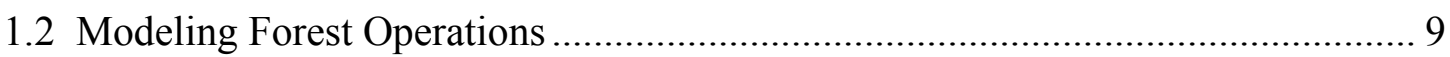

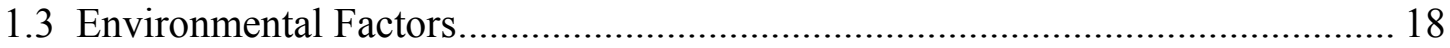

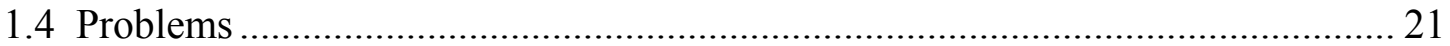

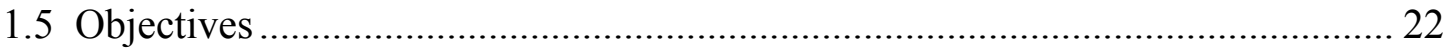

CHAPTER 2: DEVELOPMENT OF A 3D STAND GENERATOR …………….......... 24

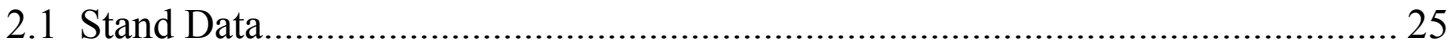

2.2 System Design and Implementation ........................................................... 26

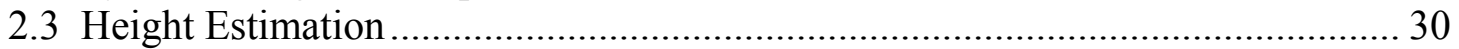

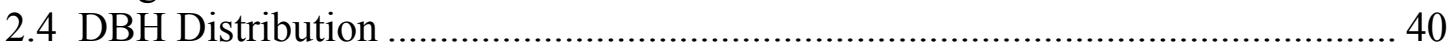

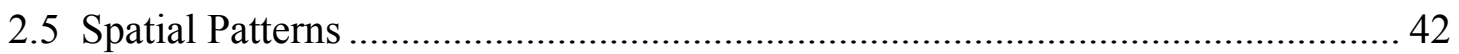

CHAPTER 3: SYSTEM MODELING OF HARVESTING OPERATIONS................... 56

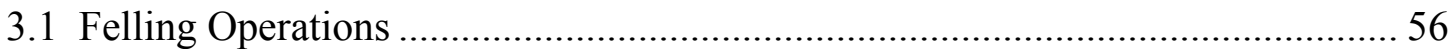

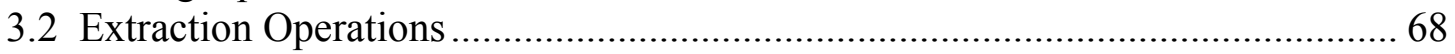

3.3 System Structure and Implementation............................................................ 72

3.4 Data Structure ............................................................................................ 75

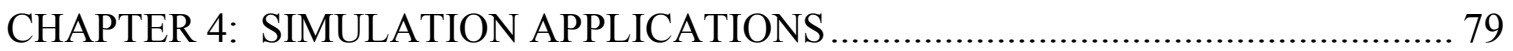

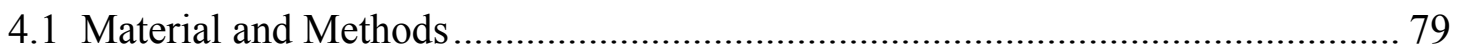

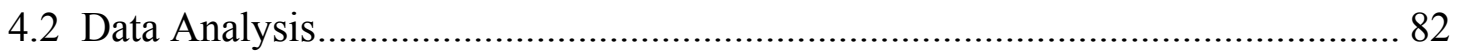

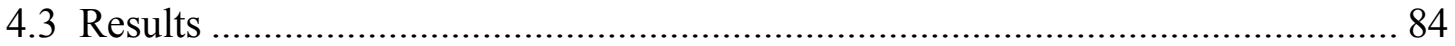

CHAPTER 5: CONCLUSIONS AND DISCUSSION .................................................... 101

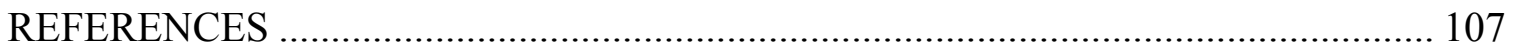

APPENDIX A: USER'S MANUAL FOR THE HARVESTING SIMULATOR ........... 115

A.1 System Requirements ........................................................................... 115

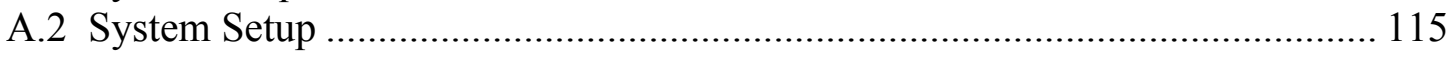

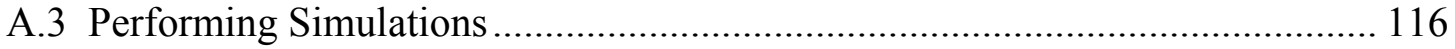

A.4 Simulation Results Analysis....................................................................... 132

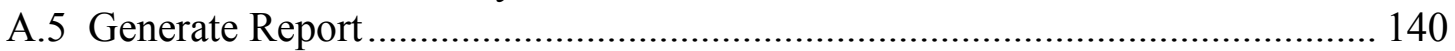




\section{LIST OF FIGURES}

Figure 2.1. Component object model of the stand generator........................................... 30

Figure 2.2. Total height vs. DBH or residuals for blue beech....................................... 33

Figure 2.3. Total height vs. DBH or residuals for black cherry ....................................... 33

Figure 2.4. Total height vs. DBH or residuals for northern red oak............................. 33

Figure 2.5. Total height vs. DBH or residuals for red maple...................................... 34

Figure 2.6. Total height vs. DBH or residuals for sassafras. ........................................... 34

Figure 2.7. Total height vs. DBH or residuals for yellow - poplar.................................. 34

Figure 2.8. Total height vs. DBH or residuals for Other Species................................... 35

Figure 2.9. Family curves for total height and merchantable height estimations............ 40

Figure 2.10. Modeling transformations. ......................................................................... 46

Figure 2.11. Flowchart of VB and VC components in the 3D stand generator system... 47

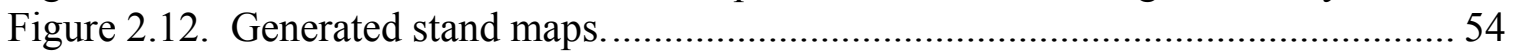

Figure 2.13. Perform forest operations. .................................................................... 55

Figure 3.1. Felling in herringbone pattern with the tops falling away from the skid road.

Figure 3.2. Flowchart of felling operations.

Figure 3.3. Algorithm of obstacle tree checking procedure for the feller-buncher. ......... 64

Figure 3.4. Algorithm for harvester checking obstacle trees.......................................... 65

Figure 3.5. Extraction patterns...........................................Error! Bookmark not defined.

Figure 3.6. Flowchart for extraction operations........................................................ 73

Figure 3.7. Components for the harvesting simulator................................................. 76

Figure 4.1. Felling hourly production. …………………..................................... 88

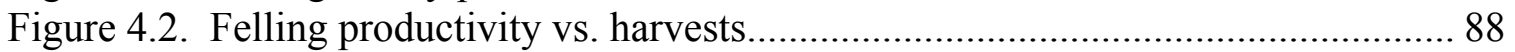

Figure 4.3. Average extraction distance vs. extraction patterns. .................................... 91

Figure 4.4. Extraction productivity vs. extraction patterns.............................................. 91

Figure 4.5. Productivity of extraction operations........................................................ 95

Figure 4.6. TI3 and TI4 levels vs. extraction machines and patterns. ........................... 95

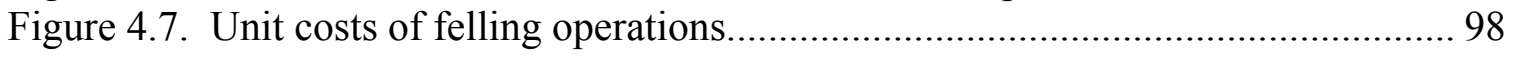

Figure 4.8. Unit costs of extraction operations.......................................................... 98

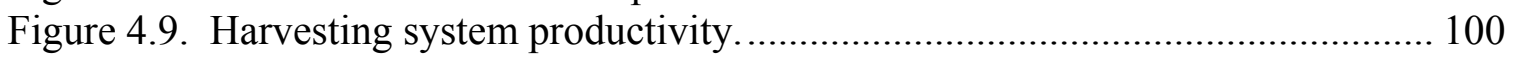

Figure 4.10. Harvesting system unit cost............................................................. 100

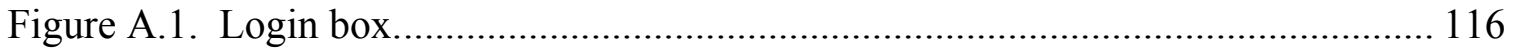

Figure A.2. MDI window of the harvesting simulator................................................ 117

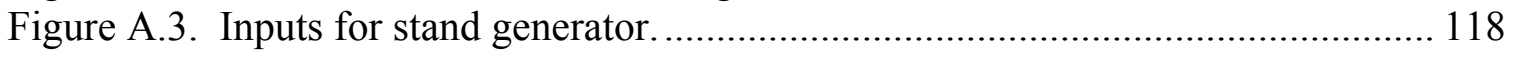

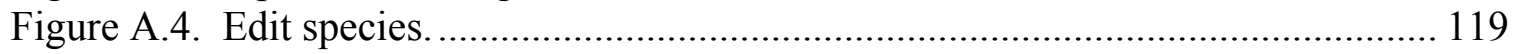

Figure A.5. Output of a generated stand............................................................. 121

Figure A.6. Inputs for felling simulation. ............................................................ 122

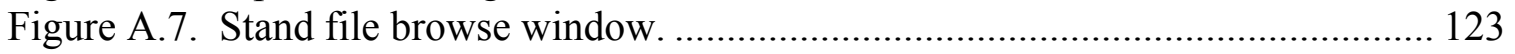

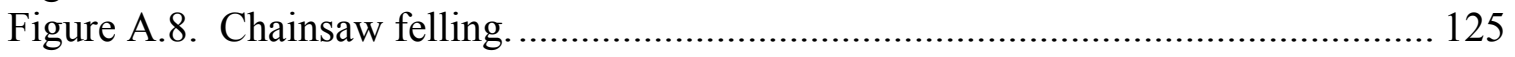

Figure A.9. Select marking rules. ..................................................................... 125

Figure A.10. Mark trees by mark...................................................................... 126

Figure A.11. Trees marked for felling.................................................................. 126 
Figure A.12. Chainsaw felling output in diameter limit cut. ................................. 127

Figure A.13. Feller-buncher felling output in selective cut.................................... 128

Figure A.14. Harvester felling in a crop tree release cut. .......................................... 128

Figure A.15. Inputs for extraction simulation......................................................... 129

Figure A.16. Cable skidding output with skidding pattern 4 (SP4) ............................ 132

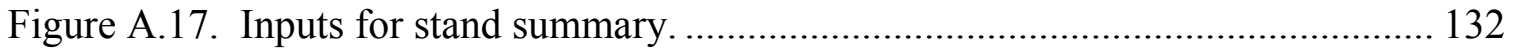

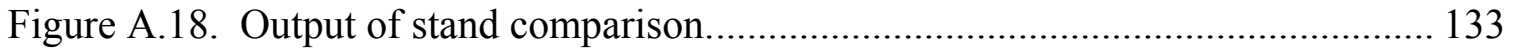

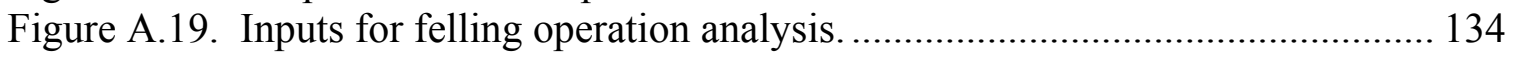

Figure A.20. Machine rate calculation..................................................................... 135

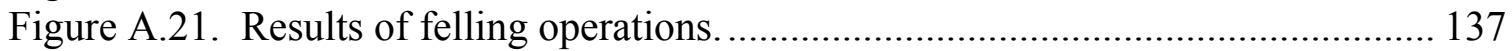

Figure A.22. Inputs for extraction operation analysis............................................. 138

Figure A.23. Analysis results for extraction operations. ........................................ 138

Figure A.24. Summary of travel intensity in a logging area of 36 acres after felling and extraction operations................................................................... 139

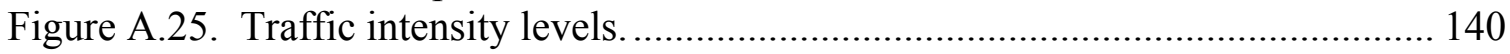

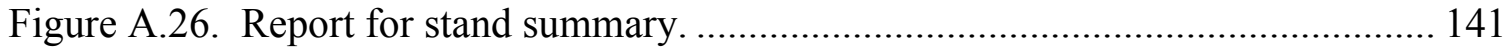

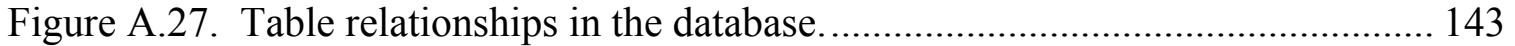

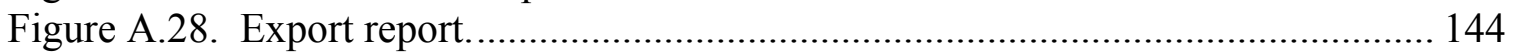

Figure A.29. Report exported in $\mathrm{html}$ format. .................................................... 144 


\section{LIST OF TABLES}

Table 2.1. Summary statistics of the datasets. .......................................................... 28

Table 2.2. Linear and non-linear DBH-height functions examined and fitted for major species on West Virginia University forest............................................. 32

Table 2.3. DBH-total height equations fitted for major species on the West Virginia University forest................................................................................. 32

Table 2.4. DBH-total/merchantable height family curves fitted for major species on West Virginia University forest.

Table 2.5. DBH-merchantable height functions fitted for major species on West Virginia

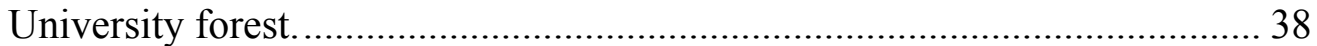

Table 2.6. DBH distribution for major species in the region....................................... 41

Table 2.7. Comparisons of characteristics between controlled and treated stand. .......... 51

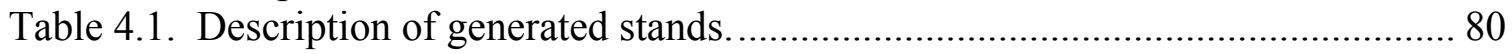

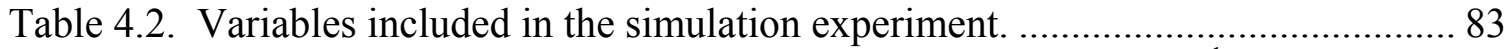

Table 4.3. Means and significance levels of felling simulation variables ${ }^{1}$...................... 86

Table 4.4. Cycle time and hourly production models for felling machines.....................87

Table 4.5. Means and significance levels of extraction simulation variables. ${ }^{1}$................ 90

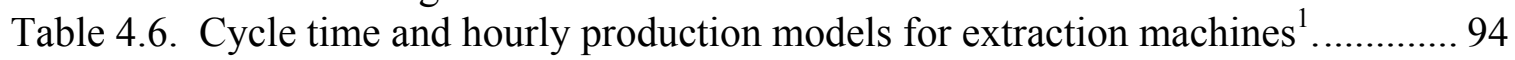

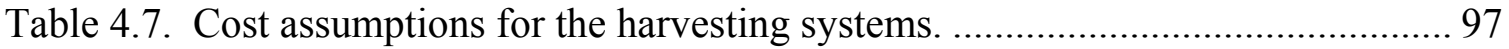

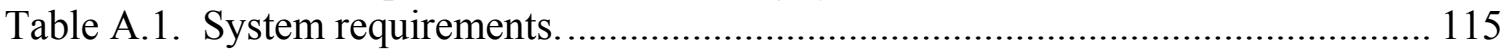




\section{LIST OF SYMBOLS/NOMENCLATURE}

\begin{tabular}{|c|c|}
\hline$C S$ & Chainsaw \\
\hline$F B$ & Feller-buncher \\
\hline$H V$ & Harvester \\
\hline$C D$ & Cable skidder \\
\hline$G D$ & Grapple skidder \\
\hline$F W$ & Forwarder \\
\hline$P M H$ & Productive machine hour \\
\hline$T I$ & Traffic intensity level \\
\hline$C C$ & Clearcut \\
\hline$C T$ & Crop tree release cut \\
\hline$D L$ & Diameter limit cut \\
\hline$S C$ & Selective cut \\
\hline$S W$ & Shelterwood cut \\
\hline$S P$ & Skidding pattern \\
\hline$F P$ & Forwarding pattern \\
\hline THT & Tree total height \\
\hline MHT & Tree merchantable height \\
\hline$C F V$ & Cubit feet volume \\
\hline TPA & Trees per acre \\
\hline BAPA & Basal area per acre \\
\hline CFVPA & Cubic feet volume per acre \\
\hline$D T$ & Distance traveled between harvested trees \\
\hline$R I$ & Removal intensity \\
\hline$A E D$ & Average extraction distance \\
\hline$P L$ & Payload \\
\hline$B Z$ & Bunch size \\
\hline
\end{tabular}




\section{INTRODUCTION}

Extending 235,000 square miles from New York to Georgia and from Virginia to Missouri, the central Appalachian hardwoods region harbors the most extensive concentration of the deciduous hardwoods in the world and represents a wide variety of tree species with different growth patterns and silvical characteristics (Hicks 1998). Many hardwoods in this region are approaching maturity. As harvests in the Pacific Northwest decline and timber prices rise, the maturing stands in this region are a rich and valuable resource that is increasingly vulnerable to exploration. Differences in species growth rates, site conditions, and values make managing the central Appalachian hardwoods even more complex (Smith 1981). Therefore, examining harvesting techniques and studying environmental impacts of timber harvesting in the central Appalachian area are becoming important to foresters, landowners, and the public.

In the central Appalachian region, steep and uneven topography contributes to some of the most difficult logging conditions (Egan 1999). Although helicopter and cable logging systems have been used in the region, ground-based systems using chainsaws and feller-bunchers for felling and skidders for extraction continue to predominate. Other systems, such as shovel logging also have emerged in this region. However, research on the interactions of stand conditions, machine attributes, harvest prescriptions, and associated environmental impacts are lacking.

Computer simulation has been successful at simulating harvesting operations due to its higher efficiency, flexibility and lower cost. It is sufficiently comprehensive to handle various types of problems envisioned in forest harvesting system (Stuart 1981). Experiments can be conducted with simulation models and a wide range of system 
configurations, operating environments, and timber utilization can be evaluated (Wang 1997) that would not be possible or cost effective with the actual harvesting system. Although timber harvesting has been studied widely by computer simulation (Winsauer 1986, Landford and Stokes 1995, Wang 1997, Aedo-Ortiz et. al. 1997), most of these efforts were focused on specific machine or harvesting system under different stand conditions.

The lack of information on the interactions of stand conditions, machine attributes and harvest prescriptions has resulted in management decisions being based on either experience or very limited field tests. However, sometimes the experience or field test do not work well because of the varied topography, site, and stand conditions in central Appalachia. Therefore, research is needed to model the harvesting operations performing a variety of partial cuts and extraction activities in the region and to objectively match systems, stands, and harvests. 


\section{CHAPTER 1: LITERATURE REVIEW}

\subsection{Forest Stand Generation}

Because of its convenience and higher efficiency, stand generation is used extensively in forest harvesting simulation models. In these models, hypothetical stands are generated based on user-supplied stand information. The two major advantages of stand generation are low costs and savings in time to obtain the data (Newnham and Maloley 1970).

Newnham (1968) reviewed most of the basic spatial distribution methods and developed a stand generator that incorporated many features of previous methodologies in which a Weibull distribution was used as the form for diameter at breast height (DBH) distributions of planted stands and the exponential function was used to characterize the reverse J - shaped DBH distributions for natural stands. A mathematical model, programmed in FORTRAN IV, was developed by Newnham and Maloley (1970) in which 2-dimensional forest stands could be generated, but no further testing was done to validate the model. Farrar (1981) developed an in situ 2-dimensional stand generator for use in harvesting machine simulators. To verify the stand generator, tree and stand characteristics created by the stand generator were compared to those of the trees in the parent forest model. In addition, productivity rates generated by machine simulator using the generated stand as its input were compared to those using the parent forest model.

Stand generation systems also are used commonly to simulate stand development and project tree growth. OAKSIM, an individual-tree growth and yield simulator, was developed for managed, even-aged, upland oak stands in the early of 
1980s (Hilt 1985). OAKSIM was written in FORTRAN and designed to evaluate stand management alternatives on a mainframe computer. Economic aspects of thinning, especially in hardwood stands, can be evaluated by OAKSIM.

The Stand and Tree Evaluation and Modeling System (STEMS) is one of the most commonly used models for projecting growth of timberland. It was developed to update large inventories of timber (Brand et al. 1987). STEMS was later became The Woodsmen's Ideal Growth projection System (TWIGS). TWIGS used the same prediction equations as STEMS, but was applied to analyze long-term management decisions. With TWIGS the user can simulate and evaluate a variety of management scenarios in terms of volume yield and economic return. Composed only of the growth and mortality models and coefficients used in STEMS and TWIGS, GROW was then developed. GROW can be integrated as a subroutine to perform more complex growth simulations. STEMS runs on a mainframe computer while TWIGS operates on a PC under MS DOS. Both STEMS and TWIGS analyze only one stand at a time. STEMS can regenerate the stand following clearcut or shelterwood cut while TWIGS can perform economic analysis, which is not available in STEMS. GROW requires the user to program output, input, and management routines. All of these programs were written in FORTRAN.

The Decision Tree System (DTREES), a menu driven shell program, was derived from STEMS and GROW programs and used to determine a harvest schedule. It also provides a list of alternative management routines for each forest stand by simulating management activities and responses (Pelkki and Rose 1988). Three components are included in the DTREES: a silvicultural expert system to make harvest prescriptions, the 
GROW subroutine to project tree lists, and a regeneration model to regenerate stands after harvests.

The California Conifer Timber Output Simulator (CACTOS) was an interactive computer program designed to simulate the growth and partial harvests of conifer forest stands in northern California (Meerschaert 1987). CACTOS allows the land manager to predict frequently occurring changes in young coniferous stand. For accurate projection with CACTOS, some detailed information has to be known for each individual tree (species, dbh, height-to-crown base or live crown ratio, and per acre expansion factor). The forest Stand Generator (STAG) was developed to estimate missing tree heights, height-to-crown base measurements, or both for use in CACTOS. Both CACTOS and STAG are written in FORTRAN and run in DOS. The Silviculture of Allegheny Hardwoods (SILVAH), first developed in 1985, also included a simulator to project stand growth and development (Marquis and Ernst 1992). Since then, several versions of SILVAH have been programmed for IBM compatible machines.

More recently, Oinas and Sikanen (2000) developed a stand generator that incorporated the cutting method as one of the parameters. Instead of focusing on stand development, their stand generator is customer-oriented. Basal area, DBH, and mean height were modeled by tree species and timber volumes. Timber assortments then were calculated based on these parameters. Three parameters Weibull distribution was used to depict the frequency distribution of the stands by area. Stand age was defined randomly so it was assumed to be uniformly distributed. They also found that the distribution of the basal area was approximately normal distribution. They added a Beta distribution to 
the model to depict the volume proportions of tree species. Using this stand generator, they developed a simulation model for timber procurement process.

Spatial distributions of trees in the stand must be described in a stand generator. Spatial patterns used for stand generators generally follow one of three patterns: random, uniform, or clustered.

In random pattern, each individual tree in the generated stand is independent of all others, and each tree is allocated randomly anywhere in the stand. Any tree is equally likely to occur at any one location, and there is no apparent order for tree locations. Therefore, the position of each newly generated tree is theoretically independent to any of the other trees previously generated.

Cottam et al. (1953) developed a random pattern stand generator by generating $(\mathrm{X}, \mathrm{Y})$ coordinates randomly and then assigning them to the individual trees. Each tree then was given diameter and height characteristics. This was a very early attempt of stand generation and a distance restriction was not considered. Newnham and Maloley (1970) noted that it is unrealistic for one tree to be completely independent of the others in stand generation because of the physical size of the trees. Therefore, a minimum spacing restriction should be imposed on the stand generator to get more realistic and representative stands.

For the uniform pattern, every point is as far from its neighbors as possible (producing regularly spaced points) and points are equidistant from each other. When the uniform pattern is used for the stand generator, all possible grids for tree locations are identified based on stand density and fixed intervals, so the stand density is uniformly 
distributed through the whole stand. This kind of distribution is used most frequently for even-aged stands.

Point features of the clustered pattern are concentrated on one or a few relatively small areas and form groups. The "clump centers" are allocated first, and then trees are clumped around these centers. Thus, unlike a uniform pattern, trees are evenly distributed among the cells in the tract. A method to generate clustered stands was described by Pielou (1957) based on Neyman Type A and Thomas Series Distributions. Two parameters were used: the cluster density, or mean number of cluster centers per quadrat, and the mean number of individuals per cluster. A disadvantage of the cluster area is that it is dependent on the number of individual trees in the cluster (Newnham 1968).

Many models were reported to depict DBH distribution. Nelson (1964) developed a model using gamma distribution to predict the $\mathrm{DBH}$ distribution of loblolly pine. Bliss and Reinker (1964) reported a log-normal approach to DBH distributions in even-aged stands. Clutter and Bennett (1965) used the beta function to depict the DBH distribution in old-field slash pine plantation.

Weibull functions have been used widely in diameter distributions (Fisher and Tippett 1927, Weibull 1951, Bailey and Dell 1973). A three-parameter Weibull distribution (location parameter, scale parameter, and shape parameter) is especially popular in depicting DBH distribution. Therefore, the estimation of the three parameters is of great importance and requires attention.

Many different methods were developed to estimate the parameters. Da Silva (1986) developed percentile prediction models and recovered the parameters of two- 
parameter Weibull distributions. Cohen and Whitten (1983) reported modified maximum likelihood and modified moment estimators for the three-parameter Weibull distribution. Shiver (1988) evaluated three methods (maximum likelihood estimation, modified moments estimation, and percentile estimation) for prediction of the three parameters for unthinned slashed pine plantation. Valentine et al. (2000) selected a cumulative Weibull distribution as the target distribution of DBH of a stand generator. Diameters are sampled from the target distribution and assigned to individual trees in the generated stand first, and then the diameter is recalculated based on height and crown length.

To model irregular DBH distributions, such as thinned stands or mixed stands, Cao and Burkhart (1984) developed a method joining different segments of modified Weibull cumulative distribution functions (cdf) together to form a single smooth cdf. They reported that the segment cdf was superior to Weibull distribution for thinned stands. Some studies reported the effects of interspecific competition on DBH distributions (Burkhart and Sprinz 1984, Steven and Knowe 1992) and Da Silva (1986) and Knowe et al. (1992) incorporated the effects in diameter distribution models and found that the model works well.

Van Deusen (1986) outlined horizontal point sampling (HPS) based diameter distribution and Gove (2000) further developed this theory. Johnson's SB distribution is another popular format used to describe DBH distributions. Newberry et al. (1993) evaluated eight distribution-free methods for estimating the quartiles in the process of modeling DBH distributions with either the Weibull or Johnson's SB distributions for even-aged Douglas-fir stands in the inland Northwest and concluded that two of the methods consistently gave the best results. 


\subsection{Modeling Forest Operations}

Dynamic modeling is the collective ability to understand the implications of change over time, and system simulation refers to the mimicking of the operation of a system in a computer. Compared to the analytical approach of analyzing a model, the simulation approach is more reliable and is more flexible and convenient. Simulation modeling provides an effective and powerful approach for capturing and analyzing complex systems (Harshman).

Simulation has proven to be a suitable research method for analyzing timber harvesting operations. Due to the inherent variability in harvesting system configurations, operating environments, and potential interactions among system components, it has been very challenging to model these systems. The attempts to capture the variability of timber harvesting operations in mathematical models have fueled a proliferation of diverse models, from regression models to stochastic process models and simulation models (Baumgras et al. 1993). Initially, using logical model to duplicate harvesting operations by computer simulation appeared to be the only feasible way (Webster 1975). Computer simulation models first were used for the evaluation of new forest machinery concepts in the 1960s (feller-bunchers, debarking machines and processors) and later were used as an aid for the analyses of single machinery and whole work systems (Stampfer and Henoch 1999).

Because simulation was an efficient, low cost method of exploring the intricacies of any machine system, it became a valuable asset in identifying weaknesses or oversights of harvesting systems (Hassler et al. 1985). Side-by-side comparisons could identify the differences of harvesting systems under similar stand and operation 
conditions (Lanford and Stokes 1995), whereas field studies are limited by the cost of replicating experiments over a variety of conditions. A field study can capture only a sample of the production rates that occur during the unique conditions of a given study (Aedo-Ortiz et al. 1997). One way to predict the system performance is to build a simulation model that can be run repeatedly with different equipment interactions and working conditions (LeDoux et al. 1994).

Many forest harvesting simulation models have been developed in North American during last four decades. Those models might be classified as either tree-tomill models or phase models (Wang et al. 1998). Tree-to-mill models focus on the entire harvesting process. Phase models evaluate only a certain phase or part of the harvesting process.

\section{Numerical Simulation}

Most of the models developed before 1980 were numerical simulations with deterministic character and the interface of a computer specialist was necessary in order to interpret the user's questions into a form permissible in the model and acceptable by the computer (Wang et al. 1998). Most of the inputs are based on empirical data, average values, regression equations, and parameters for theoretical probability distributions, and an extensive fieldwork is needed to obtain these data (Goulet et al. 1979). Goulet et al. (1979) reviewed eight forest harvesting simulation models with potential for simulating southern operations and they found there is no consensus on what constitutes a harvesting model's essential elements. 
Johnson et al. (1972) used computer simulation, written in GASP II, to analyze timber-harvesting systems. Two production functions (felling and skidding) and four material-handling operations (loading, hauling, bucking, and prebunching) were simulated. Model input includes terrain condition, geographical location of the site, system composition, and stand condition. Output is system production, time required, and cost.

Webster (1975) addressed the primary principles in simulating the harvesting system: the simulator should be flexible enough to duplicate major harvesting operations, detailed enough to allow for the analysis of individual harvesting operations, and believable enough in duplicating a system's operation. Based on these principles, an event-oriented, stochastic Forest Harvest Simulation Model (FHSM) was developed (Webster 1975, Killham 1975) to duplicate major harvesting operations and different machine types. It was specifically designed to model the southern operations. FHSM can simulate 10 timber harvesting configurations (6 for saw timber and 4 for pulpwood) comprised of felling, limbing, bucking at the stump, skidding, bucking at the landing, loading, hauling, and unloading. However, no economic analysis was included.

Harvesting System Simulator (HSS), a FORTRAN-based, time and eventoriented simulation program, was designed to simulate the productive and nonproductive activities of a harvesting system (O'Hearn et al. 1976, Goulet et al. 1979). HSS can be used to model differences in stand types, volume per acre, species composition, skidding distance, terrain variation, and wood flow. Terrain and stand limitations are modeled through move or travel rate modifiers and deck locations. It was the most complex model found at that time. 
A discrete-event, FORTRAN/GASP IV based, general logging simulation model - Simulation Applied to Logging Systems (SAPLOS) was introduced by Biller et al. (1973) and Fisher et al. (1980). It was adaptable to variety of logging configurations. The design identified five critical locations where logging operations can interact - stump, skid road, landing, prehaul deck, and processing point. The data inputs include cost and system configurations, tree characteristics, and stand conditions.

The Full-Tree Chipping and Transport Simulator (FCTS) was designed to simulate in-woods full-tree chipping (Bradley et al. 1976). The model simulates the activities of feller-bunchers, skidders, a chipper with loader, trucks and vans (in the field), and dumping and scaling at the mill, and the interactions among these elements. The stand to be harvested must be provided by the user in the form of $(\mathrm{x}, \mathrm{y})$ coordinate location of trees, volume of each tree in the stand, and felling order for the feller-buncher. The individual tree maintains its identity and characteristics from stump to mill. The simulator was written in GPSS/360. Input data included stand data, machine speed, and machine capacity.

A Residue for Power (REPO) simulation program was developed to evaluate logging residue handling system in which six operations were included: yarding, chipping, sorting, loading, transporting, and unloading (Bare et al. 1976). The model consists of three components of operations, stores, and decisions. Both productive and nonproductive times are simulated. The program was written in SIMCOMP, a compartmentoriented programming language. Input data are the probability distributions derived from field tests. Other inputs include number, type, and costs of operating equipment, labor cost, diameter range of the raw material, road distance, and slope limitations. REPO 
operates as a fixed time increment simulator and does not permit the model to track the occurrence of a machine breakdown within a given time period. However, the interactions between time periods are considered.

Stuart (1981) developed a numerical simulation system for modeling individual machine activities. The program defined the working area of the machine as swath of a certain width. The machine first moved to cut the tree in the swath with the smallest xcoordinate, then moved to the tree with next smallest x-coordinate.

A computer simulation model was reported to represent a tracked feller-buncher and to evaluate the performance of a feller-buncher for thinning operations (Winsauer 1980, Winsauer et al. 1986). It was written in GPSS (General Purpose Simulation Systems). The input includes stand density, DBH, row length, thinning treatments, and machine parameters such as shear rate, travel speed, and accumulator capacity. Output is the productivity of the machine simulated. Time study data were collected for the model validation and testing.

Randhawa and Scott (1996) developed a computer-based system for model generation in timber harvesting by using an automatic model generation methodology. By searching a set of databases containing information on available technology and its impacts on production efficiency and economics, environment, and safety, the system matches the user's needs to find the optimal solution to maximize the efficiency of the production operation. The harvesting environment is defined by three sets of variables: site, stand, and requirements. The generated model then is analyzed by using a simulation model LOGSIM (Randhawa and Olsen 1990a). An object-oriented 
framework is used to represent the database and user's description of the system and Smalltalk/V is used for computer implementation.

Aedo-Ortiz et al. (1997) developed a discrete-event simulation model of harvester-forwarder systems for thinning softwoods. The model tracks the flow of the material during the harvesting and processing steps, and special attention is focused on the effectiveness of using statistical distributions from field studies. Inputs to the model include statistical distributions and linear regression equations derived from field-study data. Output is the system productivity and elemental time. Due to lack of field data, interference delays and machine breakdowns were not included in the simulation.

Stampfer and Henoch (1999) developed a harvesting system simulator (HaSyS) used to analyze the operations of chainsaw, walking harvester, and tracked harvester in combination with cable systems. HaSyS is a systematic, goal orientated simulation used to evaluate steep terrain harvesting systems. The model consists of four components: stand generation, tree search, tree removal, and process. HaSyS was written under the object oriented programming environment with VisualWorks (Smalltalk). Model inputs include system, terrain, and stand variables. Machine productivity as well as a visual display of the process layouts is the output.

Barrett (2001) reported a log trucking system simulation (LTSS) model to simulate the harvesting and trucking system of wood delivery from the in-woods landing to the receiving mill based on availability of wood at the landing, production rates at the landing, and round trip delivery time. Model inputs include harvesting and trucking production and costs. Production inputs are stand size, landing capacity, number of trucks and truck payload, harvesting, merchandising, and loading rate, time schedules and 
some elemental times. Cost inputs include annual fixed harvesting cost, hourly

harvesting labor cost, variable cost per productive hours, days worked per year, and cost per day per truck. Model outputs consist of number of loads or tons of wood produced per day and the unit cost. The model was created using the systems modeling software Stella 6.0 .

By using systems dynamic simulation, two computer simulation models were developed (McDonagh 2002) to improve timber harvesting system management. The Harvest System Assignment (HSA) was developed to evaluate the impact of stand assignment on harvest system effectiveness, and four harvesting systems are included:

manual, mechanized, shovel, and cut-to-length. Terrain, tract, and system characteristics are used as input. The Machine Allocation (MA) focuses on the system design, which is used to study the machine combination and interactions. Three phases were modeled: felling, skidding, and processing, and up to five machines can be incorporated for the study in each phase. Both HAS and MA are written in STELLA 6.0.

\section{Interactive Simulation}

Interactive simulation involves more human participation. With the interactive simulation technique, considerable machine specific models are introduced to evaluate the machine performance and productivity. Fridley et al. $(1982,1985)$ used interactive simulation to study the design of swing-to-tree feller-bunchers for thinning. The program identifies the effect of various design parameters on feller-buncher performance during thinning. Geometric path simulation consists of four main components - operating strategy, geometric machine model, stand map and thinning prescription, and computer 
simulation algorithm. Five components are included in the operating time simulation stand data file, machine model description, path-description, computer simulation program, and graphical animation. The program uses graphical animation as a type of output for verification and evaluation purpose. Output includes path and production summaries.

An interactive computer-aided design of log processing facilities was reported by combining numerical simulation with graphical animation (Garbini et al. 1984). Numerical simulation was used to predict the precise position of all stems and logs and the instantaneous state of each component of the merchandiser, and the graphical animation was used for the merchandiser display that can quickly detect the design and modeling errors resulted from the numerical simulation only. The inputs consist of the characteristics of the raw material, output product requirements, component parameters, and the overall plant design. The simulation program is written in FORTRAN and executed on a host minicomputer.

Greene and Lanford $(1984,1986)$ developed an interactive simulation program for modeling feller-bunchers. Working with this simulation, Greene et al. (1987) concluded that variability between simulation operators exists but does not appear to affect the usefulness of interactive simulation. Block and Fridley (1990) reported a threedimensional, color, interactive, real-time, computer graphics simulation of a fellerbuncher. The software allows the programmer to vary physical parameters of the fellerbuncher that will affect its performance in forest. A tool for mechanized harvesting systems design and analysis was developed (Randhawa et al. 1990a, 1990b) and is used to evaluate the automatic selection of timber harvesting equipment (Randhawa et al. 
1992). One of the unique features of this model is a front-end user interface for defining harvesting system in interactive on-line sessions enabling a user with no computer background to successfully use the model.

Bass et al. (1991) explored the methodology for real time forestry machine simulation. The interactive simulation runs on a graphics workstation while the machine control interface runs on a $\mathrm{PC}$ type microcomputer. Both are written in $\mathrm{C}$ language. Three dimensional machine parts are created with solid modeling software called GMOS. The user input control interface is an important feature to the simulation. A Data Translation AD board is used to translate the user input from the PC to the workstation. The computer processing time and the frame rate are slow because of the complexity of the images being displayed.

Wang and Greene (1999) reported an interactive simulation system for modeling stands, harvests, and machines. Simulations are performed by moving machine images within stand maps on the computer screen. Statistic analysis are performed to analyze the performance impact. Using the interactive simulation, the potential interactions of stand type, harvesting method, and equipment were evaluated (Wang et al. 1998). Three felling methods (chainsaw, feller-buncher, and harvester) and two extraction methods (grapple skidder and forwarder) were examined for both uneven-aged natural stand and even-aged planted stand. This technique provides a useful tool for comparing alternative systems in a range of harvesting situations. However, they found that this method was labor intensive, particularly for simulating skidding and forwarding. To improve the efficiency, an event-oriented VB - based, numerical ground-based timber harvesting simulation model was developed (Wang and LeDoux 2003). Graphical user 
interface (GUI) was adopted in their simulation. The model was validated using field data. However, terrain conditions of the forest site were not included in the model.

\subsection{Environmental Factors}

Mechanization of timber harvesting operations increases productivity and is less labor intensive compared to manual operations, but it also can cause more environmental concerns. Significant and widespread soil disturbance commonly are observed during timber harvesting. Soil compaction, which reduces infiltration rates and macro porosity, restricts the infiltration of water, air, heat, and nutrients, impedes root growth, and increases surface runoff and erosion, has been reported as the major damage caused by harvesting traffic (Turcotte et al. 1991, Miller et al. 1996). In addition, soil compaction has a long-term impact. Some studies showed that skid trails remain compacted and continued to have reduced tree growth even after 1.5 to several decades of harvest operations (Froehlich 1979, Hatchell et al. 1970, Wert and Thomas 1981, Corns 1988). Perry (1964) observed that 40 years is needed for an old forest road to fully recover, and logging trails on sandy soils under radiata pine (Pinus radiata) forests remained compacted 50 years after they were last used (Greacen and Sands 1980).

A study of Hatchel et al. (1970) found tree-length skidding with a crawler tractor caused a sharp increase in the bulk density of surface soils from 0.92(undisturbed) to $1.12 \mathrm{Mg} / \mathrm{m}^{3}$ after 1 or 2 trips, and a more gradual increase in density to a maximum of $1.23 \mathrm{Mg} / \mathrm{m}^{3}$ as the number of trips increased to 9. Koger et al. (1984) and Shetron et al. (1988) observed that the most increase in bulk density occurred during the first few vehicle passes over the soil and little further compaction occurred in subsequent trips. 
Campbell (1974) reported the bulk density of rut core samples increased $13 \%$ for 15 trips with a rubber-tired skidder. Compaction reduced macro pore space to approximately $80 \%$ of that on nontrafficked plots (Aust et al. 1995). Miller et al. (1996) reached a similar conclusion at three coastal Washington locations. They observed that bulk density in the 0 to 8 centimeters depth on primary skid trails after logging averaged 41$52 \%$ greater than nontrail areas and it still exceeded that outside trail by $20 \%$ eight years later. However, King and Haines (1979) found no significant increase in soil bulk density following thinning in southern pine plantations.

Axle load and number of machine passes were identified as the most important variables that influence soil compaction (Canillas and Salokhe 2002). Site disturbance can be evaluated physically by the location and distribution of traffic intensities (Carter and McDonald 1998) or number of machine passes (McMahon, 1997). Site impacts were assessed by using global positioning systems (GPS) to track forest harvesting equipment and traffic intensity (McDonald et al. 1998a, 1998b). GPS units were attached to fellerbuncher and skidders in two clearcuts. Raster maps were produced with cell $(0.5 \times 0.5 \mathrm{~m})$ values equal to the number of tire passes over the location. Results indicated that the GPS-based approach was comparable to that expected from an intensive visual inspection. However, there was no clear correlation between observed numbers of machine passes and changes in measured soil properties.

Carter et al. (1999) studied the impact of traffic intensity on soil response by evaluating soil physical properties at select point locations corresponding to specific traffic intensity. They found that maximum compaction occurred after three passes which was consistent with previous studies in which most soil compaction occurred 
during the first three to six passes (Froehlich et al. 1981). Traffic intensities recorded were highest in landings and skid trails. Taylor et al. (2001) reviewed the previous research involving GPS in monitor traffic intensity and machine performance and discussed future trends in precision forestry for intensive forest operations. They concluded that GPS technology had great value in tracking machines moving through the forest canopy with quantified accuracy. However, it would be very helpful in optimizing performance and reducing site impacts if the locations and sizes of felled trees can be mapped and used to extraction operations.

Four traffic intensity levels were defined to evaluate site disturbance caused by timber harvesting operations (Carruth and Brown, 1996): TI1 (trees on the plot have been felled), TI2 (trees on the plot have been felled and removed; no other traffic has passed through the plot.), TI3 (trees on the plot have been felled and removed, and trees outside the plot have been skidded through the plot; passes with a loaded machine are between 3 and 10.), and TI4 (more than ten loaded machine passes have been made through the plot.). Introducing these four levels of traffic intensity into computer simulations, Wang et al. $(1998,2003)$ evaluated the traffic intensity level of extraction machines across the harvest treatments and extraction patterns.

A fuzzy logic-based model was developed to estimate and classify soil compaction (de Araújo and Saraiva 2003). Two inference systems are included in the model: one computes soil structure changes resulting from machine traffic and the other classifies the compaction level. Axle load, soil water content and initial soil bulk density were identified as the most important factors for the compaction process and used for the model input. The model performance was evaluated statistically. 
An economic model for soil compaction was developed to evaluate the effect of compaction on stand productivity under different harvest specifications (Stewart et al. 1998). A single skid trail pattern is used in this model and designated trails were reused at each entry. The model allows the user to select the annual percentage of recovery from soil compaction. Four components are included in the model process: the skid trail component relating the planned skid trail density to the number of vehicle trips over various areas of the site, the bulk-density component computing changes in bulk density of soil from the level of compaction-causing activity, the site-productivity component linking changes in bulk density and site productivity, and the production-cost component relating changes in the management plan to changes in the production rate of the harvest system. Model results were consistent with field studies.

\subsection{Problems}

Based on the literature review, the following problems are highlighted.

(1) Many previous stand generators are 2-dimentional displays. For better visualization, a 3D stand generator is necessary. No DBH distribution model and stand generator were reported for central Appalachian hardwoods. The validation test of the stand generator also is needed to ensure that the generated stands are the representative of the actual stands.

(2) Although timber harvesting effects on soil disturbance have been studied extensively, most of the studies are region- and equipment-specific and long-term effects of compaction are not documented well. In the central Appalachian hardwood region, studies on the environmental effects of timber harvesting is necessary. 
(4) While commonly used, cable skidding is seldom studied in the central Appalachian area. A cable skidding simulation model is needed to better understand this skidding method and its related production and cost results.

(5) The potential performance of the cut-to-length harvesting systems needs to be evaluated in the central Appalachian area.

(6) The interactions among stand, harvest, and machine are not documented well for this region.

\subsection{Objectives}

The objectives of this dissertation are to:

(1) Develop a 3D stand generator for central Appalachian hardwood forests to obtain stand map data for representative forest stands in the region and define harvesting and silvicultural prescriptions.

(2) Model two typical harvesting systems widely used in this region: chainsaw felling and cable skidding and feller-buncher felling and grapple skidding. The cut-to-length (CTL) system using harvester and forwarder is modeled and examined under the considerations of harvesting Appalachian hardwoods.

(3) Develop a numerical simulation model of forest harvesting operations to efficiently handle a variety of partial cuts and extraction activities in the region. 
(4) Identify the traffic intensity of skidding/forwarding configurations. Evaluate the traffic intensity based on various machine payloads, landing locations, and topographies.

(5) Statistically analyze the interactions of stand, harvest, and machine. 


\section{CHAPTER 2: DEVELOPMENT OF A 3D STAND GENERATOR}

Stand generators are a computer programs used to depict the physical characteristics of stands based on user's input. They have been used extensively in forest harvesting simulation models because of their convenience and efficiency. stated that a major advantage of using stand generator in harvesting simulation models is the savings of time and money in obtaining stand data (Newnham and Maloley 1970). Several models are available for simulating growth or harvesting operations in forest stands. However, most were designed for specific species and regions. Many of the earliest models were FORTRAN-based and displays were 2-dimensional (2D).

The 3-dimensional (3D) modeling approach was introduced in 1990s and has been applied in forest stand visualization (Reutebuch et al. 1997). The Stand Visualization System (SVS) developed by Robert McGaughey (1997) is a stand visualizing program used widely in North American. It provides a visual display of stand level forests. Overhead, profile, and perspective views of a stand are enabled, and stand components can be differentiated by using different plant forms, colors, or other types of marking. Various silvicultural treatments can be performed on the stand by marking stand components and specifying treatments. Stand conditions, including the diameter, height distribution, species composition, and related treatments can be displayed by calling the appropriate functions. Designed as a visualization system, SVS can display only existing data derived either from field collection or from the output of Forest Vegetation Simulator (FVS). Users do not have the flexibility to control detailed information, such as DBH distribution or the spatial pattern of the stand to be displayed. In addition, although some silvicultural treatments are enabled in SVS, the production/cost analysis 
related to the treatments is lacking. To better visualize and incorporate the region's species-specific DBH distribution and height models, a 3D stand generator is needed for central Appalachian hardwood forests (Wang et al. 2002).

\subsection{Stand Data}

Two datasets were used to describe the relationship between DBH and height, and model DBH distributions (Table 2.1). The dataset provided by the USDA Forest Service (USFS dataset) was collected in the Monongahela National Forest in West Virginia. A total of 185 1/20-acre plots in 10 even-aged (35 years old) hardwood stands were measured. The other dataset was collected from a 75 years old second-growth hardwood forest fro the West Virginia University forest (WVU dataset). Measurements were made on 18.626 trees with 3065 variable-radius plots. Thirty-seven 37 species were included in the datasets.

The DBH ranged from 1.0 to 21 inches with an average of 4.5 inches in the USFS dataset, while the DBH averaged 14.6 inches and ranged from 2 to 42 inches in the WVU dataset (Table 2.1). Total and merchantable heights were measured and recorded for each individual tree in the WVU dataset. In the USFS dataset, five trees in each plot were selected randomly to obtain total height measurements. The total height varied from 25 to 95 feet with an average height of 64 feet in the USFS dataset; in the WVU dataset, the total height averaged 81 feet and varied from 8 to 143 feet. A cruising program was used to summarize the data in these two datasets. In order to facilitate the analyses, 7 major species were identified and categorized based on the number of trees and basal area per acre and the rest of species were classified as "Other" in both datasets 
(Table 2.1). American beech (Fagus grandifolia), black cherry (Prunus serotina), northern red oak (Quercus rubra), red maple (Acer rubrum), sugar maple (Acer saccharum), sweet birch (Betula lenta), and sassafras (Sassafras albidum) were the major species in USFS stands and accounted for $72 \%$ of the total trees measured while blue beech (Carpinus caroliniana), black cherry, chestnut oak (Quercus montana), northern red oak, red maple, sassafras, and yellow-poplar (Liriodendron tulipifera) were the major species in the WVU dataset and accounted for $83 \%$ of the total trees measured.

\subsection{System Design and Implementation}

The Component Object Model (COM) was employed in the design of this stand generator and broke the stand generator down into components in the format of either dynamic libraries (DLLs) or executables (EXEs). Each component in the system can act as both server and client. A server is a component that exposes interfaces while a client consumes functions or methods via interface. There are three major features making Object Oriented Programming (OOP) unique and preferred by most of the programmers: encapsulation, inheritance, and polymorphism. Encapsulation is a technique for minimizing interdependencies among separately written modules by defining strict external interfaces. It assures that compatible changes can be made safely, which facilitates program evolution and maintenance. Inheritance is the key for code-reusability. It enables the programmers to localize shared behavior in the superclass and isolate just the new or changed behavior in the subclass that inherits from the super class.

Inheritance makes the program small and run faster without repetitive compilation of the 
same code. Polymorphism ensures flexible modification systems can be implemented (Cox 1987, Choudhury 1999).

COM makes full use of the three OOP principles of encapsulation, inheritance, and polymorphism. COM is a language-independent standard, which make it possible to develop and subsequently use components with different languages such as Visual Basic, Visual C++, Visual J++, and others (Lewis 1999). 
Table 2.1. Summary statistics of the datasets.

\begin{tabular}{|c|c|c|c|c|c|c|c|c|c|c|c|}
\hline \multirow{2}{*}{ Datasets ${ }^{*}$} & \multirow{2}{*}{ Species } & \multirow{2}{*}{$\begin{array}{l}\text { No. of } \\
\text { trees }\end{array}$} & \multirow[b]{2}{*}{$\%$} & \multicolumn{4}{|c|}{ DBH (inches) } & \multicolumn{4}{|c|}{ Total height (feet) } \\
\hline & & & & Mean & $\begin{array}{l}\text { Std. } \\
\text { Dev. }\end{array}$ & Min. & Max. & Mean & $\begin{array}{l}\text { Std. } \\
\text { Dev. }\end{array}$ & Min. & Max. \\
\hline \multirow{8}{*}{ USFS } & $\begin{array}{l}\text { American } \\
\text { beech }\end{array}$ & 453 & 8 & 2.5 & 1.8 & 1.0 & 14.0 & 53.3 & 9.3 & 43.0 & 61.0 \\
\hline & $\begin{array}{l}\text { Black } \\
\text { cherry }\end{array}$ & 646 & 11 & 7.6 & 3.8 & 1.0 & 20.0 & 69.2 & 11.4 & 41.0 & 94.0 \\
\hline & $\begin{array}{l}\text { Northern } \\
\text { red oak }\end{array}$ & 324 & 6 & 4.0 & 2.9 & 1.0 & 21.0 & 60.0 & 13.2 & 35.0 & 95.0 \\
\hline & $\begin{array}{l}\text { Red } \\
\text { maple }\end{array}$ & 764 & 13 & 4.2 & 2.6 & 1.0 & 19.0 & 60.4 & 11.4 & 38.0 & 85.0 \\
\hline & $\begin{array}{l}\text { Sugar } \\
\text { maple }\end{array}$ & 1180 & 19 & 4.1 & 3.0 & 1.0 & 19.0 & 63.5 & 7.5 & 45.0 & 80.0 \\
\hline & $\begin{array}{l}\text { Sweet } \\
\text { birch }\end{array}$ & 476 & 8 & 4.2 & 2.4 & 1.0 & 12.0 & 60.8 & 8.2 & 49.0 & 85.0 \\
\hline & Sassafras & 420 & 7 & 3.8 & 2.9 & 1.0 & 20.0 & 51.1 & 11.9 & 34.0 & 62.0 \\
\hline & Other & 1714 & 28 & 4.2 & 3.2 & 1.0 & 19.0 & 60.6 & 12.5 & 25.0 & 83.0 \\
\hline \multirow{8}{*}{ WVU } & $\begin{array}{l}\text { Blue } \\
\text { beech }\end{array}$ & 334 & 2 & 10.1 & 3.9 & 3.0 & 27.0 & 64.5 & 17.3 & 20.0 & 113.0 \\
\hline & $\begin{array}{l}\text { Black } \\
\text { cherry }\end{array}$ & 1079 & 6 & 15.0 & 4.3 & 4.0 & 32.0 & 84.5 & 16.3 & 20.0 & 139.0 \\
\hline & $\begin{array}{l}\text { Chestnut } \\
\text { oak }\end{array}$ & 2527 & 14 & 13.0 & 4.5 & 4.0 & 36.0 & 75.0 & 13.7 & 8.0 & 115.0 \\
\hline & $\begin{array}{l}\text { Northern } \\
\text { red oak }\end{array}$ & 3651 & 20 & 16.4 & 5.4 & 3.0 & 42.0 & 85.1 & 15.5 & 10.0 & 140.0 \\
\hline & $\begin{array}{l}\text { Red } \\
\text { maple }\end{array}$ & 3047 & 16 & 11.1 & 4.6 & 2.0 & 34.0 & 70.0 & 19.0 & 9.0 & 135.0 \\
\hline & Sassafras & 290 & 2 & 10.7 & 2.7 & 5.0 & 19.0 & 63.4 & 14.3 & 24.0 & 103.0 \\
\hline & $\begin{array}{l}\text { Yellow - } \\
\text { poplar }\end{array}$ & 4246 & 23 & 17.4 & 4.7 & 4.0 & 40.0 & 95.7 & 14.9 & 9.0 & 143.0 \\
\hline & Other & 3151 & 17 & 14.4 & 5.2 & 2.0 & 40.0 & 78.3 & 17.1 & 9.0 & 136.0 \\
\hline
\end{tabular}

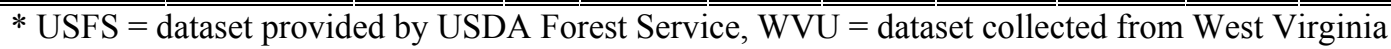
University forest. 
This 3D stand generator system consists of two main components - a Microsoft Visual Basic (MS VB) and a Microsoft Visual C++ (MS VC) (Figure 2.1a). A component is a compiled piece of code that can provide a service to the system. The stand generator users access the resources in these two components via the COM interfaces such as IStandGenerator in the model. However, the users are able to find out what interfaces the component supports by using the generic interface called IUnknown. The COM interface is the mechanism by which a user or a client interacts with a component while an interface is a contract between a consumer and a component that describes the component's functionality to the user without describing the implementation (Lewis 1999). Every COM object must implement the IUnknown interface. The architecture of a COM interface includes a binary description of the layout of a block of memory containing an array of function pointers (Figure 2.1b). This array has a fixed structure, and is known as a virtual method table (vtable). The pointers in the array point to the functions of the COM object that can be called by the user. Each interface has its own vtable layout, and a COM object can expose to any members of the interface. 

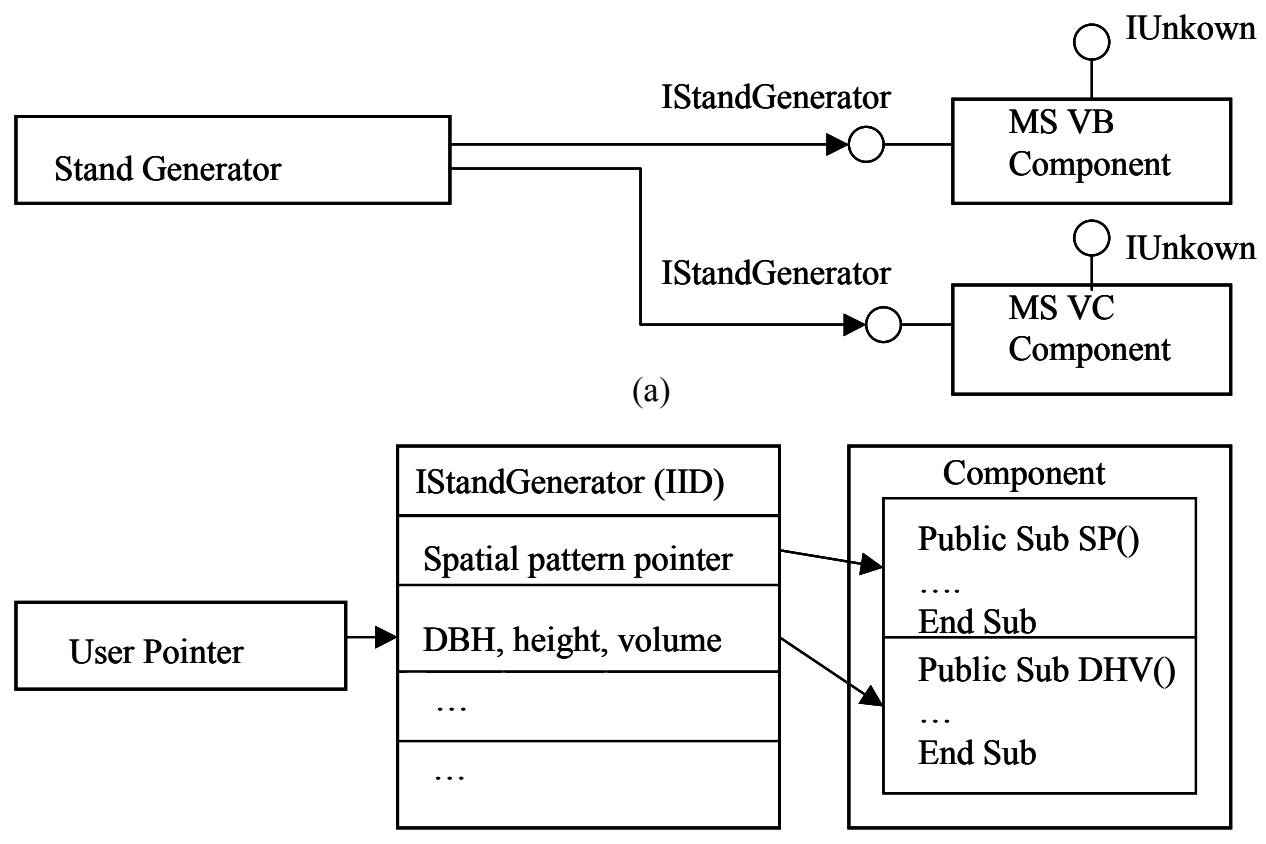

(b)

Figure 2.1. Component object model of the stand generator.

\subsection{Height Estimation}

Estimates of tree volume are an important product of the stand generator. Local volume tables/equations (Wiant 1978, Wiant 1986, Rennie 1996) require an estimate of total height and merchantable height. Total tree height has been modeled as a function of diameter at breast height (DBH) both linearly and non-linearly. Curtis (1967) summarized the available height-DBH models and compared the performances of 13 linear models fitted to second growth Douglas-fir. Since then, many new models have been developed for different species in different regions. Huang et al. (1992) compared and evaluated 20 non-linear height-DBH functions for major species in Alberta. Bechtold et al. (1998) presented a general linear height equation currently used by USDA Southern Research Station Forest Inventory and Analysis (FIA) and modified the model for ocular estimates. The height-diameter relationship for sugar maple was also explored 
in an uneven-aged Northern hardwood stand (Kenefic and Nyland 1999). Few references are available for modeling the merchantable height. Ek et al. (1984) developed a nonlinear model, which described the merchantable height as a function of DBH, site index, and basal area per acre. Borders et al. (1990) modeled the merchantable height as a function of the total height and the ratio of top merchantable diameter to DBH for loblolly pine.

In this study, the models have been developed to estimate the total height and merchantable height based on the WVU data set, which facilitated the use of local volume equations (Rennie 1996, Wiant 1978 and 1986). Total tree height was recorded in feet while the merchantable height was measured in the number of 16 -foot logs. Three linear and five non-linear models were fitted for the major species in the region for the estimation of the total height (Table 2.2). The best model for each major species was selected (Table 2.3) based on the following criteria: (1) root mean square error (RMSE), (2) F- and P-values, (3) coefficient of correlation $\left(\mathrm{R}^{2}\right)$, and the plot of residual vs. predicted height. It was noticed that the residuals increased with the increase of the modeled total height (Figure 2.2 - Figure 2.8.). It indicated that the total height estimation is less accurate at the top section. 
Table 2.2. Linear and non-linear DBH-height functions examined and fitted for major species on West Virginia University forest.

\begin{tabular}{lll}
\hline \hline & Model $^{*}$ & Reference \\
\hline (1) & $H=a+b D+c D^{2}$ & $\begin{array}{l}\text { Curtis 1967, Kenefic and Nyland } \\
1999\end{array}$ \\
(2) & $L o g H=a+b D^{-1}$ & Curtis 1967, Clutter et al. 1983 \\
(3) & $H=a+b\left(\log _{10} D\right)^{0.5}+c D^{2}$ & Bechtold et al. 1998 \\
(4) & $H=1.3+a\left(1-e^{-b D^{c}}\right)$ & Huang et al. 1992 \\
(5) & $H=1.3+a\left(1-e^{-b D}\right)^{c}$ & Huang et al. 1992 \\
(6) & $H=1.3+a e^{b /(D+c)}$ & Huang et al. 1992 \\
(7) & $H=1.3+a /\left(1+b^{-1} D^{-c}\right)$ & Huang et al. 1992 \\
(8) & $H=1.3+e^{a+b D^{c}}$ & Huang et al. 1992 \\
\hline \hline
\end{tabular}

*a, b, and c are the coefficients. In equations (1) to (3), $\mathrm{H}$ in feet, D in inches; otherwise $\mathrm{H}$ in meter and $\mathrm{D}$ in $\mathrm{cm}, \mathrm{Log}$ is natural logarithm.

Table 2.3. DBH-total height equations fitted for major species on the West Virginia University forest.

\begin{tabular}{llllll}
\hline \hline Species & Fitted model $^{*}$ & RMSE & $\mathrm{R}^{2}$ & $\mathrm{~F}$ & P-value \\
\hline Blue beech & LogH $=4.66-4.56 D^{-1}$ & 0.1933 & 0.60 & 478.66 & 0.0001 \\
$\begin{array}{l}\text { Black } \\
\text { cherry }\end{array}$ & LogH $=4.81-5.33 D^{-1}$ & 0.1746 & 0.46 & 673.95 & 0.0001 \\
$\begin{array}{l}\text { Chestnut } \\
\text { oak }\end{array}$ & LogH $=4.66-4.23 D^{-1}$ & 0.1599 & 0.50 & 1694.57 & 0.0001 \\
$\begin{array}{l}\text { Northern } \\
\text { red oak }\end{array}$ & $H=1.3+34.06 e^{-12.10 /(D-2.15)}$ & 3.2810 & 0.55 & 74929 & 0.0001 \\
$\begin{array}{l}\text { Red maple } \\
\begin{array}{l}\text { Sassafras } \\
\text { Yellow- }\end{array}\end{array}$ & $H=1.3+26.57\left(1-e^{-0.07 D}\right)^{1.71}$ & 3.2640 & 0.71 & 44138 & 0.0001 \\
poplar & LogH $=4.90-5.63 D^{-1}$ & 0.1407 & 0.63 & 3237.01 & 0.0001 \\
\begin{tabular}{l} 
Other \\
\hline \hline
\end{tabular} & $H=1.3+32.11 e^{-10.65 /(D-3.41)}$ & 3.4514 & 0.65 & 49903 & 0.0001 \\
\hline
\end{tabular}

* Log = natural logarithm; $\mathrm{H}=$ total height; $\mathrm{D}=\mathrm{DBH}$. 


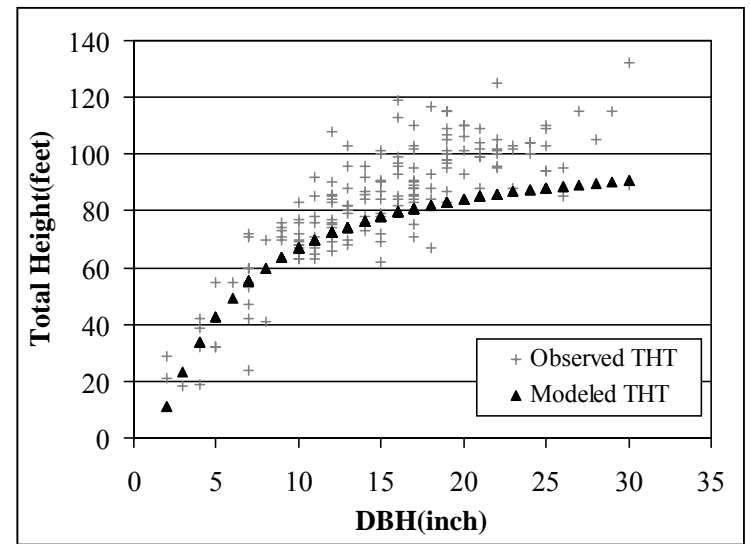

(a)

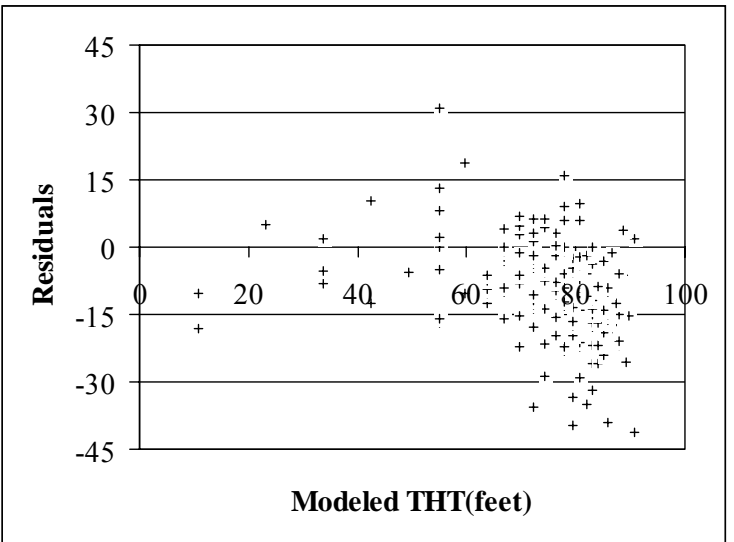

(b)

Figure 2.2. Total height vs. DBH or residuals for blue beech.

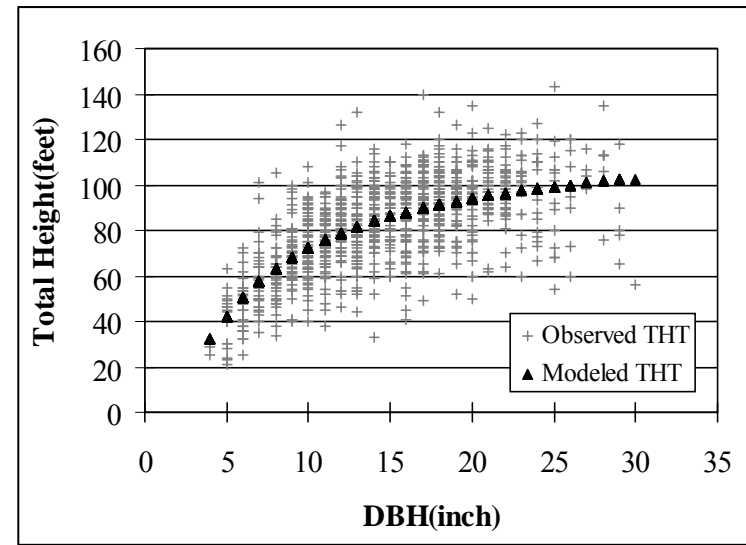

(a)

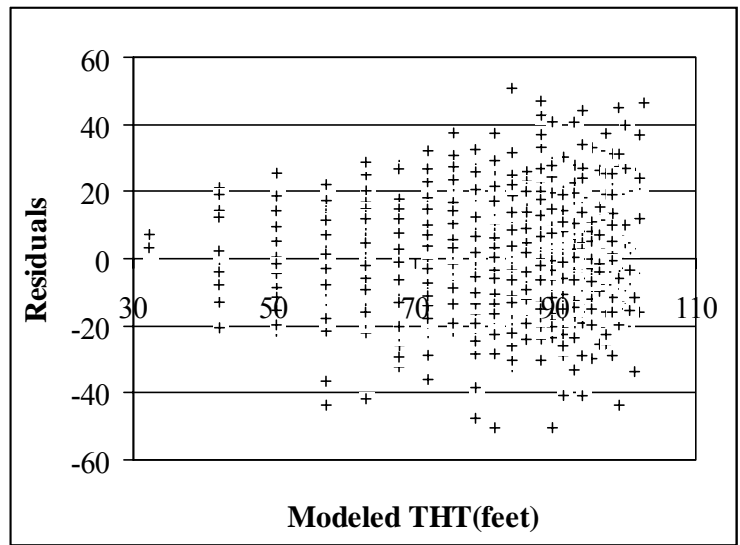

(b)

Figure 2.3. Total height vs. DBH or residuals for black cherry.

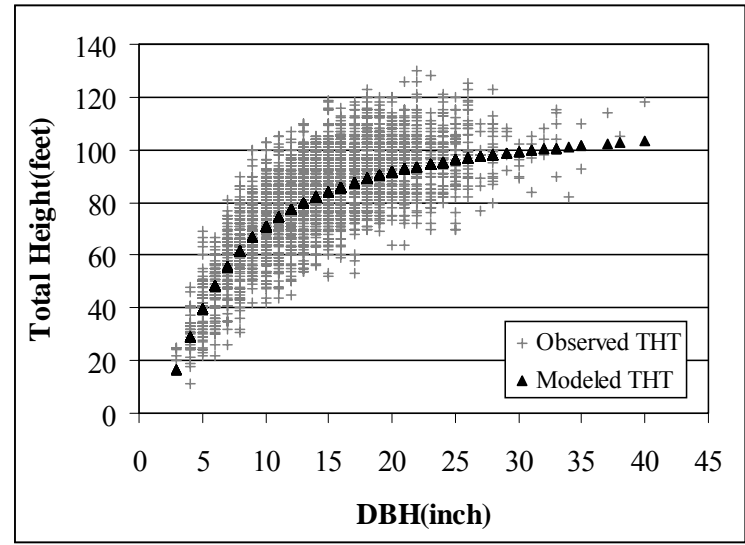

(a)

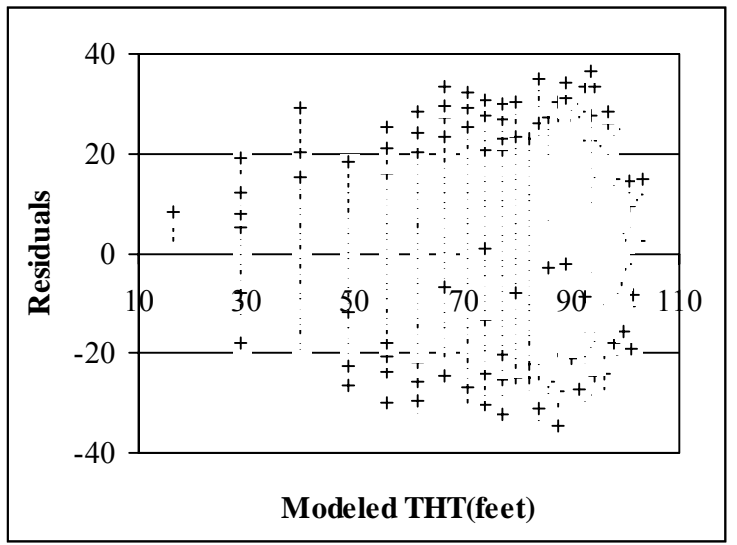

(b)

Figure 2.4. Total height vs. DBH or residuals for northern red oak. 


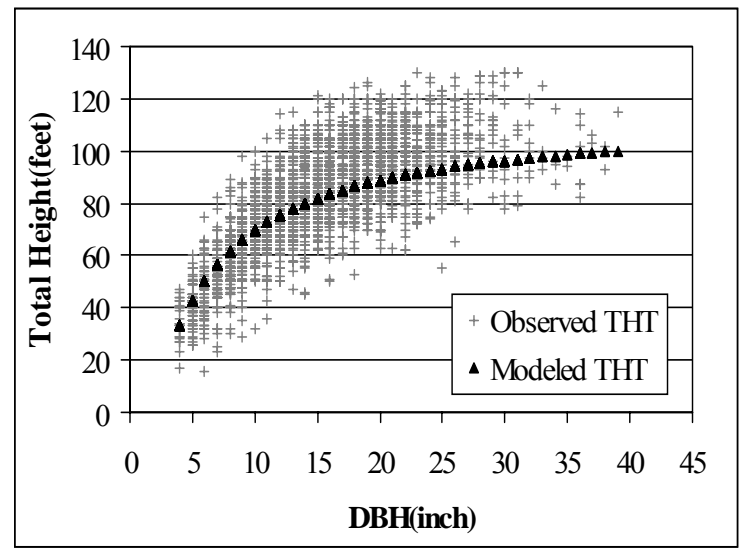

(a)

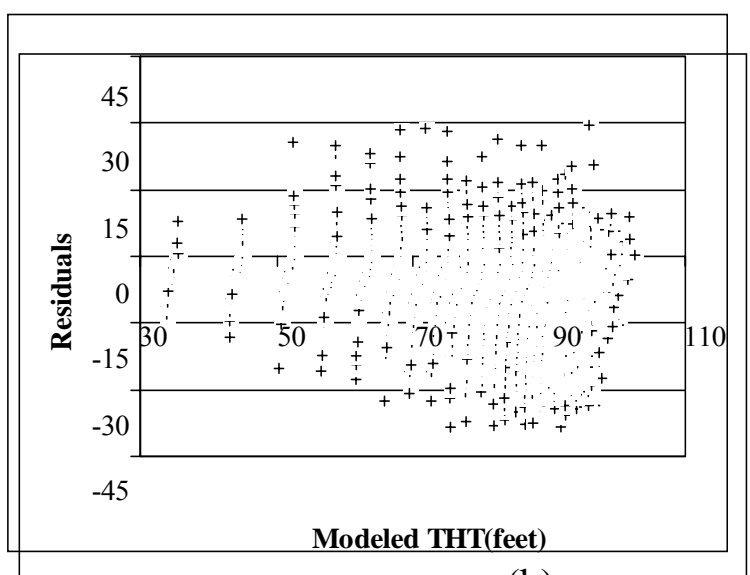

(b)

Figure 2.5. Total height vs. DBH or residuals for red maple.

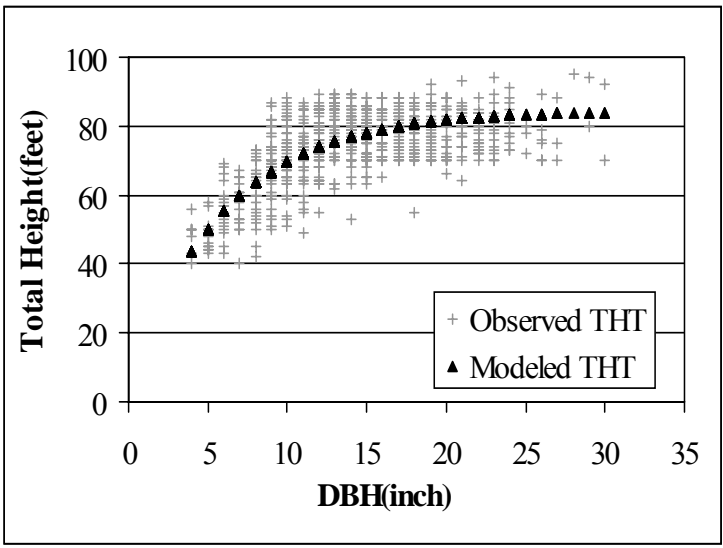

(a)

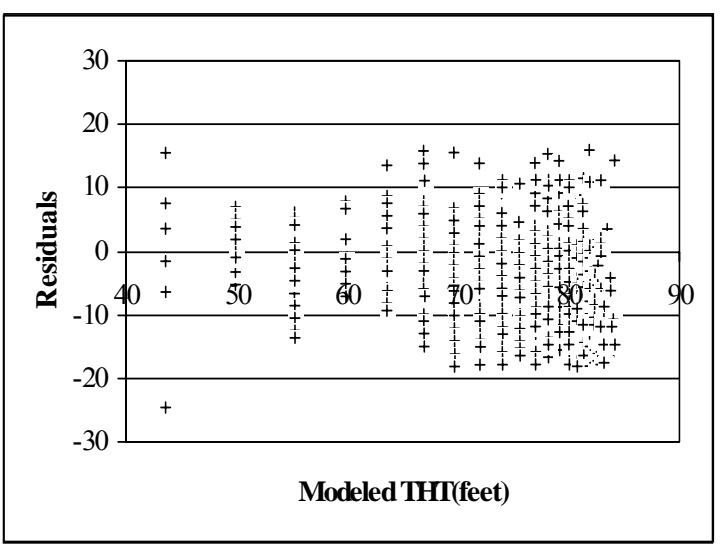

(b)

Figure 2.6. Total height vs. $\mathrm{DB} \mathrm{H}$ or residuals for sassafras.

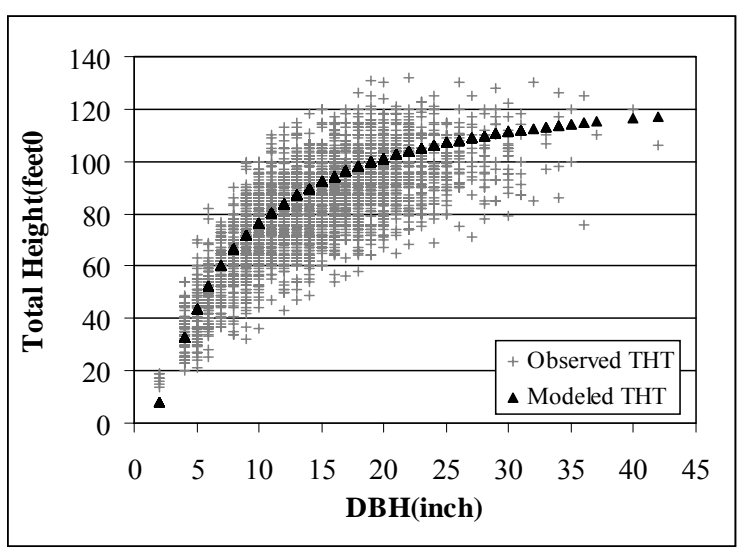

(a)

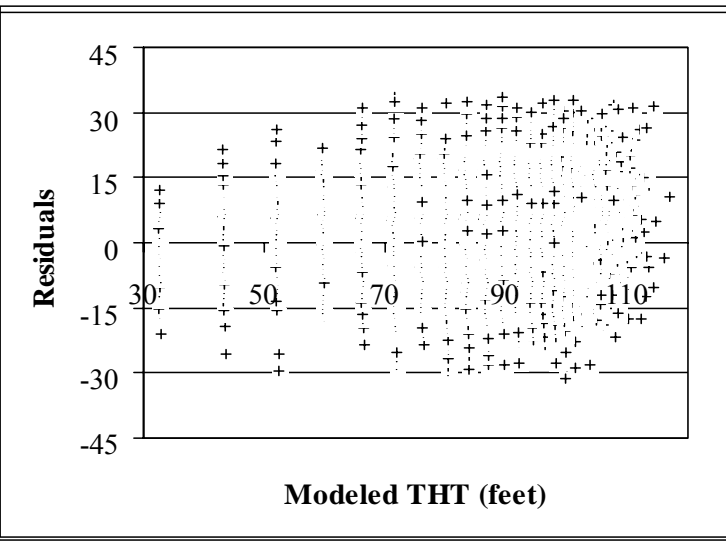

(b)

Figure 2.7. Total height vs. DBH or residuals for yellow - poplar. 


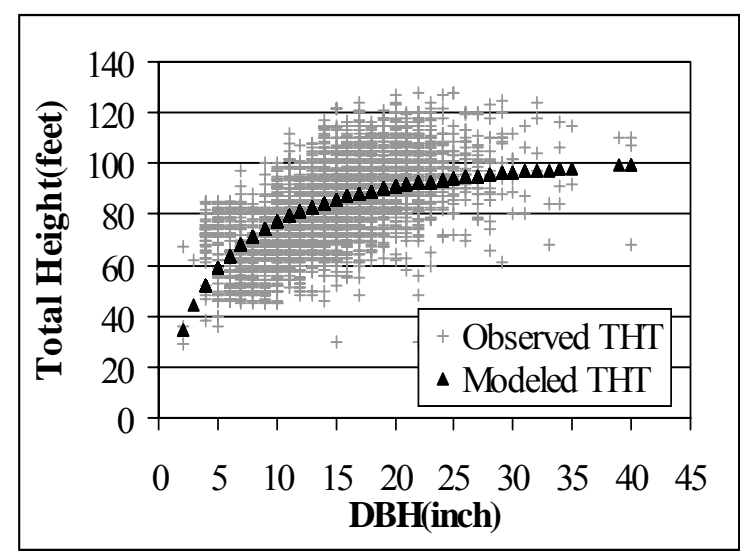

(a)

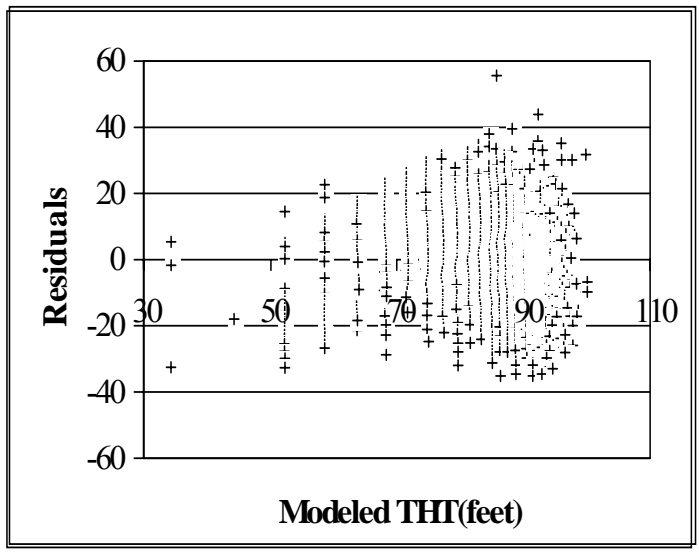

(b)

Figure 2.8. Total height vs. DBH or residuals for Other Species.

The merchantable height also was modeled as a function of $\mathrm{DBH}$, which was assumed to be in the same family as the selected DBH-total height equations for each species. Family lines are lines that have either equal slopes or common intercepts (Ergun 1956). Equation (2) in Table 2.2 is used as the prototype for the family curves of the tree height. There are two cases for fitting the tree height family curves.

Case I: Common intercepts. Curves with common intercepts can be expressed as follows:

$$
\left\{\begin{array}{l}
\log \left(T h t_{i}\right)=a_{0}+b_{0}\left(\frac{1}{D_{i}}\right) \\
\log \left(M h t_{i}\right)=a_{0}+b^{\prime}\left(\frac{1}{D_{i}}\right)
\end{array}\right.
$$

Where, $T h t_{i}=$ total height for ith observation (ith tree).

$$
M h t_{i}=\text { merchantable height for ith observation (ith tree). }
$$


$a_{0}$ is the common intercept for both total height and merchantable height equations.

$b_{0}, b^{\prime}$ are the slope for total height and merchantable height equation, respectively.

$D_{i}=$ diameter at breath height (inch) for ith observation (ith tree).

Equation (2) in Table 2.2 was first fitted for total height data. Then the slope $\left(b^{\prime}\right)$ for merchantable height equation was calculated based on equation (2.1).

$$
b^{\prime}=\frac{\sum\left(\left(\log \left(M h t_{i}\right)-a_{0}\right) D_{i}\right)}{n}
$$

Where, $n=$ number of observations (trees).

Equation (2.2) can be further simplified as

$$
b^{\prime}=\frac{\sum \log \left(M h t_{i}\right)}{n}-\frac{a_{0} \sum D_{i}}{n}
$$

Let $\overline{\log (M h t)}=\frac{\sum \log \left(M h t_{i}\right)}{n}$ and $\bar{D}=\frac{\sum D_{i}}{n}$, then equation (2.3) can be

expressed as

$$
b^{\prime}=\overline{\log (M h t)}-a_{0} \bar{D}
$$

Therefore, the merchantable height equation having the same intercept with the total height equation can be expressed as follows:

$$
\log \left(M h t_{i}\right)=a_{0}+\left(\overline{\log (M h t)}-a_{0} \bar{D}\right)\left(\frac{1}{D_{i}}\right)
$$


Case II: Common slopes. Curves with common slopes can be expressed as

follows:

$$
\left\{\begin{array}{l}
\log \left(T h t_{i}\right)=a_{0}+b_{0}\left(\frac{1}{D_{i}}\right) \\
\log \left(M h t_{i}\right)=a^{\prime}+b_{0}\left(\frac{1}{D_{i}}\right)
\end{array}\right.
$$

Where, $a^{\prime}$ is the intercept for merchantable height equation.

Using the same method as above, intercept $\left(a^{\prime}\right)$ for merchantable height equation are calculated as follows:

$$
a^{\prime}=\frac{\sum \log \left(M h t_{i}\right)}{n}-\frac{b_{0} \sum\left(\frac{1}{D_{i}}\right)}{n}
$$

Let $\overline{D^{-1}}=\frac{\sum\left(\frac{1}{D_{i}}\right)}{n}$, then the merchantable height equation having the same slope with the total height equation can be expressed as follows:

$$
\log \left(M h t_{i}\right)=\left(\overline{\log \left(M h t_{i}\right)}-b_{0} \overline{D^{-1}}\right)+b_{0}\left(\frac{1}{D_{i}}\right)
$$

Based on the above equations, both family curves (common intercept and common slope) were fitted for eight individual tree species to get the merchantable height models. The fitting results were compared with the original data statistically and graphically (Figure 2.3). The merchantable height models having common intercept with the total height model presented a better estimation both statistically and biologically (Table 2.4). The merchantable height models having common slope with the total height model consistently underestimated merchantable height and had larger root mean square 
error (RMSE). Therefore, common intercept models were used to predict the merchantable height (Table 2.5).

Table 2.4. DBH-total/merchantable height family curves fitted for major species on West Virginia University forest.

\begin{tabular}{lllllll}
\hline \multirow{2}{*}{ Species } & \multirow{2}{*}{$a_{0}$} & \multirow{2}{*}{$b_{0}$} & \multicolumn{2}{c}{ Common Intercept } & \multicolumn{2}{c}{ Common Slope } \\
\cline { 5 - 7 } & & & $b^{\prime}$ & RMSE & $a^{\prime}$ & RMSE \\
\hline Blue beech & 4.66 & -4.56 & 20.52 & 1.32 & 3.35 & 4.25 \\
Black cherry & 4.81 & -5.33 & 23.21 & 1.07 & 3.34 & 3.89 \\
Chestnut oak & 4.66 & -4.23 & 25.44 & 0.95 & 3.22 & 2.97 \\
Northern red oak & 4.80 & -5.41 & 25.72 & 1.15 & 3.32 & 4.32 \\
Red maple & 4.73 & -4.88 & 26.50 & 1.12 & 3.26 & 5.26 \\
Sassafras & 4.63 & -5.11 & 22.46 & 0.93 & 3.32 & 3.15 \\
Yellow- poplar & 4.90 & -5.63 & 26.57 & 1.24 & 3.41 & 2.59 \\
Other & 4.76 & -5.38 & 24.56 & 0.31 & 3.34 & 2.94 \\
\hline \hline
\end{tabular}

Table 2.5. DBH-merchantable height functions fitted for major species on West Virginia University forest.

\begin{tabular}{ll}
\hline \hline Species & Model $^{*}$ \\
\hline Blue beech & LogMht $=4.66-20.52 D^{-1}$ \\
Black cherry & LogMht $=4.81-23.21 D^{-1}$ \\
Chestnut oak & LogMht $=4.66-25.44 D^{-1}$ \\
Northern red oak & LogMht $=4.80-25.72 D^{-1}$ \\
Red maple & LogMht $=4.73-26.50 D^{-1}$ \\
Sassafras & LogMht $=4.63-22.46 D^{-1}$ \\
Yellow-poplar & LogMht $=4.90-26.57 D^{-1}$ \\
Other & LogMht $=4.76-24.56 D^{-1}$ \\
\hline \hline
\end{tabular}

$*$ Mht $=$ merchantable height in feet; $\mathrm{D}=$ diameter at breast height in inch . 


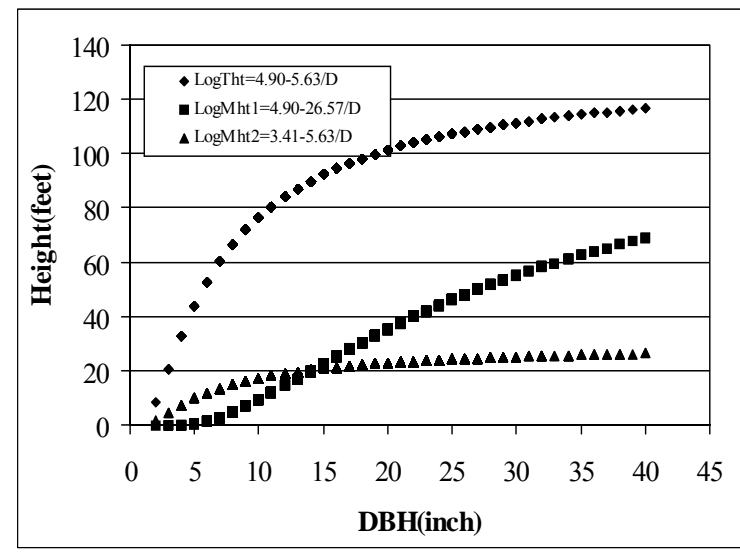

(a) blue beech

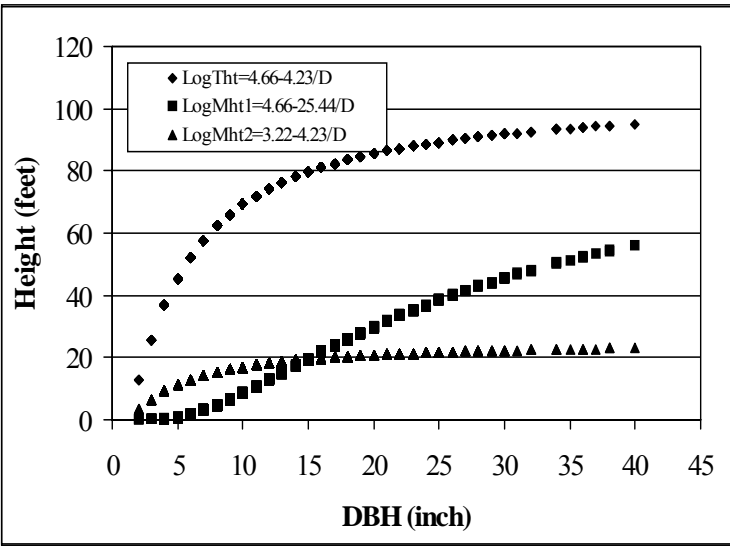

(c) chestnut oak

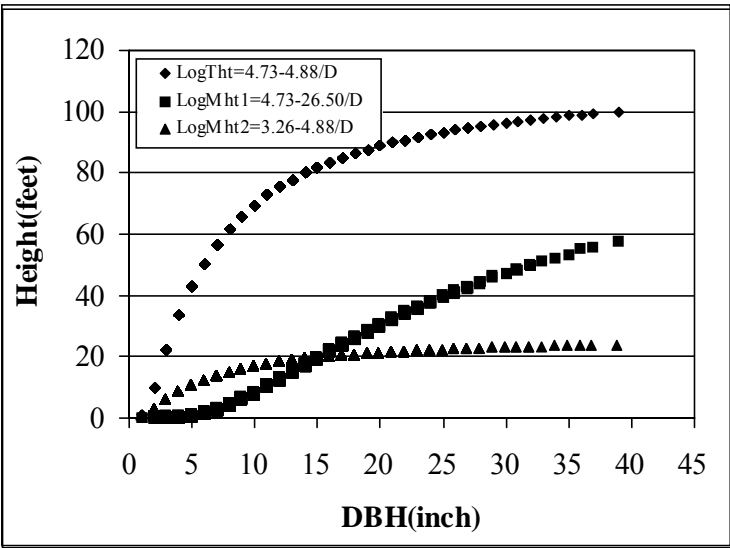

(e) red maple

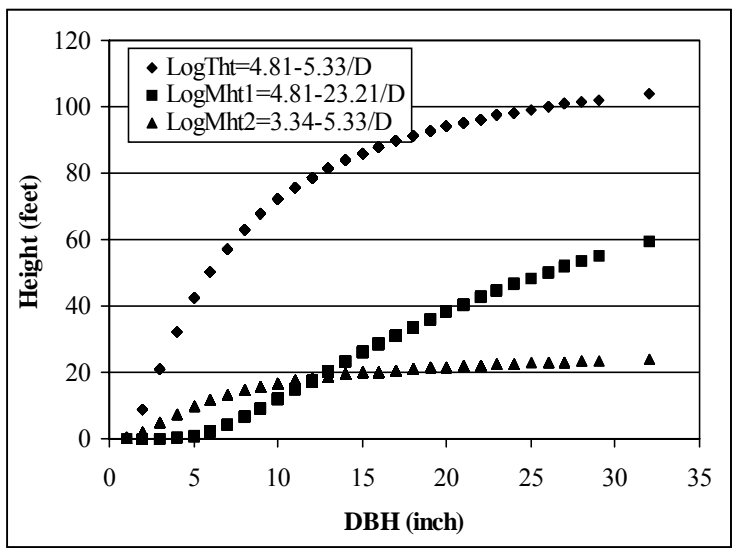

(b) black cherry

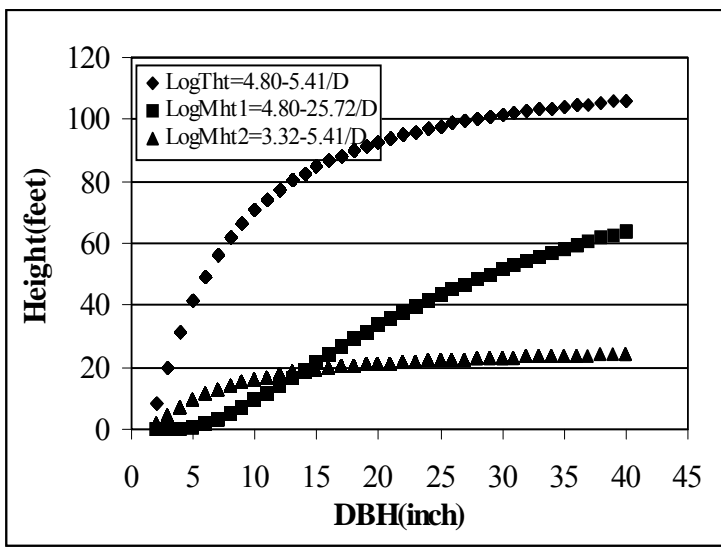

(d) northern red oak

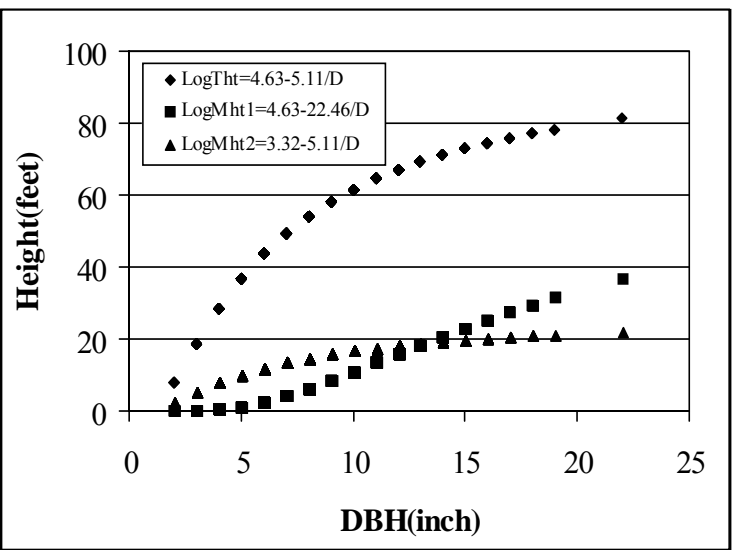

(f) sassafras 


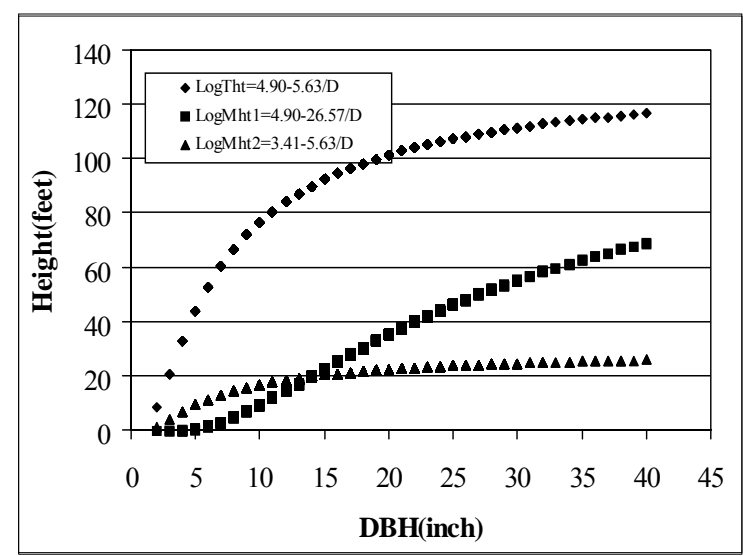

(g) yellow-poplar

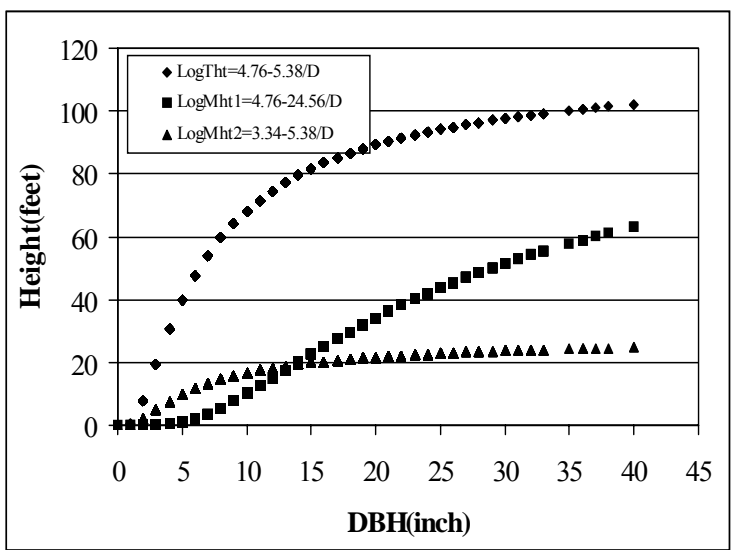

(h) other species

Figure 2.9. Family curves for total height and merchantable height estimations.

\subsection{DBH Distribution}

Many distribution functions such as beta, gamma, and Weibull have been used to describe the diameter distributions of stands. The Weibull function, however, has been widely used due to its simplicity and flexibility (Bailey and Dell 1973). The threeparameter Weibull distribution is especially popular for depicting diameter distributions.

ExpertFit was used to automatically and accurately determine which of 39 probability distributions best represents the DBH distribution of each major species in this study. The ExpertFit contains four modules: reading data, fitting the model, testing the model, and applying the model (Law and Vincent 1999). The best probability density function (pdf) for each major species was selected based on the distribution function differences and goodness-of-fit tests (Table 2.6). The distribution function differences show the differences between the selected distribution function and the sample distribution function over the range of the data. The small vertical differences (errors) indicated that these models provide good fits. 
Table 2.6. DBH distribution for major species in the region.

\begin{tabular}{|c|c|c|c|c|c|c|}
\hline \multirow{2}{*}{$\begin{array}{l}\text { Data } \\
\text { sets }\end{array}$} & \multirow{2}{*}{ Species } & \multirow{2}{*}{ Model $^{1}$} & \multicolumn{3}{|c|}{ Parameters } & \multirow{2}{*}{$\begin{array}{l}\text { Average } \\
\text { distribution } \\
\text { difference }^{2}\end{array}$} \\
\hline & & & Location & Scale & Shape & \\
\hline \multirow{8}{*}{ USFS } & American beech & Log-Logistic & 1.5 & 1.178 & 1.7019 & 0.0397 \\
\hline & Black cherry & Weibull & 1.5 & 7.5131 & 1.5503 & 0.0177 \\
\hline & Northern red oak & Exponential & 1.5 & 3.7857 & - & 0.0233 \\
\hline & Red maple & Weibull & 1.5 & 3.6682 & 1.115 & 0.0357 \\
\hline & Sugar maple & Exponential & 1.5 & 3.6441 & - & 0.0219 \\
\hline & Sweet birch & Weibull & 1.5 & 3.6029 & 1.3609 & 0.0317 \\
\hline & Sassafras & Lognormal & 1.5 & 0.6876 & 0.8488 & 0.0378 \\
\hline & Other & Exponential & 1.5 & 3.6181 & - & 0.0222 \\
\hline \multirow{9}{*}{ WVU } & Blue beech & Exponential & 3.5 & 2.7778 & - & 0.0531 \\
\hline & Black cherry & Weibull & 3.5 & 5.9275 & 0.9934 & 0.0469 \\
\hline & Black gum & Weibull & 3.5 & 1.9661 & 0.9684 & 0.0383 \\
\hline & Chestnut oak & Weibull & 3.5 & 9.3349 & 1.8949 & 0.0190 \\
\hline & Northern red oak & Weibull & 3.5 & 9.0814 & 1.5634 & 0.0315 \\
\hline & Red maple & Weibull & 3.5 & 4.4921 & 1.0977 & 0.0309 \\
\hline & Sassafras & Gamma & 3.5 & 3.9693 & 1.8895 & 0.0380 \\
\hline & Yellow poplar & Weibull & 3.5 & 11.0718 & 2.1586 & 0.0351 \\
\hline & Other & Exponential & 3.5 & 5.6202 & - & 0.0203 \\
\hline
\end{tabular}

${ }^{1}$ General forms of the distributions:

Weibull: $\quad f(d)=a b^{-a}(d-c)^{a-1} \exp \left[-\left(\frac{d-c}{b}\right)^{a}\right]$

Log-logistic: $\quad f(d)=a\left(\frac{d-c}{b}\right)^{a-1} / b\left[1+\left(\frac{d-c}{b}\right)^{a}\right]^{2}$

Exponential: $\quad f(d)=\frac{1}{b} \exp \left[\frac{-(d-c)}{b}\right]$

Lognormal: $\quad f(d)=\frac{1}{(d-c) \sqrt{2 \pi a^{2}}} \exp \left[\frac{-[\operatorname{Ln}(d-c)-b]^{2}}{2 a^{2}}\right]$

Gamma: $\quad f(d)=\frac{(d-c)^{a-1}}{b^{a} \Gamma(\alpha)} \exp \left[\frac{-(d-c)}{b}\right]$

Where, $\mathrm{a}, \mathrm{b}$, and $\mathrm{c}$ are parameters; $\mathrm{d}$ is the $\mathrm{DBH}(\mathrm{inch}) ; \Gamma(\alpha)$ is the gamma function.

${ }^{2}$ The difference between selected distribution function and the sample distribution function over the range of the data. 


\subsection{Spatial Patterns}

Spatial pattern is an important aspect of the stand generator that has to be considered during the development process.

Both random and clustered patterns were modeled for the natural hardwood stands in the region. If a random spatial pattern is requested, a ratio of the stand density to the total number of possible tree locations based on minimum $\mathrm{X}$ and $\mathrm{Y}$ spacing first is calculated by:

$$
\gamma=\frac{S D \times X_{\min } \times Y_{\min }}{43560}
$$

Where $\gamma=$ ratio of the stand density to the number of possible tree locations;

$$
\begin{aligned}
& \mathrm{SD}=\text { stand density (trees per acre); } \\
& \mathrm{X}_{\min }=\text { minimum } \mathrm{X} \text { spacing (feet); } \\
& \mathrm{Y}_{\min }=\text { minimum } \mathrm{Y} \text { spacing (feet) }
\end{aligned}
$$

Then a random number with a uniform distribution between 0.0 and 1.0 is generated for each possible tree location. If this number is less than or equal to the ratio described, the coordinate location is assigned a tree. If the random number is greater than the ratio, the coordinate location is considered to be unoccupied (Farrar 1981). The minimum $\mathrm{X}$ and $\mathrm{Y}$ spacings are considered in this procedure when natural stands are modeled. At each location, tree DBH is assigned randomly. Total height, merchantable height, and volume of that tree then are calculated based on the assigned DBH.

When the clustered pattern is used, cluster centers specified by the user was located randomly within a plot. By generating the $\mathrm{X}$ and $\mathrm{Y}$ coordinates randomly using a pair of random numbers, each tree is provided an initial location. Distances from that 
tree to each of the cluster centers are determined and the nearest center is selected. The distance from this center to the tree then is multiplied by a random number between 0.0 and 1.0 to give a new location for that tree relative to the cluster center (Farrar 1981). New coordinates then are calculated for the tree and the distances between that location and the neighboring trees are checked to assure that minimum nearest distances are maintained. If a tree location has violated the distance parameter, the procedure is repeated; otherwise, the location is assigned as a tree location.

\subsection{Programming Components}

The VB component was implemented to provide the interfaces, which allows the user to get input, assign tree characteristics, calculate the DBH distribution, display the $2 \mathrm{D}$ stand map, and save the generated stand map. The VC component can retrieve the generated stand data from the database, display the 3D stand map, and perform basic functionality on the 3D stand map (Figure 2.11).

Once the stand generator is started, the user needs to enter species composition, stand density, DBH range, spatial pattern, and stand age. Along with the DBH distribution, the stand information also is displayed with the stand map. The outputs of the stand generator is either a 2D or 3D map along with a data file in the formats of both ASCII and relational database.

A Microsoft Foundation Class (MFC) based Open Graphics Library (OpenGL) programming was adopted for 3D stand modeling. Because of its power and higher flexibility, OpenGL is used extensively for creating high quality $2 \mathrm{D}$ or $3 \mathrm{D}$ images (Woo et al. 1999). Two OpenGL libraries, OpenGL Utility Library (GLU) and OpenGL Utility 
Toolkit (GLUT), were incorporated in the project for the programming component. The former is used for performing some lower-level OpenGL commands, such as setting up matrices for specific viewing orientations and projections, performing polygon tessellation, and rendering surfaces. The latter contains more complicated routines, such as opening windows for drawing, detecting input, and creating more complicated 3D objects. An OpenGL Rendering Context (GLRC), the complete set of OpenGL state variables, is required for drawing OpenGL images.

\section{Modeling Transformations}

In order to make the generated 3D stand image look more realistic on the 2D computer screen, some transformations were used in the application. The viewing transformation is specified with gluLookAt(), which is a built-in function of GLU library to define the position of the camera (or eyes position). In this 3D stand generator system, the viewing position was implemented to change with the view modes of projective view, profile view, and overhead view. Three basic transformations of rotate, scale, and translate were modeled in the system and represented by three functions of glRotate*(), glScale*(), and glTranslate*() respectively in OpenGL (Figure 2.10 ).

Rotate. Rotate is performed by calling glRotate* $(\alpha, \mathrm{x}, \mathrm{y}, \mathrm{z})$ which generates the rotation matrix by defining the axis to be rotated about (x-axis, $y$-axis, or z-axis) and the degrees to be rotated $(\alpha)$. The matrix of rotation $\alpha$ angle around $\mathrm{x}$-axis can be derived and expressed as (Woo et al. 1999): 


$$
R_{x}(\alpha)=\left[\begin{array}{cccc}
1 & 0 & 0 & 0 \\
0 & \cos \alpha & -\sin \alpha & 0 \\
0 & \sin \alpha & \cos \alpha & 0 \\
0 & 0 & 0 & 1
\end{array}\right]
$$

$\mathrm{P}=(\mathrm{x}, \mathrm{y}, \mathrm{z}, 1) \mathrm{T}$ is a vector before rotation, which contains the coordinate of a tree and 1 for a homogeneous coordinate. If $\mathrm{P}$ is rotated to $\mathrm{P}^{\prime}=\left(\mathrm{x}^{\prime}, \mathrm{y}^{\prime}, \mathrm{z}^{\prime}, 1\right) \mathrm{T}$ by $\alpha$ around the $\mathrm{x}$-axis, the rotation process is expressed as:

$$
\begin{aligned}
& \mathrm{P}^{\prime}=\mathrm{R}_{\mathrm{x}}(\alpha) \times P \\
& {\left[\begin{array}{c}
\mathrm{x}^{\prime} \\
\mathrm{y}^{\prime} \\
\mathrm{z}^{\prime} \\
1
\end{array}\right]=\left[\begin{array}{cccc}
1 & 0 & 0 & 0 \\
0 & \cos \alpha & -\sin \alpha & 0 \\
0 & \sin \alpha & \cos \alpha & 0 \\
0 & 0 & 0 & 1
\end{array}\right]_{R_{X}} \times\left[\begin{array}{c}
x \\
y \\
z \\
1
\end{array}\right]=\left[\begin{array}{c}
x \\
y \cos \alpha-z \sin \alpha \\
y \sin \alpha+z \cos \alpha \\
1
\end{array}\right]} \\
& \left(\mathrm{x}^{\prime}, \mathrm{y}^{\prime}, \mathrm{z}^{\prime}, 1\right)^{\mathrm{T}}=(x, y \cos \alpha-z \sin \alpha, y \sin \alpha+z \cos \alpha, 1)^{\mathrm{T}}
\end{aligned}
$$

The coordinates of the trees originally drawn in a stand map on the screen are $\left(\mathrm{x}_{1}, \mathrm{y}_{1}, \mathrm{z}_{1}\right),\left(\mathrm{x}_{2}, \mathrm{y}_{2}, \mathrm{z}_{2}\right), \cdots,\left(\mathrm{x}_{\mathrm{n}}, \mathrm{y}_{\mathrm{n}}, \mathrm{z}_{\mathrm{n}}\right)$, respectively. If the whole stand map is rotated by $\alpha$ around the $\mathrm{x}$-axis and tree coordinates are transformed to $\left(\mathrm{x}_{1}^{\prime}{ }_{1}, \mathrm{y}_{1}^{\prime}{ }_{1}, \mathrm{z}^{\prime}{ }_{1}\right),\left(\mathrm{x}_{2}^{\prime}, \mathrm{y}_{2}^{\prime}, \mathrm{z}_{2}{ }_{2}\right), \cdots$ $\left(\mathrm{x}_{\mathrm{n}}^{\prime}, \mathrm{y}_{\mathrm{n}}^{\prime}, \mathrm{z}_{\mathrm{n}}^{\prime}\right)$, the matrix containing the locations of the trees (TS) before transformation is:

$$
T S=\left[\begin{array}{ccccc}
x_{1} & x_{2} & \ldots & x_{n-1} & x_{n} \\
y_{1} & y_{2} & \ldots & y_{n-1} & y_{n} \\
z_{1} & z_{2} & \ldots & z_{n-1} & z_{n} \\
1 & 1 & \ldots & 1 & 1
\end{array}\right]
$$

And the matrix after transformation is:

$$
T S^{\prime}=\left[\begin{array}{ccccc}
x_{1}^{\prime} & x_{2}^{\prime} & \ldots & x_{n-1}^{\prime} & x_{n}^{\prime} \\
y_{1}^{\prime} & y_{2}^{\prime} & \ldots & y_{n-1}^{\prime} & y_{n}^{\prime} \\
z_{1}^{\prime} & z_{2}^{\prime} & \ldots & z_{n-1}^{\prime} & z_{n}^{\prime} \\
1 & 1 & \ldots & 1 & 1
\end{array}\right]
$$


Based on equation (2.11), the relationship between $T S$ and $T S$ 'then is:

$$
\begin{aligned}
& {\left[\begin{array}{ccccc}
x_{1}^{\prime} & x_{2}^{\prime} & \ldots & x_{n-1}^{\prime} & x_{n}^{\prime} \\
y_{1}^{\prime} & y_{2}^{\prime} & \ldots & y_{n-1}^{\prime} & y_{n}^{\prime} \\
z_{1}^{\prime} & z_{2}^{\prime} & \ldots & z_{n-1}^{\prime} & z_{n}^{\prime} \\
1 & 1 & \ldots & 1 & 1
\end{array}\right]=R_{x}(\alpha) \times\left[\begin{array}{ccccc}
x_{1} & x_{2} & \ldots & x_{n-1} & x_{n} \\
y_{1} & y_{2} & \ldots & y_{n-1} & y_{n} \\
z_{1} & z_{2} & \ldots & z_{n-1} & z_{n} \\
1 & 1 & \ldots & 1 & 1
\end{array}\right]} \\
& \text { or } T S^{\prime}=R_{x}(\alpha) \times T S
\end{aligned}
$$

Similarly, the matrices can be rotated around the y-axis and z-axis, and the whole stand map can be rotated around y-axis and z-axis.

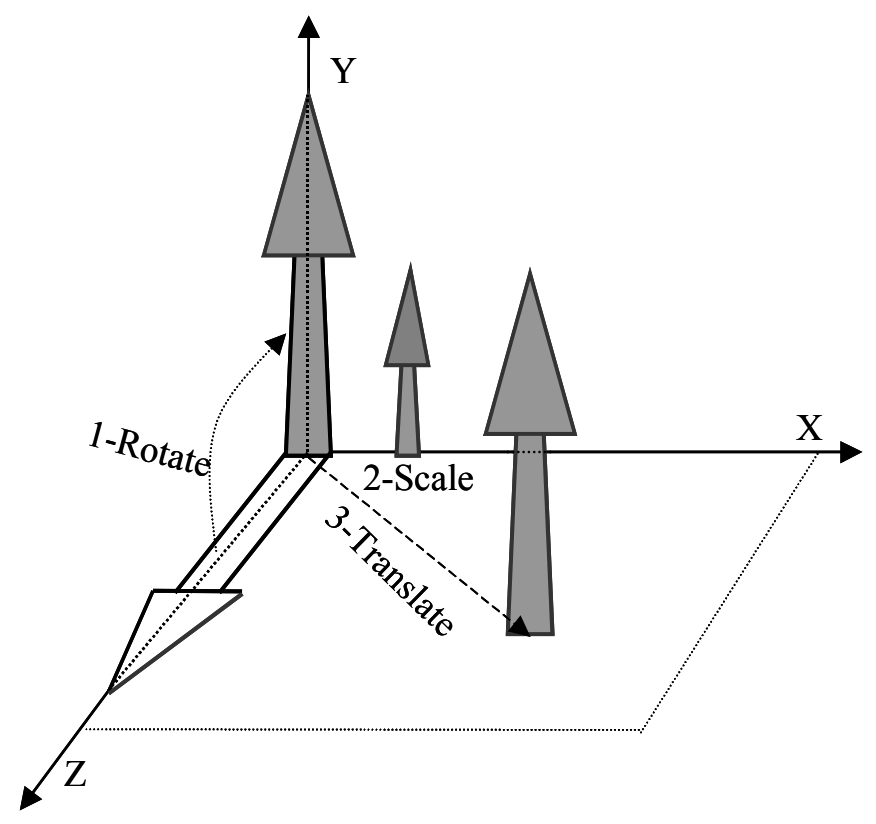

Figure 2.10. Modeling transformations. 


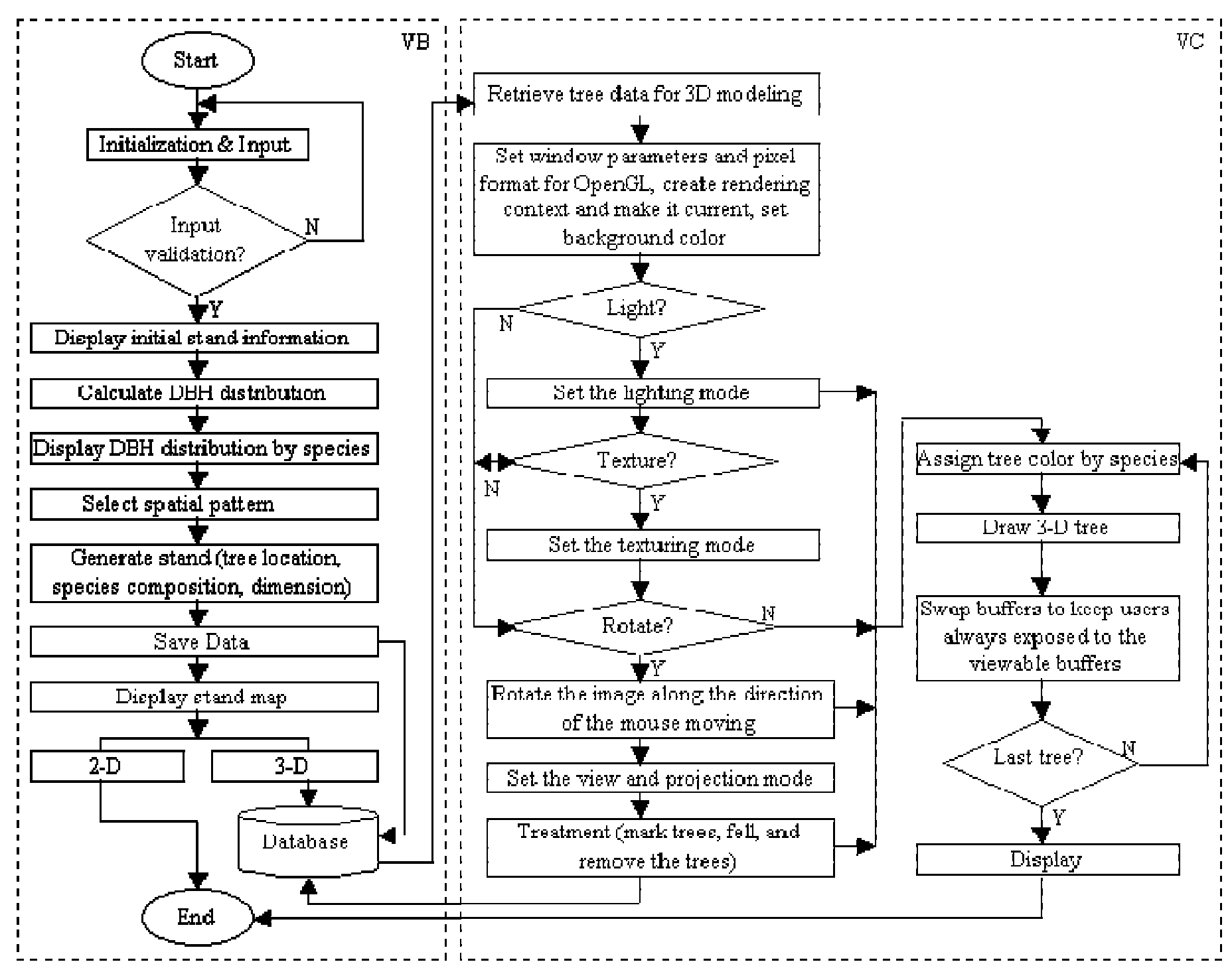

Figure 2.11. Flowchart of VB and VC components in the 3D stand generator system. 
Scale. Scale is performed by calling the g1Scale*(Sx ,Sy, Sz) function which creates the scale matrix $\Delta \mathrm{S}$.

$$
\Delta S=\left[\begin{array}{cccc}
S_{x} & 0 & 0 & 0 \\
0 & S_{y} & 0 & 0 \\
0 & 0 & S_{z} & 0 \\
0 & 0 & 0 & 1
\end{array}\right]
$$

Where Sx, Sy, and Sz are the scales to $\mathrm{x}, \mathrm{y}$, and $\mathrm{z}$ coordinate of each tree. Using the same method as for the rotation, the scale matrix model for the whole stand map is:

$$
\left[\begin{array}{ccccc}
x_{1}^{\prime} & x_{2}^{\prime} & \ldots & x_{n-1}^{\prime} & x_{n}^{\prime} \\
y_{1}^{\prime} & y_{2}^{\prime} & \ldots & y_{n-1}^{\prime} & y_{n}^{\prime} \\
z_{1}^{\prime} & z_{2}^{\prime} & \ldots & z_{n-1}^{\prime} & z_{n}^{\prime} \\
1 & 1 & \ldots & 1 & 1
\end{array}\right]=\Delta S \times\left[\begin{array}{ccccc}
x_{1} & x_{2} & \ldots & x_{n-1} & x_{n} \\
y_{1} & y_{2} & \ldots & y_{n-1} & y_{n} \\
z_{1} & z_{2} & \ldots & z_{n-1} & z_{n} \\
1 & 1 & \ldots & 1 & 1
\end{array}\right]
$$

or $T S^{\prime}=\Delta S \times T S$

Where TS' is the scale matrix that contains the coordinates of trees being scaled on the stand map after scaling transformation.

Translate. Similarly, the translation is performed by calling glTranslate* $(\mathrm{dx}, \mathrm{dy}, \mathrm{dz})$ function which generates the following translation matrix $\Delta \mathrm{T}$.

$$
\Delta T=\left[\begin{array}{cccc}
1 & 0 & 0 & d x \\
0 & 1 & 0 & d y \\
0 & 0 & 1 & d z \\
0 & 0 & 0 & 1
\end{array}\right]
$$

Where, $d x, d y, d z$ are the values needed to translate along $x$-axis, $y$-axis, and zaxis respectively. Based on equation (2.16), TS and TS' are rotated by: 


$$
\begin{aligned}
& {\left[\begin{array}{ccccc}
x_{1}^{\prime} & x_{2}^{\prime} & \ldots & x_{n-1}^{\prime} & x_{n}^{\prime} \\
y_{1}^{\prime} & y_{2}^{\prime} & \ldots & y_{n-1}^{\prime} & y_{n}^{\prime} \\
z_{1}^{\prime} & z_{2}^{\prime} & \ldots & z_{n-1}^{\prime} & z_{n}^{\prime} \\
1 & 1 & \ldots & 1 & 1
\end{array}\right]=\Delta T \times\left[\begin{array}{ccccc}
x_{1} & x_{2} & \ldots & x_{n-1} & x_{n} \\
y_{1} & y_{2} & \ldots & y_{n-1} & y_{n} \\
z_{1} & z_{2} & \ldots & z_{n-1} & z_{n} \\
1 & 1 & \ldots & 1 & 1
\end{array}\right]} \\
& \text { or } T S^{\prime}=\Delta T \times T S
\end{aligned}
$$

Where, $T S^{\prime}$ is the matrix that contains the coordinates of trees after translation on the stand map.

\section{Projection Transformation}

Projection transformation determines how objects are projected onto the screenthat is, the field of view, the objects inside it, and to some extent the appearance of those objects. Two kinds of projection modes were implemented in the system - perspective and parallel projections. The perspective projection matches how things are seen in daily life: which is that more distant objects appear smaller. The parallel (orthographic) projection maps objects directly onto the screen without affecting their relative sizes.

When a 3D stand map is being drawn in the system, SwapBuffers()always is called to swap the viewable and reusable buffers. By doing this, the user can reuse the viewable buffers while the drawing process is still being conducted. This reduces the time required to perform the $3 \mathrm{D}$ stand generation.

\subsection{Model Validation}

The 3D stand generator was validated by comparing tree characteristics of controlled stands with treated stands (Table 2.7). Comparable variables include stand 
density (trees per acre), DBH, total height, basal area per acre, volume per acre, and major species composition. Two natural hardwood stands were used as the controlled stands. Stand 1 was derived from the USFS dataset with 462 trees per acre, average DBH of 5.49 inches, average total height of 54.75 feet, basal area of 101.10 square feet per acre, and 1612.84 cubic feet per acre, respectively. The major species in stand 1 included sugar maple 37\%, American basswood 21\%, sweet birch 14\% American beech 10\%, and other hardwoods 18\%. Stand 2 was mapped in the West Virginia University forest. Stand density was 194 trees per acre with an average DBH of 14.05 inches, average total height 69.3 feet, 231.7 square feet per acre basal area, and 5116 cubic feet per acre. Thirty treated stands were generated for validation based on each controlled stand.

The stand generator was implemented to generate the exact trees per acre specified by the user. Average of DBH, total height, basal area per acre, and volume per acre of generated stands were compared to the means of corresponding variables of controlled stands. Differences never exceeded 10 percent. Major species composition also was compared with consistent and relatively lower differences $(<2 \%)$ noticed between the controlled stand and the generated stands.

Dunnett's two-tailed t-test was used to test if any generated stand was significantly different from the control stand (mapped stand) (Table 2.4). This test controls the Type I experimentwise error for comparisons of all treatments against a control, which is more powerful than a test designed to compare each mean with each other mean. Dunnett's test is conducted by computing a t-test between each experimental group and the control. 
Table 2.7. Comparisons of characteristics between controlled and treated stand.

\begin{tabular}{|c|c|c|c|c|c|c|c|c|c|c|c|c|c|c|c|c|}
\hline & \multicolumn{8}{|c|}{ USFS Stand (35 years old) } & \multicolumn{8}{|c|}{ WVU Stand (75 years old) } \\
\hline & \multirow{2}{*}{\multicolumn{2}{|c|}{$\begin{array}{l}\text { Controlled } \\
\text { stand }\end{array}$}} & \multirow{2}{*}{$\begin{array}{l}\text { Treated } \\
\text { stands }\end{array}$} & \multirow{2}{*}{$\begin{array}{c}\text { Difference } \\
(\%)\end{array}$} & \multicolumn{4}{|c|}{ Dunnett's t Tests $^{1}(\alpha=0.05)$} & \multirow{2}{*}{\multicolumn{2}{|c|}{$\begin{array}{c}\text { Controlled } \\
\text { stand }\end{array}$}} & \multirow{2}{*}{$\begin{array}{c}\text { Treated } \\
\text { stands }\end{array}$} & \multirow{2}{*}{$\begin{array}{c}\begin{array}{c}\text { Difference } \\
(\%)\end{array} \\
\end{array}$} & \multicolumn{4}{|c|}{ Dunnett's t Tests ${ }^{2}(\alpha=0.05)$} \\
\hline & & & & & $\mathrm{T}$ & $\mathrm{F}$ & DF & $\mathrm{P}$ & & & & & $\mathrm{T}$ & $\mathrm{F}$ & DF & $\mathrm{P}$ \\
\hline $\begin{array}{l}\text { Stand density } \\
\text { (trees/ac) }\end{array}$ & \multicolumn{2}{|l|}{462} & 462 & 0.00 & - & - & - & - & \multicolumn{2}{|l|}{194} & 194 & 0.00 & - & - & - & - \\
\hline DBH (inch) & \multicolumn{2}{|l|}{5.49} & 5.32 & -3.09 & 3.0103 & 0.04 & 14291 & 1.0000 & \multicolumn{2}{|c|}{14.05} & 14.32 & 1.92 & 3.0613 & 0.23 & 6080 & 1.0000 \\
\hline $\begin{array}{l}\text { Total height } \\
\text { (feet) }\end{array}$ & \multicolumn{2}{|l|}{54.75} & 55.17 & 0.77 & 3.0103 & 0.01 & 14291 & 1.0000 & \multicolumn{2}{|c|}{69.3} & 67.69 & -2.32 & 3.0613 & 0.03 & 6080 & 1.0000 \\
\hline $\begin{array}{l}\text { Basal area } \\
\left(\mathrm{ft}^{2} / \mathrm{ac}\right)\end{array}$ & \multicolumn{2}{|c|}{101.10} & 100.62 & -0.48 & 2.0453 & 1.10 & 29 & 0.3019 & \multicolumn{2}{|c|}{231.7} & 253.54 & 9.43 & 2.0423 & 0.30 & 29 & 0.5855 \\
\hline $\begin{array}{l}\text { Volume } \\
\left(\mathrm{ft}^{3} / \mathrm{ac}\right)\end{array}$ & \multicolumn{2}{|c|}{1612.84} & 1638.92 & 4.60 & 2.0453 & 3.91 & 29 & 0.0575 & \multicolumn{2}{|c|}{5116} & 4923.23 & -3.77 & 2.0423 & 0.00 & 29 & 0.9544 \\
\hline \multirow{5}{*}{$\begin{array}{l}\text { Species } \\
\text { Composition } \\
(\%)\end{array}$} & $\begin{array}{l}\text { Sugar } \\
\text { maple }\end{array}$ & 37 & 37.1 & 0.30 & & & & & $\begin{array}{l}\text { Yellow } \\
\text { poplar }\end{array}$ & 40 & 40.2 & 0.50 & \multirow{5}{*}{2.3060} & \multirow{5}{*}{0.00} & \multirow{5}{*}{8} & \multirow{5}{*}{1.0000} \\
\hline & $\begin{array}{l}\text { American } \\
\text { basswood }\end{array}$ & 21 & 21.0 & 0.00 & & & & & $\begin{array}{l}\text { Black } \\
\text { cherry }\end{array}$ & 18 & 18.1 & 0.55 & & & & \\
\hline & $\begin{array}{l}\text { Sweet } \\
\text { birch }\end{array}$ & 14 & 14.1 & 0.70 & 2.3060 & 0.00 & 8 & 1.0000 & $\begin{array}{l}\text { Red } \\
\text { maple }\end{array}$ & 16 & 15.9 & -0.63 & & & & \\
\hline & $\begin{array}{l}\text { American } \\
\text { beech }\end{array}$ & 10 & 9.9 & -1.00 & & & & & $\begin{array}{l}\text { Red } \\
\text { oak }\end{array}$ & 15 & 14.9 & -0.67 & & & & \\
\hline & Others & 18 & 17.9 & -0.55 & & & & & Others & 11 & 10.8 & -1.82 & & & & \\
\hline
\end{tabular}

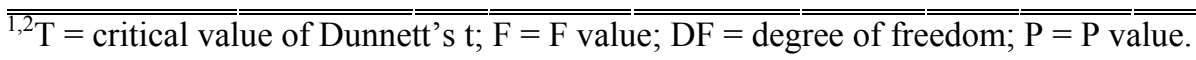


Each DBH class, total height, basal area per acre, and volume per acre were compared with the corresponding variables or classes in 30 generated stands. There was no significant difference in DBH class between the controlled and generated stands for both the USFS stand $(\mathrm{DF}=14291 ; \mathrm{P}=1.0000)$ and $\mathrm{WVU}$ stand $(\mathrm{DF}=6080 ; \mathrm{P}=1.0000)$. Total height of each individual tree in controlled stand was not significantly different from that in generated stands $(\mathrm{USFS}$ stand $\mathrm{DF}=14291 ; \mathrm{P}=1.0000, \mathrm{WVU}$ stand $\mathrm{DF}=$ $6080 ; \mathrm{P}=1.0000)$. Comparisons of basal area per acre also indicated no significant differences existed between the controlled and generated stands (USFS stand DF $=29 ; \mathrm{P}$ $=0.3019, \mathrm{WVU}$ stand $\mathrm{DF}=29 ; \mathrm{P}=0.5855)$. The volume per acre in the controlled stand did not differ from that in the generated stands (USFS stand DF $=29 ; \mathrm{P}=0.0576, \mathrm{WVU}$ stand $\mathrm{DF}=29 ; \mathrm{P}=0.9544)$. No significant differences in major species composition were identified between the mapped and generated stands (USFS stand DF $=8 ; \mathrm{P}=$ 1.0000, WVU stand $\mathrm{DF}=8 ; \mathrm{P}=1.0000)$.

\subsection{Application Example}

A natural hardwood stand in central Appalachia was generated to illustrate the performance of the 3D stand generator. The stand was assumed to have a $40 \%$ yellowpoplar $40 \%, 30 \%$ red oak, $15 \%$ chestnut oak, and $15 \%$ red maple. The stand density is 400 trees per acre and plot size is 0.4 acre. It also is assumed that the stand is about 75 years old with trees randomly distributed.

Once the above information was entered, a 2D stand map was generated and displayed (Figure 2.12(a)) along with the stand information (species composition, spatial pattern, DBH range, stand density, plot size, and stand age), DBH distribution by species 
(displayed by line or bar) and species color legend. By changing the species input, the user can view the DBH distribution pattern for each individual species or for the entire plot. Meanwhile a stand map data file is created and saved in the system. The 3D stand map is displayed by changing the display mode to 3D (Figure 2.12(b)). Some functionality can be performed on the 3D stand map. For example, the image can be rotated left or right continuously to examine the stand structure from different directions. The user also can change crown height and diameter by using the "tree design" module. In order to differentiate species on the map, a unique color is randomly generated and assigned to each individual species. Additionally, tree height and DBH are also drawn to scale for better visualization.

Perspective and parallel projection and three view modes of projective view, profile view, and overhead view also are added to the system. Perspective projection and projective view are the default projection and view modes, respectively (Figure 2.12(b)). Profile view and overhead view can be enabled by changing the view mode in the menu bar (Figure 2.12(c) and 2.12(d)). The 3D component also allows the user to mark trees to be harvested, fell marked trees, remove the felled trees, and save the operational data into the database for later analyses (Figure 2.13(a), 2.13(b), and 2.13(c)). Additionally, user is allowed to mark the trees by species, $\mathrm{DBH}$, tree height, or combine them together. 


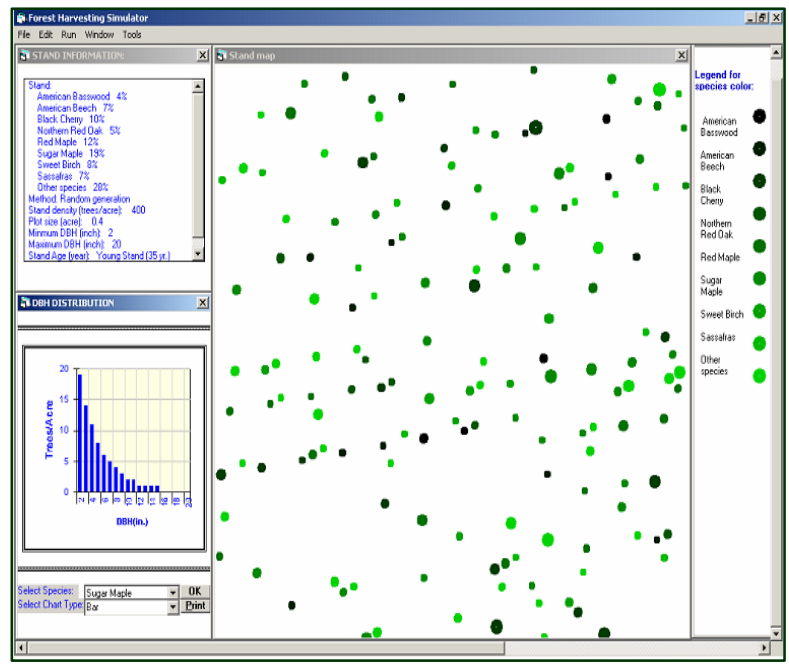

(a)

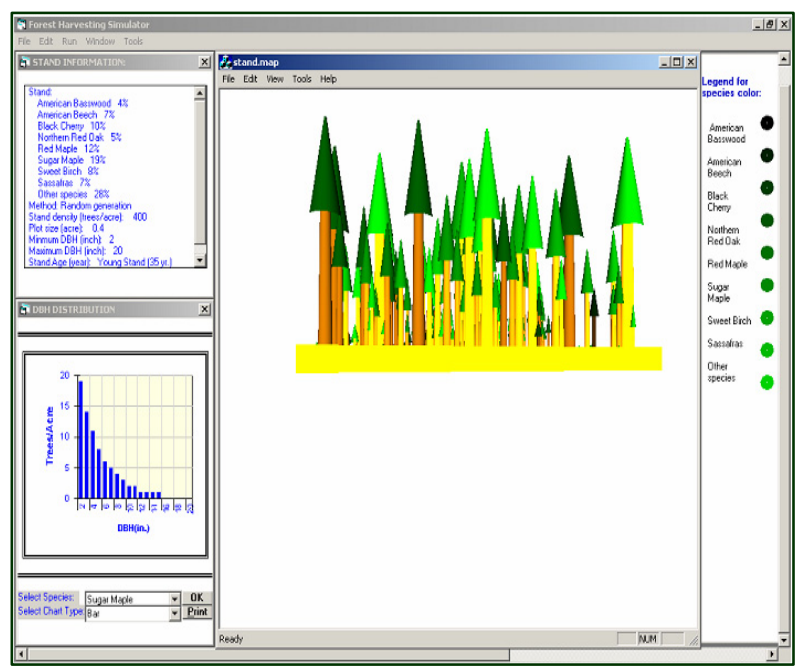

(c)

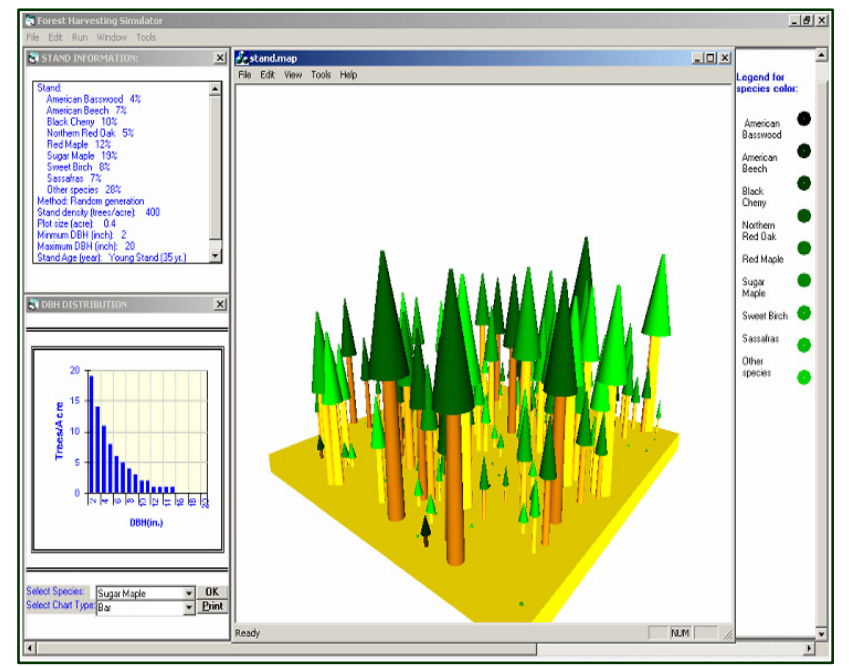

(b)

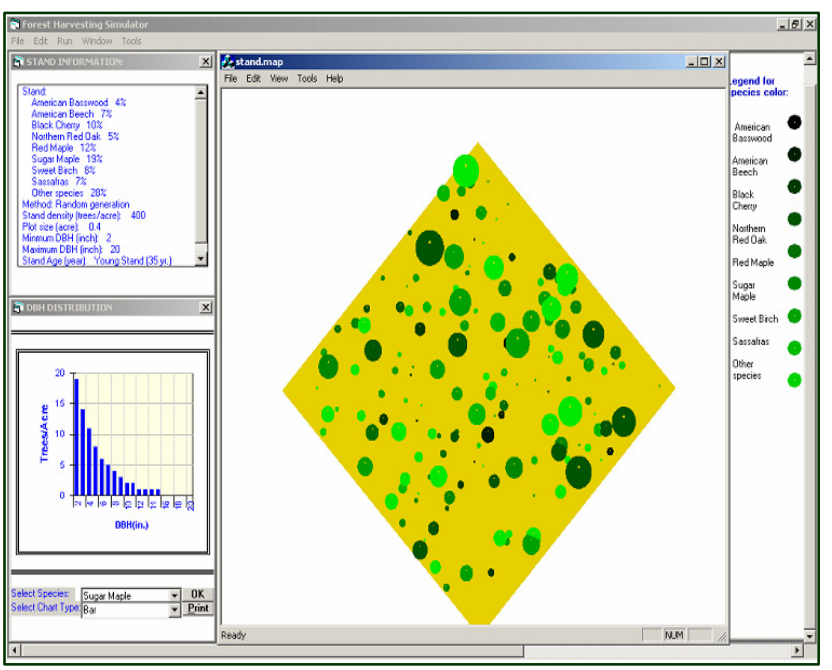

(d)

Figure 2.12. Generated stand maps. 


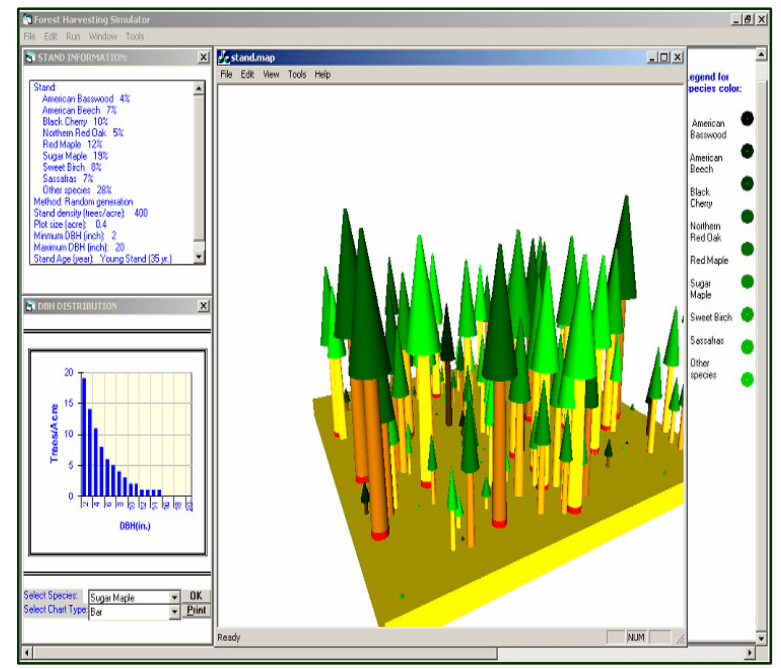

(a) Mark trees

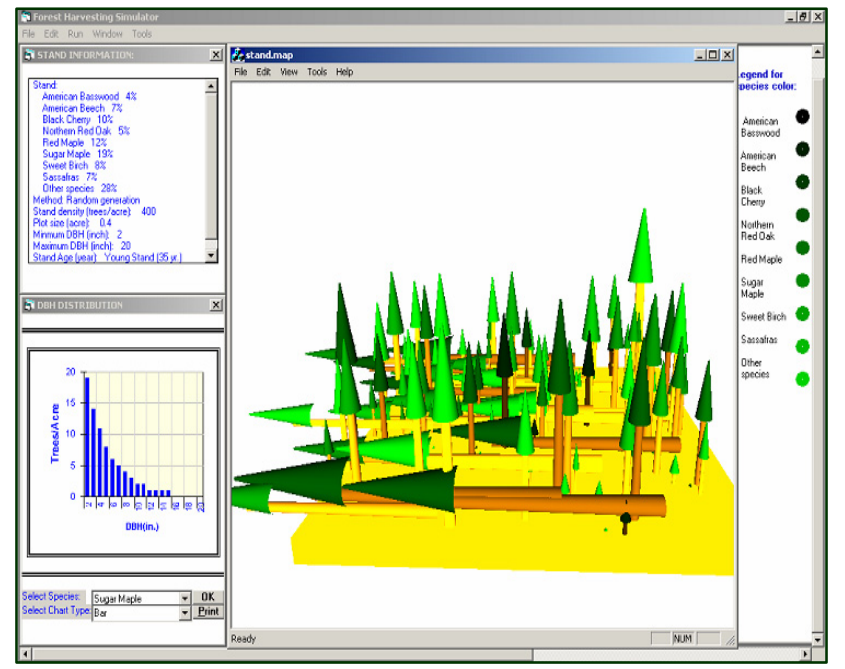

(b) Felling

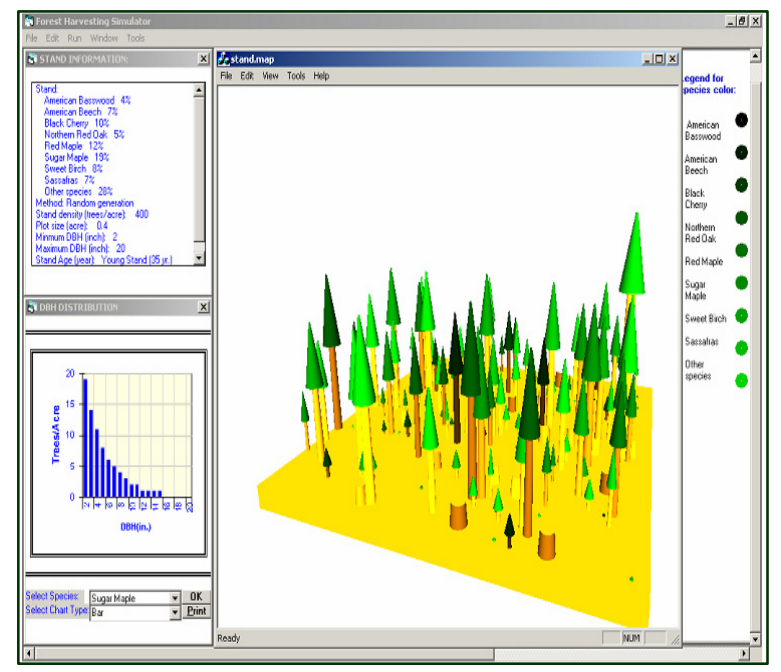

(c) Extraction

Figure 2.13. Perform forest operations. 


\section{CHAPTER 3: SYSTEM MODELING OF HARVESTING OPERATIONS}

\subsection{Felling Operations}

Three felling machines were modeled and simulated for central Appalachian hardwood forests: chainsaw (CS), drive-to-tree feller-buncher (FB), and cut-to-length single grip harvester (HV).

\section{Chainsaw}

Four delay free functions were modeled for chainsaw felling operations based on the results reported by Long (2003).

(1) Walk to Tree: Begins when feller starts toward the tree to be cut. Ends when feller reaches the tree. Distance and time walked to each individual tree were recorded.

(2) Acquire: Begins when feller starts clearing around tree and judging felling direction. Ends when feller is ready to cut the tree. Acquiring time was calculated and recorded as a function of $\mathrm{DBH}$ of the tree to be cut.

(3) Cut Tree: Begins when feller starts cutting the wedge of the tree. Ends when tree hits the ground. Cutting time was recorded as a function of DBH of the tree cut.

(4) Top/Delimb: Begins when feller starts delimbing tree. Ends when tree is finished and feller starts toward next tree to be cut. It is a common practice of delimbing hardwoods by chainsaw. Topping/delimbing time was modeled as a function of DBH of the tree cut. 
Order and location of each felled tree and the corresponding tree species, DBH, merchantable height, total height, and tree volume were recorded and saved to a database. Directional felling was assumed for the chainsaw felling operation. Two felling patterns (Simmons 1979) adopted either in a Herringbone pattern with tops falling away from the road, or felling with tops toward the road (Figure 3.1). . Skid roads were assumed on two sides of the felling plot. If the tree selected to be cut on is the left side of the plot centerline, the tree will be cut down with the butt towards the left, and vice versa.

Generally, the feller will start from one end of the felling plot and move to the nearest tree to be cut and fell the selected tree in a narrow swath (user defined). When one swath is finished, the feller will move to the next nearest swath and continue to cut trees until all

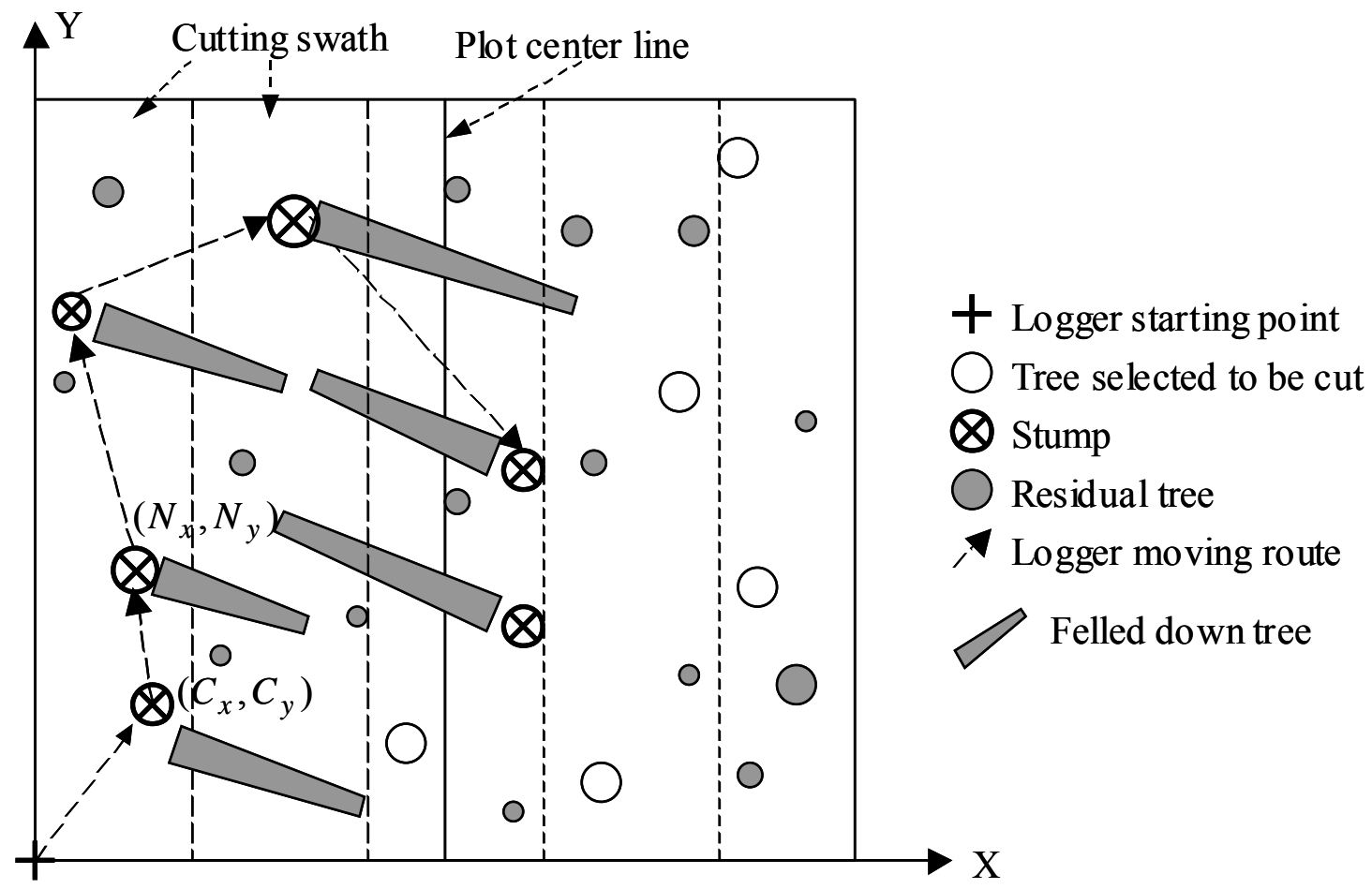

trees selected to be cut are felled (Figure 3.2).

Figure 3.1. Felling in herringbone pattern with the tops falling away from the skid road. 


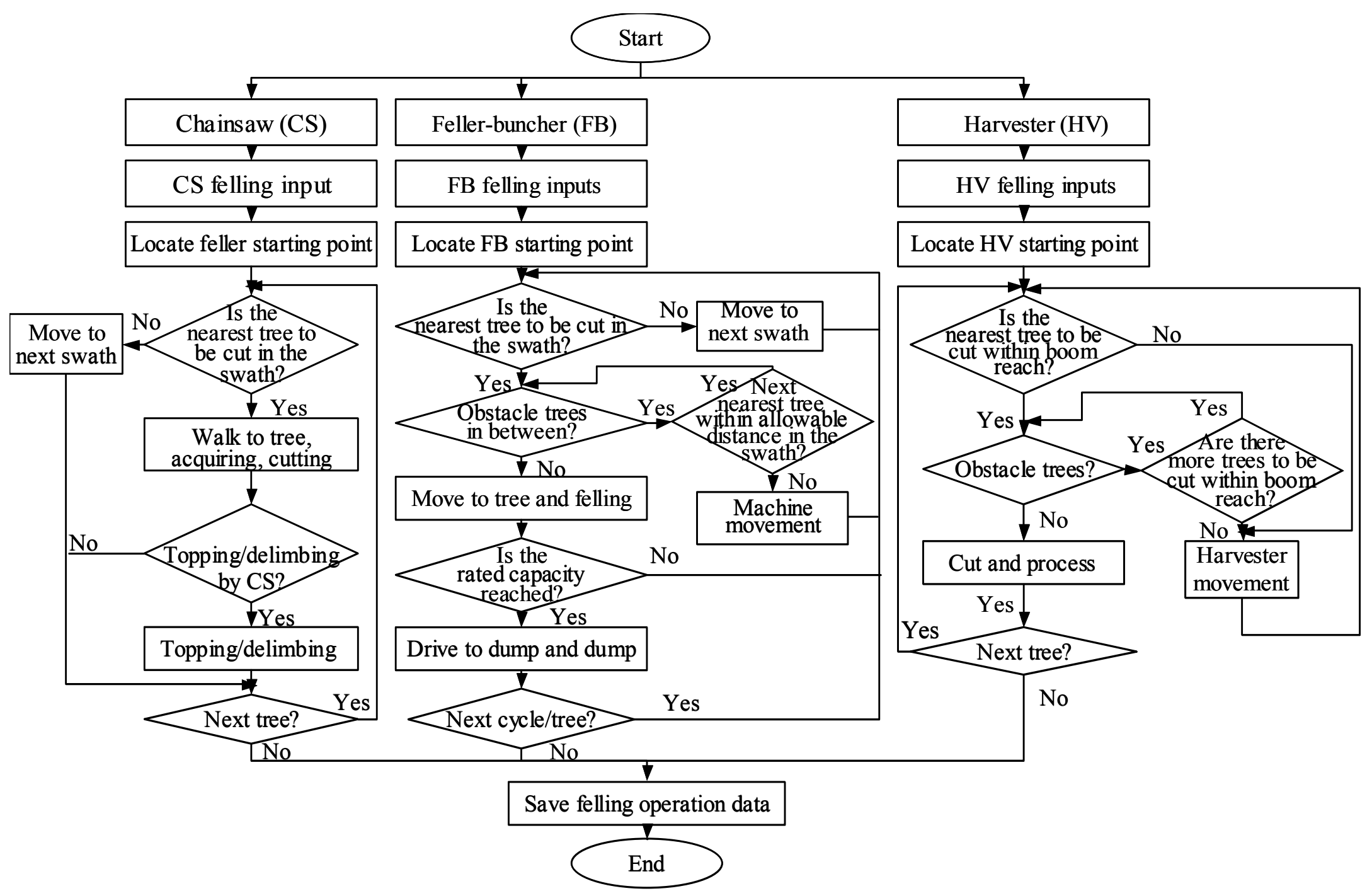

Figure 3.2. Flowchart of felling operations. 
If the location of the current cut tree is defined as $\left(C_{x}, C_{y}\right)$ and the next tree to be cut is $\left(N_{x}, N_{y}\right)$, then the distance between cutting trees $(d)$ and the time to walk to the tree $(t)$ can be calculated as follows:

$$
\left\{\begin{array}{l}
d=\sqrt{\left(N_{y}-C_{y}\right)^{2}+\left(N_{x}-C_{x}\right)^{2}} \\
t=\frac{d}{\text { walk speed }}
\end{array}\right.
$$

\section{Feller-Buncher}

Four functions were modeled for the drive-to-tree feller-buncher and the elemental times were calculated based on the results reported by Long (2003).

(1) Drive to tree: Begins when the feller-buncher finishes the previous cycle and starts toward the next tree to be cut. Ends when feller-buncher reaches the tree. Distance and driving time to each individual tree are recorded.

(2) Cut: Begins when felling head is positioned on the tree and ends when the tree is completely severed from the stump. Cutting time is calculated as a function of DBH and merchantable height of the cutting tree.

(3) Drive to dump: Begins when the feller-buncher moves from the stump with the tree and ends when movement is stopped.

(4) Dump: Begins when feller-buncher is ready to dump the tree and ends when tree hits the ground.

The feller-buncher is first located at one end of the felling plot and then moves parallel to the rows (15-20 feet width) of the trees (Wang and Green 1999, Wang 2003). The nearest marked tree is identified first. Before cutting a selected tree, an "obstacle 
tree checking" procedure is examined to avoid residual tree damage. If some residual trees (obstacle trees) are found between the tree to be cut and the current machine location, the next nearest tree is searched and checked. If the next nearest tree within allowable distance (10 feet) in the same swath is found, another "obstacle tree checking" procedure is conducted to check obstacle trees in the machine route. If no obstacle tree is found between the next nearest tree and the current machine location, the machine will move to the next nearest tree and cut it. If the next nearest tree check is negative or the obstacle tree checking is positive, the feller-buncher must detour to cut the nearest tree and avoid obstacle trees at the same time. Once a tree is cut, it is added to the felling head, and the rated capacity of the felling head is checked before the feller-buncher moves to next tree to be cut. If the rated capacity of the felling head is reached, the fellerbuncher moves to the location of the bunch to be built and drops the trees from the felling head. As each is finished, the feller-buncher moves to the next nearest row and repeats this procedure until all trees selected to be cut in a felling plot are cut (Figure 3.2).

Each standing tree is first presumed as a potential obstacle to the tree to be cut and its position is checked (Figure 3.3 (a)). If $A\left(X_{1}, Y_{1}\right)$ is the current location of the machine, and $B\left(X_{2}, Y_{2}\right)$ is the coordinate of the nearest tree selected to be cut, the line $\overline{A B}$ is the expected machine-moving route between trees $\mathrm{A}$ and $\mathrm{B}$ if there are no obstacle trees on the route. $M\left(X_{3}, Y_{3}\right)$ is the coordinate of the tree being checked as a potential obstacle tree. Next, $\mathrm{d}$ is the perpendicular distance from point $M$ to line $\overline{A B}$ in feet, $r$ is half the DBH of the tree examined (in inches), and $R$ is the sum of $r$ and the protection distance in feet (1.0 feet in this study). The width of the protection distance can be express as $R-r / 12$. A minimum protection distance restriction of 1.0 feet was used in 
the search algorithm to avoid the residual tree damage. If line $\overline{A B}$ passes through any portion of the protection buffer or the tree checked, then the tree being checked is considered as an obstacle tree.

The line segment $\overline{A B}$ can be expressed as:

$$
y=\frac{Y_{1}-Y_{2}}{X_{1}-X_{2}} x+\left(Y_{1}-X_{1} \frac{Y_{1}-Y_{2}}{X_{1}-X_{2}}\right)
$$

The distance $(d)$ from the center of the tree being checked $M\left(X_{3}, Y_{3}\right)$ to line

$\overline{A B}$ can be calculated as:

$$
d=\frac{\left|\left(Y_{1}-Y_{3}\right)\left(X_{2}-X_{1}\right)-\left(Y_{2}-Y_{1}\right)\left(X_{1}-X_{3}\right)\right|}{\sqrt{\left(Y_{2}-Y_{1}\right)^{2}+\left(X_{2}-X_{1}\right)^{2}}}
$$

If $d<=r / 12+1.0$, then there is some portion of a tree across line $\overline{A B}$ or the tree is within the protection distance, this tree is an obstacle. To avoid residual tree damage, the machine continues to check if the next nearest tree $C\left(X_{4}, Y_{4}\right)$ is within the cutting strip. At the same time, the distance from the current machine location to the next nearest tree (if it is within the cutting strip) $d_{A C}$ also is checked to ensure the next tree to be cut is not too far from the machine. If the distance to the next nearest tree is less than or equal to the distance to the nearest tree plus 10 feet (equation (3.4)) and there are no obstacle trees on the route, then the machine moves to $C\left(X_{4}, Y_{4}\right)$ and cuts the next nearest tree, otherwise the machine will detour (to avoid obstacle trees) and cut the tree at $B\left(X_{2}, Y_{2}\right)$. 


$$
\left\{\begin{array}{l}
d_{A C}<=d_{A B}+10 \\
d_{A C}=\sqrt{\left(Y_{4}-Y_{1}\right)^{2}+\left(X_{4}-X_{1}\right)^{2}} \\
d_{A B}=\sqrt{\left(Y_{2}-Y_{1}\right)^{2}+\left(X_{2}-X_{1}\right)^{2}}
\end{array}\right.
$$

Where $d_{A C}=$ distance between point $A$ and point $C$, feet;

$$
d_{A B}=\text { distance between point } A \text { and point } B \text {, feet. }
$$

To find the next location where the machine should move to cut the tree at $B\left(X_{2}, Y_{2}\right)$, a group of lines parallel to line $\overline{A B}$ are drawn. Among the parallel lines, there must be two lines $a b$ and $c d$ tangent to the protection buffer circle at point $E\left(X_{5}, Y_{5}\right)$ and $F\left(X_{6}, Y_{6}\right)$, respectively (Figure 3.3(b)). The equation for parallel line is expressed as: $y=a x+b$.

Where, $a=\frac{Y_{1}-Y_{2}}{X_{1}-X_{2}}$.

Since lines $a b$ and $c d$ are tangent to the protection buffer circle, the distance $\left(d_{M E}\right.$ or $\left.d_{M F}\right)$ from the center of the circle (location of obstacle tree) $M\left(X_{3}, Y_{3}\right)$ to line $a b$ and $c d$ is equal to the radius of the circle $R$, or:

$$
d_{M E} \text { or } d_{M F}=\frac{\left|a X_{3}-Y_{3}+b\right|}{\sqrt{a^{2}+1}}=R
$$

Solving equation (3.5) yields $b=\left(Y_{3}-a X_{3}\right) \pm R \sqrt{a^{2}+1}$.

The coordinates for point $E\left(X_{5}, Y_{5}\right)$ and $F\left(X_{6}, Y_{6}\right)$ then are determined by solving the following group of functions.

$$
\left\{\begin{array}{l}
y=a x+b \\
\left(x-X_{3}\right)^{2}+\left(y-Y_{3}\right)^{2}=R^{2}
\end{array}\right.
$$


The following equation can be derived from equation (3.6).

$$
\begin{aligned}
& (1+a) x^{2}-2\left(X_{3}-a b+a Y_{3}\right) x=R^{2}-\left(X_{3}{ }^{2}+Y_{3}{ }^{2}\right)+2 b Y_{3}-b^{2} \\
& \text { If } m=X_{3}-a b+a Y_{3} \text { and } k=R^{2}-\left({X_{3}}^{2}+Y_{3}{ }^{2}\right)+2 b Y_{3}-b^{2} \text {, then equation (3.7) }
\end{aligned}
$$

can be rewritten as

$$
(1+a) x^{2}-2 m x-k=0
$$

Solving equation (3.8) for $\mathrm{x}$ yields:

$$
x=\frac{m \pm \sqrt{m^{2}+(1+a) k}}{1+a}
$$

the two possible solutions of $x\left(x_{a}\right.$ and $\left.x_{b}\right)$ are:

$$
x_{a}=\frac{m+\sqrt{m^{2}+(1+a) k}}{1+a} \text { and } x_{b}=\frac{m-\sqrt{m^{2}+(1+a) k}}{1+a} \text {. Consequently, }
$$

$E\left(X_{5}, Y_{5}\right)$ and $F\left(X_{6}, Y_{6}\right)$ can be expressed as follows.

$$
\begin{gathered}
E\left\{\begin{array}{l}
X_{5}=\min \left(x_{a}, x_{b}\right) \\
Y_{5}=a X_{5}+b
\end{array}\right. \\
F\left\{\begin{array}{l}
X_{6}=\max \left(x_{a}, x_{b}\right) \\
Y_{6}=a X_{6}+b
\end{array}\right.
\end{gathered}
$$

The obstacle checking procedure will be repeated to see if any residual trees remain between points $E$ and $B$ or between points $F$ and $B$, respectively. If there are residual trees under the above condition, then the checking procedure are repeated again until no obstacle trees are found on the machine-moving route. If one of the checking results is negative (no residual tree in-between) and the other is positive, the machine moves to the point having a negative checking result (no residual tree in-between). If both the checking results are negative (no residual tree in-between), then a minimum 
moving distance restriction (equation 3.10) will be used to make sure that the machine always follows the shortest route.

$$
d_{\text {move }}=\min \left\{d_{A E}, d_{A F}\right\}
$$

Where, $d_{\text {move }}=$ feller-buncher moving distance, feet;

$$
\begin{aligned}
& d_{A E}=\text { distance between point } \mathrm{A} \text { and } \mathrm{E} \text {, feet; } \\
& d_{A F}=\text { distance between point } \mathrm{A} \text { and } \mathrm{F} \text {, feet. }
\end{aligned}
$$

If $d_{A E}<=d_{A F}$, feller-buncher will first move to point $E\left(X_{5}, Y_{5}\right)$. Otherwise, the feller-buncher will move to point $F\left(X_{6}, Y_{6}\right)$. To cut the tree at point $B\left(X_{2}, Y_{2}\right)$, the above procedures will be repeated until no obstacle trees are found and the feller-buncher can move directly to the tree to be cut.

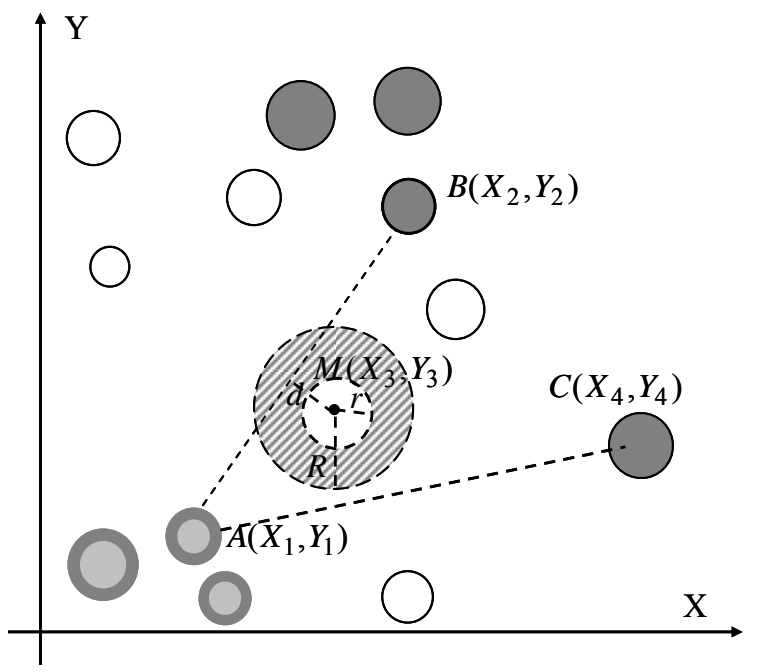

(a)

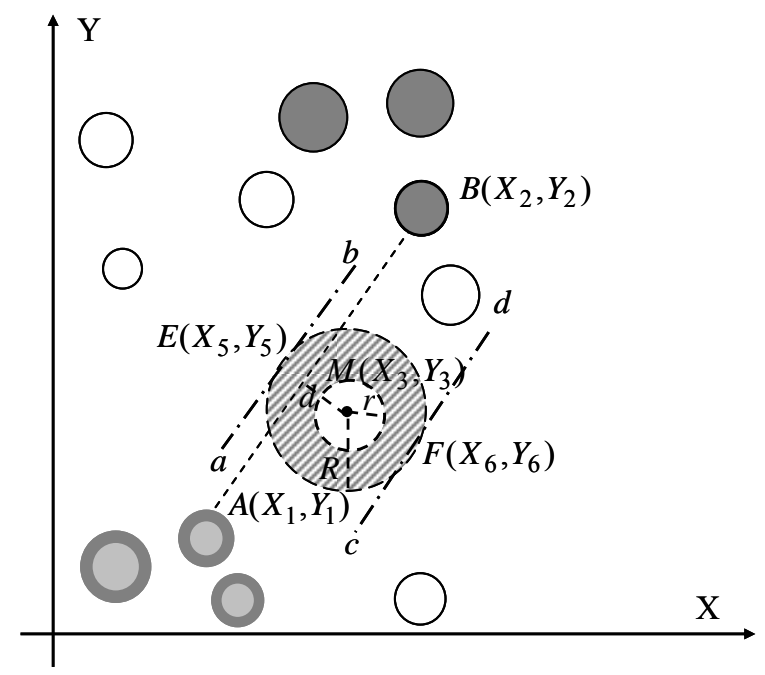

(b)

Figure 3.3. Algorithm of obstacle tree checking procedure for the feller-buncher. 


\section{Harvester}

Six functions were modeled for the harvester (Wang and Greene 1999): move, boom extend/retreat, cut, swing boom, process, and dump. Several trees within the boom reach could be cut and processed at one machine stop. Processed logs are piled on either side of the harvester trail for later forwarding. The harvester usually runs along a straight trail and the trail width is set to 13 feet in this model. All trees on the trail must be removed for the machine movement and trees on either side of the trail can be cut based on the harvesting and processing options (Figure 3.2).

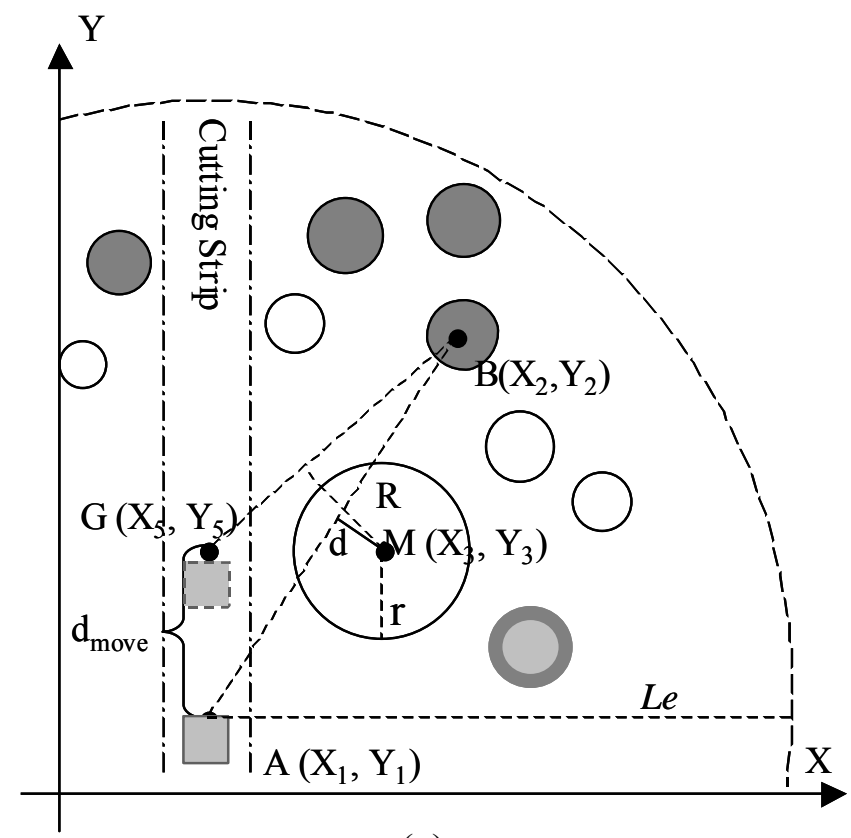

(a)

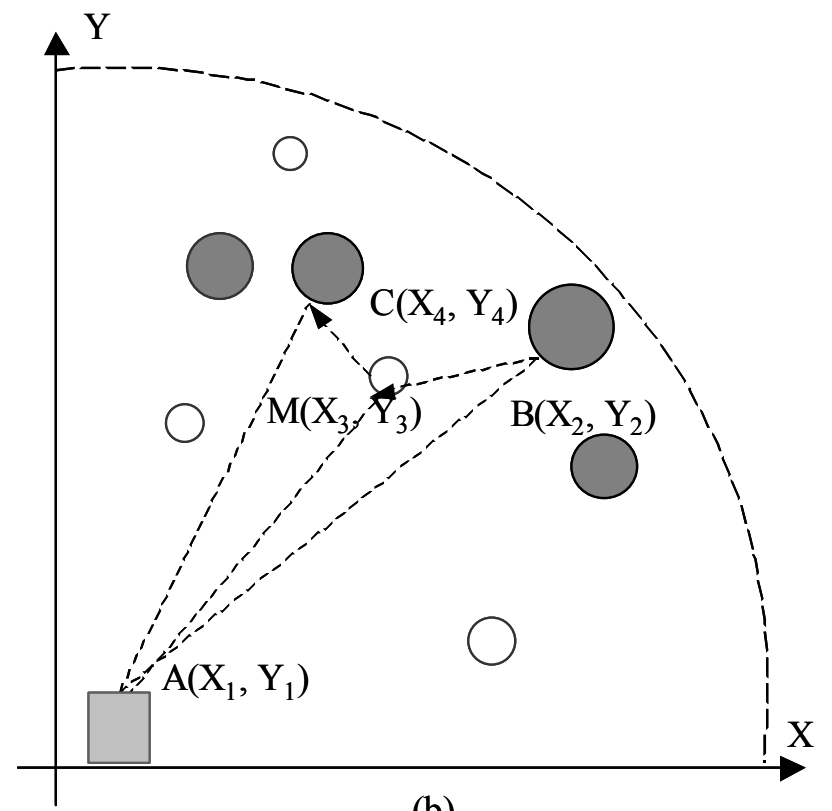

(b) Tree selected to be cut $\bigcirc$ Residual tree $\bigcirc$ Stump $\square$ Harvester

Figure 3.4. Algorithm for harvester checking obstacle trees. 
Obstacle tree checking also is performed for the harvester before cutting a tree (Wang et al. 2003). Each standing tree is presumed to be a potential obstacle tree and its location is checked (Figure 3.4(a)). If the maximum boom reach is $L_{\text {boom }}$, and the boom reach ratio (the effective boom reach over the maximum boom reach) is $r_{\text {boom }}$, then the effective boom reach $\left(L_{e}\right)$ is $L_{e}=L_{\text {boom }} * r_{\text {boom }}$.

If $d \leq r / 12+1.0$ (again assuming a 1.0 feet minimum protection distance), then there is some portion of a tree across line $\overline{A B}$ or the tree is within the protection distance, so the tree is an obstacle. Consequently, the machine has to move to point $G\left(X_{5}, Y_{5}\right)$ to cut the selected tree. To avoid residual tree damage, $R \geq r / 12+1.0$. Because the harvester always moves on a straight line, the following condition will be true: $X_{5}=X_{1}$. Then the next machine location $G\left(X_{5}, Y_{5}\right)$ can be derived. Line $\overline{B G}$ can be expressed as follows:

$$
y=\frac{Y_{5}-Y_{2}}{X_{1}-X_{2}} x+\left(Y_{2}-X_{2} \frac{Y_{5}-Y_{2}}{X_{1}-X_{2}}\right)
$$

If $a=\frac{Y_{5}-Y_{2}}{X_{1}-X_{2}}$ and $b=Y_{2}-X_{2} \frac{Y_{5}-Y_{2}}{X_{1}-X_{2}}$, then the following equations is derived:

$$
\begin{aligned}
& R=\frac{\left|a X_{3}-Y_{3}+b\right|}{\sqrt{a^{2}+1}} \\
& b=Y_{2}-a^{*} X_{2}
\end{aligned}
$$

Substituting $b$ in equation (3.13) into equation (3.12), results in equation (3.14).

$$
R^{2}\left(a^{2}+1\right)=\left[a\left(X_{3}-X_{2}\right)+\left(Y_{2}-Y_{3}\right)\right]^{2}
$$

Setting $k_{1}=\frac{X_{3}-X_{2}}{R}$ and $k_{2}=\frac{Y_{2}-Y_{3}}{R}$, equation (3.14) can be rewritten as 


$$
a^{2}+1=\left(a k_{1}+k_{2}\right)^{2} \text { and }\left(k_{1}^{2}-1\right) a^{2}+2 k_{1} k_{2} a+k_{2}^{2}-1=0
$$

Solving this quadratic equation for $a$ results in:

$$
a=\frac{-k_{1} k_{2} \pm \sqrt{k_{1}^{2}+k_{2}^{2}-1}}{k_{1}^{2}-1}
$$

When $a>0$ the machine cuts the trees on right side of the trail and when $a<=0$ the machine cuts the trees on left side of the trail. Therefore, the next machine location can be expressed as follows:

$$
\left\{\begin{array}{l}
X_{5}=X_{1} \\
Y_{5}=a X_{1}+\left(Y_{2}-a X_{2}\right)=a\left(X_{1}-X_{2}\right)+Y_{2}
\end{array}\right.
$$

To avoid residual tree damage, the machine-move distance is defined as $d_{i}=|A G|=\left|Y_{5}-Y_{1}\right|$. If no obstacle trees exist, the tree can be cut at the current machine location, and the machine then moves to the next stop: $d_{\text {move }}=\min \left\{d_{i}\right\}$.

If the boom is already extended (Figure 3.5(b)), the machine is at point $A\left(X_{1}, Y_{1}\right)$, the boom is at point $B\left(X_{2}, Y_{2}\right)$, and the next tree to be cut is at point $C\left(X_{3}, Y_{3}\right)$. Before swinging the boom directly from point $B$ to point $A$, the presence of residual trees between line $\overline{A B}$ and line $\overline{A C}$ must be checked (Eliasson 1998). Mathematically, the following conditions indicate if a tree is an obstacle:

$$
\begin{aligned}
& \operatorname{Min}\left\{\left|S_{\overline{A B}}\right|,\left|S_{\overline{A C}}\right|\right\} \leq\left|S_{\overline{A M}}\right| \leq \operatorname{Max}\left\{\left|S_{\overline{A B}}\right|,\left|S_{\overline{A C}}\right|\right\} \\
& d_{A M} \leq d_{A B},
\end{aligned}
$$

where, $S_{\overline{A B}}, S_{\overline{A C}}, S_{\overline{A M}}$ are the slopes for lines $\overline{A B}, \overline{A C}$, and $\overline{A M}$, respectively, and $d_{A M}, d_{A B}$ are the distances from point $A$ to $M$, and from point $A$ to $B$ (feet), respectively. Mathematically, this relationships are expressed as: 


$$
\begin{aligned}
S_{\overline{A B}} & =\frac{Y_{2}-Y_{1}}{X_{2}-X_{1}} ; S \frac{Y_{4}-Y_{1}}{A C}=\frac{X_{4}-X_{1}}{X_{3}}=\frac{Y_{3}-Y_{1}}{X_{3}-X_{1}} \\
d_{A M} & =\sqrt{\left(Y_{1}-Y_{3}\right)^{2}+\left(X_{1}-X_{3}\right)^{2}} \\
d_{A B} & =\sqrt{\left(Y_{1}-Y_{2}\right)^{2}+\left(X_{1}-X_{2}\right)^{2}}
\end{aligned}
$$

If the conditions in equation (3.18) are met, the checked tree is an obstacle. To cut the tree at $C\left(X_{3}, Y_{3}\right)$ from boom position $B\left(X_{2}, Y_{2}\right)$, the boom has to retreat from $B$ to $M$ first, and then extend from $M$ to $C$ if no other trees exist between line $\overline{A M}$ and line $\overline{A C}$. If no obstacle trees are found, the boom will swing directly from $B$ to $C$.

\subsection{Extraction Operations}

\section{Extraction Patterns}

The five extraction patterns modeled were similar to the patterns described by Wang and LeDoux (2003). Skidding pattern 1 (SP1) of free-style skidding has no designated skidding trails. The skidder can always skid the nearest tree or log bunches and then travel back to the landing (Figure 3.5 (a)). Skidding pattern 2 (SP2) has one primary skid trail running through the middle of the site (Figure 3.5 (b)). The skidder starts from the landing and follows the primary skid trail to pick up the nearest tree or log bunches. After the skidder is fully loaded, it returns to the primary skid trail toward the landing. With skidding pattern 3 (SP3) one diagonal primary skid trail runs from the landing to the diagonal corner of the site (if the landing is at one corner of the site) (Figure 3.5 (c)). Two diagonal primary skid trails running from the landing to the corners of the site exist for skidding pattern 4 (SP4) (Figure 3.5 (d)). Skidding pattern 5 (SP5) 
has two primary skid trails across the site (Figure 3.5 (e)); these two trails divide the skidding site into three even sections. The skidder starts at the landing, locates the nearest tree or log bunches to be skidded, and then drives back to the landing along the skid trail. With forwarding pattern 1 (FP 1), the forwarder starts from the landing and follows the trails of the harvester, and no additional skid trails are needed (Figure 3.5 (f)).

\section{Cable Skidder}

Cable skidding can be used for slopes up to $40 \%$ and usually are employed for all types of soils. Four functions were modeled for cable skidder skidding. The elemental time for each function was calculated based on results from Long (2003).

(1) Travel empty: Begins when skidder leaves landing with empty cable and ends when skidder arrives at logs to be skidded and is ready for skidding.

(2) Choke: Begins when skidder operator gets out to choke logs and ends when skidder is full and ready to return to the landing.

(3) Travel loaded: Begins when skidder starts toward landing full of logs and ends when skidder reaches landing with logs and ready to unload.

(4) Unchoke: Begins when skidder operator gets out to unchoke logs and ends when all logs unchoked and skidder is ready to leave landing for another load. 


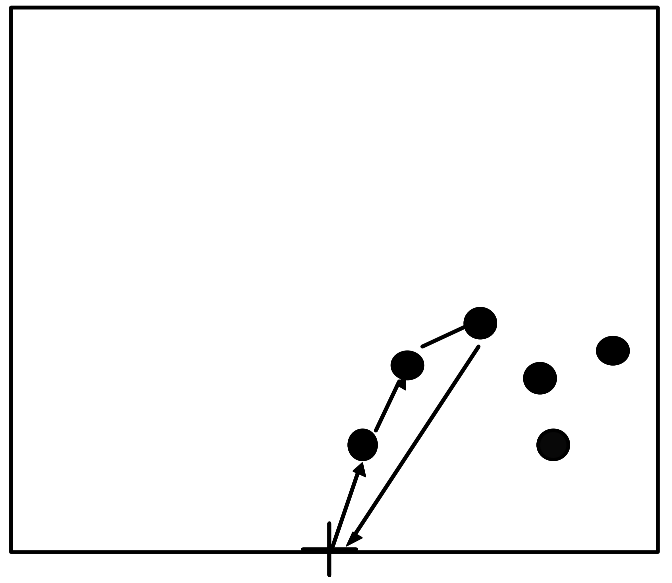

(a) Skidding pattern 1 (SP1)

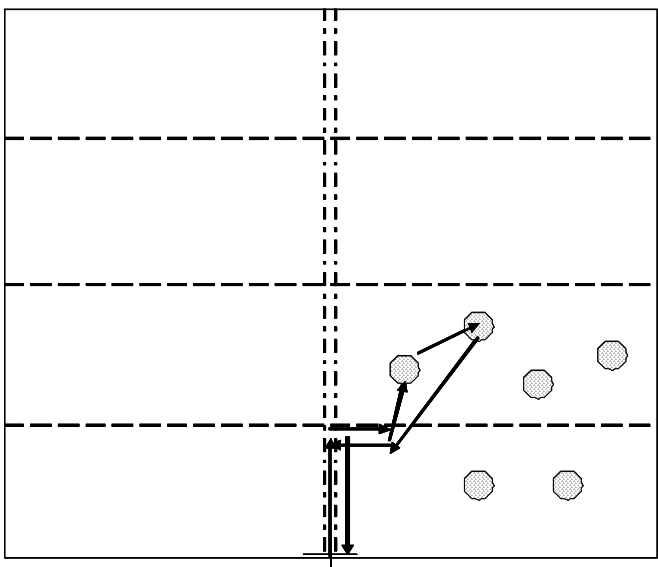

(b) Skidding pattern 2 (SP2)

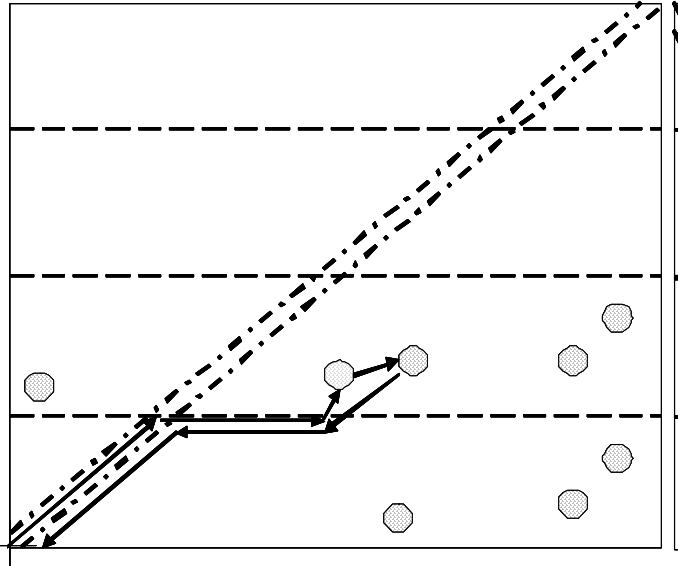

(c) Skidding pattern 3 (SP3)

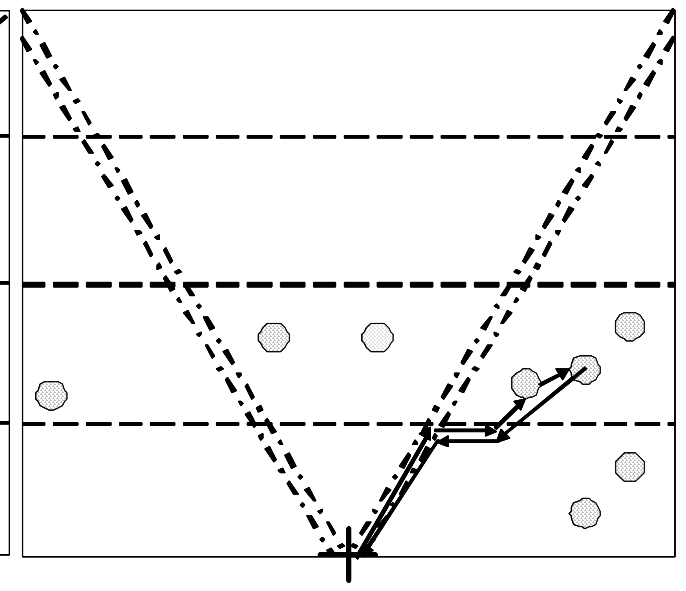

(d) Skidding pattern 4 (SP4)

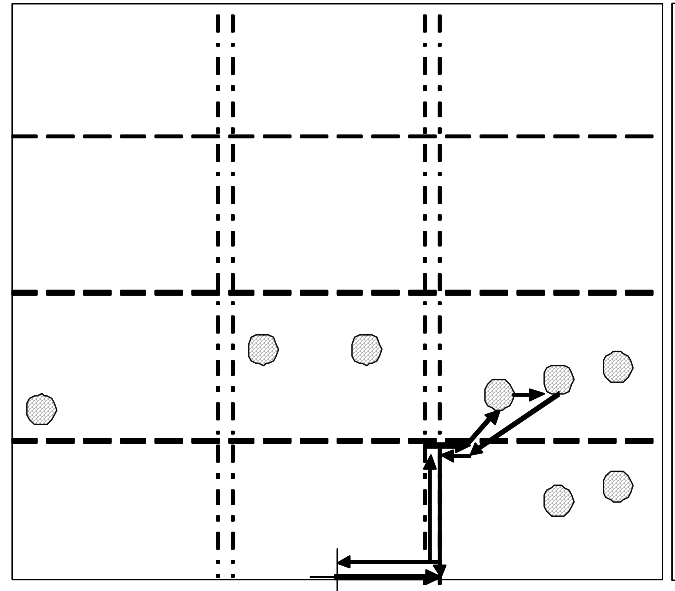

(e) Skidding pattern 5 (SP5)

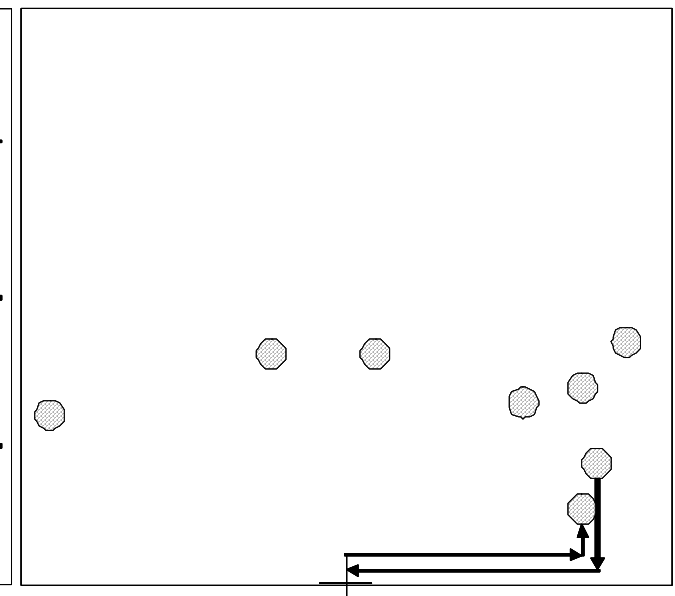

(f) Forwarding pattern 1(FP1)

Figure 3.5. Extraction patterns.

\footnotetext{
+ Landing $\bigcirc$ Tree or log bunches $\rightarrow$ Machine path $\mathbf{z}: \mathbf{z}$ Primary skid trail- _ . Branch skid trail
} 
The cable skidder starts from the landing for each cycle and the nearest felled tree within cable reach is located and an "obstacle check" procedure is performed (Figure 3.6). If no obstacle piles are found, the felled tree or log will be choked. Otherwise, the next nearest felled tree/log within cable reach will be located and the obstacle checking procedure will be repeated before choking this tree or log. If no obstacle trees are found at the current machine location, the machine moves forward to choke the nearest felled tree within the cable reach. If the rated capacity of cable skidder is reached, the skidder returns to the landing and unchokes the logs. Otherwise, the above procedure will be repeated until the rated capacity is reached. The machine always stays on the skid trails and the cable is extended to the felled trees/logs.

\section{Grapple Skidder}

A grapple skidder is a rubber tired four-wheel-drive machine with a maneuverable grappling device at the back of the machine. Four functions were modeled for grapple skidder skidding. The elemental time for each function is calculated based on results from Long (2003).

(1) Travel empty: Begins when skidder leaves landing with empty grapple and ends when skidder arrives at logs to be skidded and is ready for skidding.

(2) Grapple: Begins when skidder starts to gather a load and ends when skidder is full.

(3) Travel loaded: Begins when skidder starts toward landing full of logs and ends when skidder reaches landing with logs and is ready to unload. 
(4) Release: Begins when skidder opens the grapple to drop logs and ends when skidder is ready to leave landing for another load.

\section{Forwarder}

The forwarder moves along the harvester trail, grabs the logs from each pile, and places them in the bunk at the back of the machine. When the payload is reached, the forwarder returns to the landing and unloads the logs (Figure 3.10). Four functions are simulated for the forwarder: move to load, load, travel loaded, and unload.

\subsection{System Structure and Implementation}

Object Oriented Programming (OOP) is utilized to enhance the reusability of the program through Microsoft Visual Basic. 


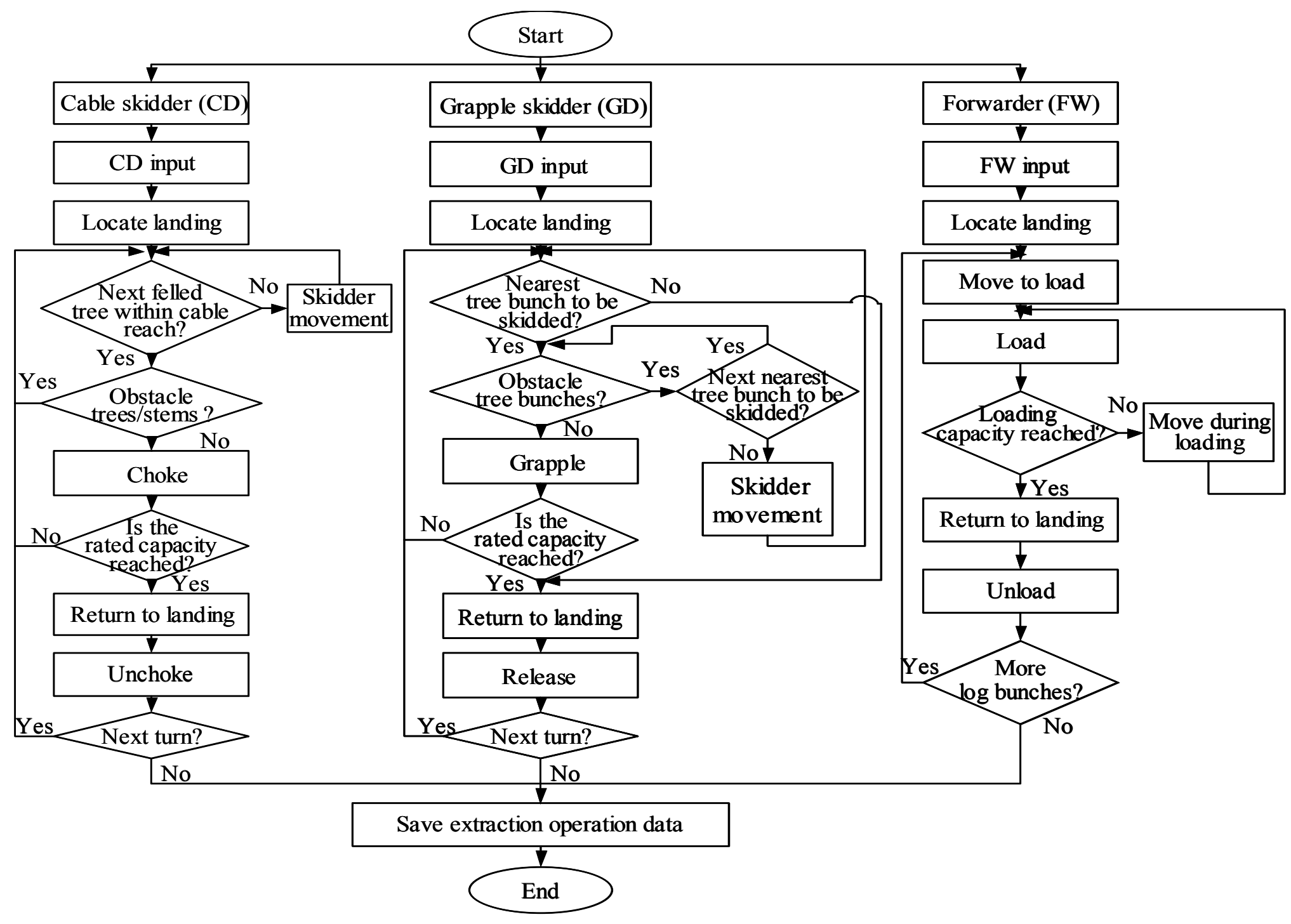

Figure 3.6. Flowchart for extraction operations. 
Three major modules were used in the harvesting system simulator: RUN, ANALYSIS, and REPORT (Figure 3.7). RUN was the major part, consisting of the stand generator, felling simulator, and extraction simulator.

The stand generator is used to generate stands in the harvesting simulations based on the user's input. Once stand generator is initiated, a window pops up automatically, allowing the user to input related stand information, such as species composition, spatial pattern, DBH range, stand age, etc. All input parameters are validated by the system; for example, the species composition for each individual species must be always less than or equal to $100 \%$, and the total composition must equal $100 \%$. After all input parameters are validated, a 2-dimensional (2D) or 3-dimensional (3D) stand map can be displayed in a large window. Stand information and DBH distribution also are displayed in two small windows. The generated stand file then is saved in both ASCII text file and relational database formats.

Felling simulation can be implemented by retrieving existing stand data, either generated by the stand generator or mapped from the field. Three felling machines are available in the system - chainsaw, feller-buncher, and harvester. Once the felling machine is selected, the user sets the machine specifications. Harvesting methods included are clearcut (CC), shelterwood cut (SW), diameter limit cut (DL), selective cut (SC), and crop tree release cut (CT). Based on the harvesting method selected, trees selected to cut are marked by DBH, species, or height. The user also can go to the stand file and mark trees individually. A felling operation map indicating the machine running path then be displayed in a large window, with two small windows containing the related 
felling information and felling command buttons, respectively. The felling machine running path file is saved as ASCII text files and relational database formats.

Felling data are retrieved from the database and a felling plot is repeated several times for extraction simulation. Extraction machines available are cable skidder (CD), grapple skidder (GD), and forwarder (FW). The system can simulate five skidding patterns and one forwarding pattern. Both the extraction machine running path file and the traffic intensity file are saved as ASCII text files and relational database formats. All the files saved previously can be retrieved and analyzed by the ANALYSIS module. The REPORT module generates and displays the final reports by querying the relational database. The report format is predefined.

\subsection{Data Structure}

A relational database model is used for the system, which is defined as a collection of relations that contains all the information to be stored in the database (Jackson 1988). The relational database model is implemented based on an entityrelationship (ER) model and data are presented as a collection of tables (entities). Entity is defined as the thing(s) of interest and relationship is defined as an association, or connection, between two or more entities. An ER model is a conceptual data model that views the real world as entities and relationships. A basic component of the model is the Entity-Relationship diagram that is used to represent data objects visually (Jackson 1988). ER models have been widely used because they are easily transformed into relational tables and easy to be understood by the end user. 


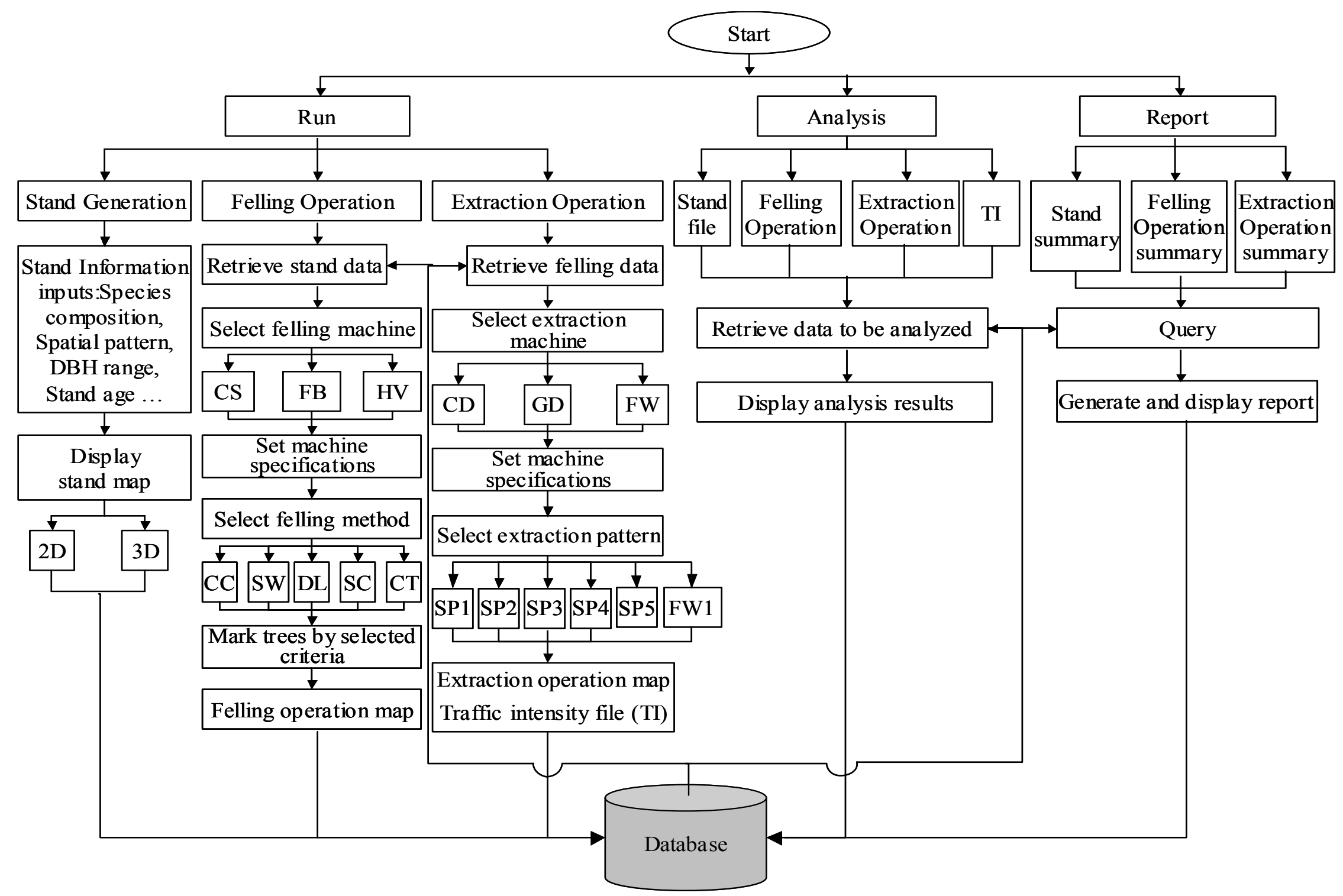

Figure 3.7. Components for the harvesting simulator. 
There are nine entity types in this relational database model (Figure 3.8). Each is presented by individual table with fields representing the attributes that describes the entity with which they are associated. For each entity type, a primary key, which is underlined in the ER diagram (Figure 3.8), is defined to uniquely identify each entity instance.

There are three basic types of relationship connectivity: one-to-one (1:1), oneto-many (1:n), and many-to-many (m:n). Entity type Stand and Species have a (1:n) relationship in which Spp_ID is the foreign key for entity Stand that used for navigating instances of these two entities. Each individual tree has only one species name, but one species can associate with zero, one, or more than one trees. There is a $(1: n)$ relationship between Stand and Felling, and between Felling and Extraction with Sd_name and F_name is the foreign key for Felling and Extraction, respectively. The relationship between Extraction and TI is (1:1). There is also a 1:n relationship between StandSum and Stand, FellSum and Felling, and ExtracSum and Extraction. Operation time and cycle related information is stored in another entity type called Time/Cycle Track, which has a (1:1) relationship with entity type FellSum and ExtraSum using the original felling or extraction operation file as the primary key. 


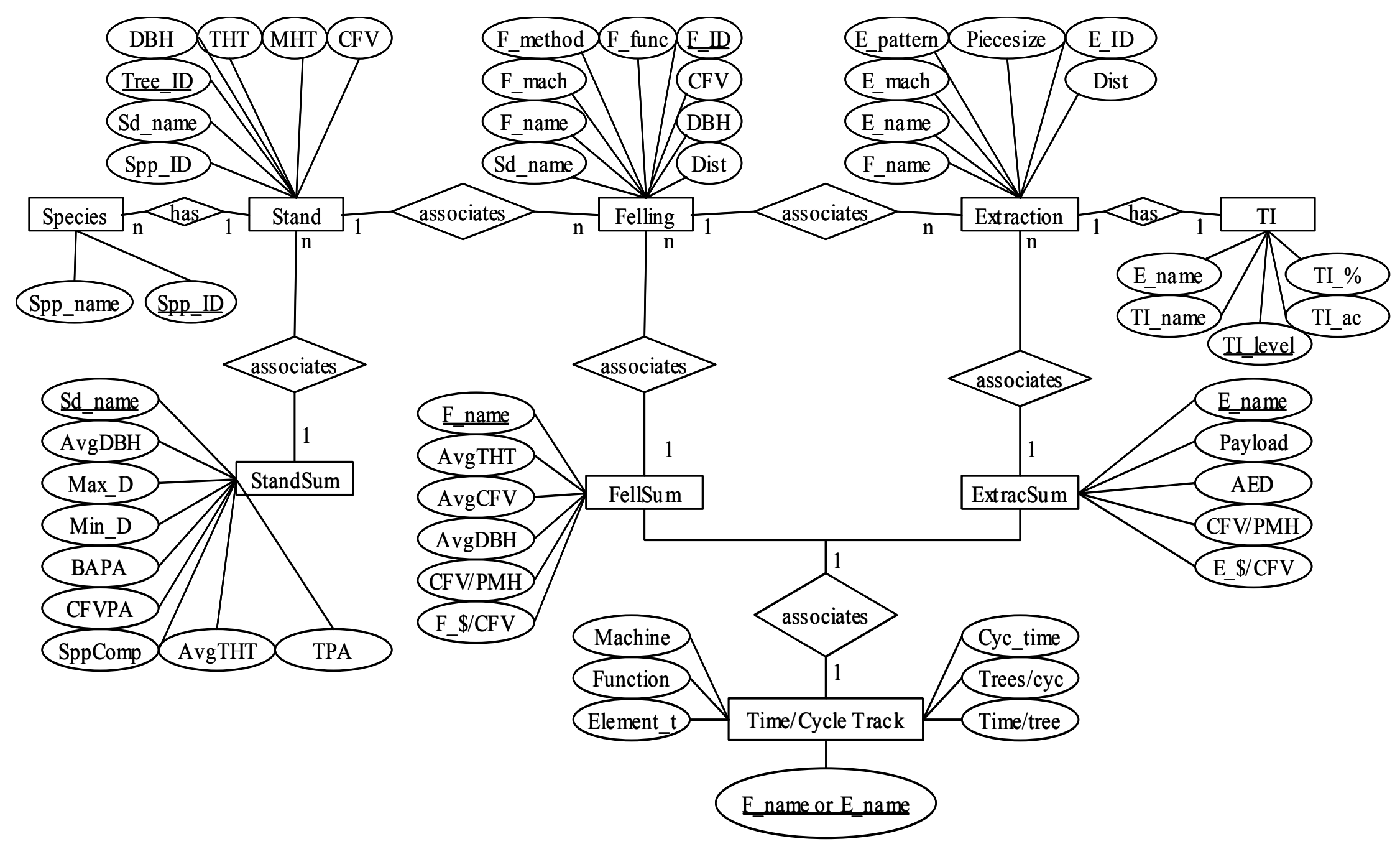

Figure 3.8. ER data model of the harvesting simulation system. 


\section{CHAPTER 4: SIMULATION APPLICATIONS}

\subsection{Material and Methods}

\subsubsection{Stands}

Five natural Appalachian hardwood stands of 30 to 70 years old were generated with the 3D stand generator described in Chapter 2. Each stand was 1.0 acre in size and with random spatial distribution. Stand densities were 531, 376, 290, 236 and 195 trees per acre with an average DBH of 5.18, 6.57, 8.33, 11.42 and 12.15 inches for 30, 40, 50, 60, and 70 year-old stand, respectively (Table 4.1). Total height was between 49.64 and 70.55 feet. The basal area varied from 114.07 to $225.05 \mathrm{ft}^{3} /$ acre and volume per acre ranged from $998.12 \mathrm{ft}^{3}$ to $4350.16 \mathrm{ft}^{3}$. Major species included sugar maple, black cherry, northern red oak, American basswood, and yellow-poplar.

\subsubsection{Harvesting Systems}

Two commonly used harvesting systems of chainsaw (CS)/cable skidder (CD) and feller-buncher (FB)/grapple skidder (GD) in central Appalachia plus harvester $(\mathrm{HV}) /$ forwarder $(\mathrm{FW})$ system were examined in the simulation study. Functions modeled in the systems were similar to those described by Wang and Greene (1999) and Long (2003):

Chainsaw: walk to tree, acquire, cut, and top/delimb;

Cable skidder: travel empty, choke, travel loaded, and unchoke;

Feller-buncher: drive to tree, cut tree, drive to dump, and dump;

Grapple skidder: travel empty, grapple, travel loaded, and release; 
Harvester: move, boom extend/retreat, cut, swing boom, process, and dump;

Forwarder: move to load, load, travel loaded, and unload.

Table 4.1. Description of generated stands.

\begin{tabular}{|c|c|c|c|c|c|c|c|c|c|}
\hline Stand & $\begin{array}{l}\text { Age } \\
\text { (year) }\end{array}$ & Trees/acre & $\frac{\mathrm{DB}}{\text { Mean }}$ & $\begin{array}{l}\mathrm{H} \text { (in } \\
\text { Min. }\end{array}$ & $\frac{\mathrm{ch})}{\text { Max. }} \underset{\text { (ft.) }}{\text { THT }}$ & $\begin{array}{c}\text { BA/acre } \\
\left(\mathrm{ft}^{2}\right)\end{array}$ & $\begin{array}{c}\text { Vol/acre } \\
\left(\mathrm{ft}^{3}\right)\end{array}$ & $\begin{array}{c}\text { Species } \\
\text { Composition (\%) }\end{array}$ & \\
\hline 1 & 30 & 531 & 5.18 & 2 & 16.9749 .64 & 114.07 & 998.12 & $\begin{array}{l}\text { American basswood } \\
\text { American beech } \\
\text { Red maple } \\
\text { Sugar maple } \\
\text { Sweet birch } \\
\text { Others }\end{array}$ & $\begin{array}{r}11 \\
10 \\
7 \\
30 \\
10 \\
32\end{array}$ \\
\hline 2 & 40 & 376 & 6.57 & 2.03 & 20.8654 .7 & 133.69 & 1789.77 & $\begin{array}{l}\text { American basswood } \\
\text { Blackcherry } \\
\text { Northern Red oak } \\
\text { Sugar maple } \\
\text { Yellow-poplar } \\
\text { Others }\end{array}$ & $\begin{array}{r}13 \\
25 \\
9 \\
31 \\
7 \\
15\end{array}$ \\
\hline 3 & 50 & 290 & 8.33 & 2.12 & 25.955 .74 & 178.54 & 3205.56 & $\begin{array}{l}\text { Black cherry } \\
\text { Northern Red oak } \\
\text { Red maple } \\
\text { Sugar maple } \\
\text { Yellow-poplar } \\
\text { Others }\end{array}$ & $\begin{array}{l}15 \\
13 \\
16 \\
11 \\
27\end{array}$ \\
\hline 4 & 60 & 236 & 11.42 & 4.02 & 28.6166 .5 & 233.14 & 4152.22 & $\begin{array}{l}\text { American basswood } \\
\text { Black birch } \\
\text { Northern Red oak } \\
\text { Red maple } \\
\text { Sugar maple } \\
\text { Others }\end{array}$ & $\begin{array}{l}1 \\
1 \\
2 \\
1 \\
1\end{array}$ \\
\hline 5 & 70 & 195 & 12.15 & 4.03 & 30.5770 .55 & 225.05 & 4350.16 & $\begin{array}{l}\text { Black Cherry } \\
\text { Red Maple } \\
\text { Red Oak } \\
\text { Yellow-poplar } \\
\text { Others }\end{array}$ & $\begin{array}{l}16 \\
13 \\
16 \\
38\end{array}$ \\
\hline
\end{tabular}


Felling simulations were performed on a 1.0-acre plot, which was replicated 36 times and created a total of 36 acres of each stand for extraction simulations. Operating patterns of the harvesting machine and travel intensity categories were the same as described by Wang and Greene (1999). The felling machine first was located at one end of the felling plot, and moved parallel to a swath of trees. When the end of the swath was reached, the machine turned back and started down the nearest swath until all trees selected to be cut were cut. Five skidding patterns of SP1, SP2, SP3, SP4, and SP5 were simulated for the cable skidding and the grapple skidding and one forwarding pattern (FP1) was defined for the forwarder, as described in Chapter 3. The landing was assumed to be in the middle of one side of the logging site, and the main skid roads followed the pattern defined in Chapter 3.

Four travel intensity categories were used to monitor the traffic of skidders and forwarder (Carruth and Brown 1996):

TI1 - Trees on the plot were felled.

TI2 - Trees that stood on the plot were removed and no other traffic passed through the plot.

TI3 - Trees that stood on the plot were removed and trees outside the plot were skidded through the plot. Passes with a loaded machine were between 3 and 10.

TI4 - More than 10 loaded machine passes were made through the plot.

\subsubsection{Harvesting Prescriptions}

Clearcut (CC), shelterwood (SW), crop tree release (CT), diameter limit (DL), and selective cuts (SC) were included in the simulation. Shelterwood and selective cuts 
removed $80 \%$ and $30 \%$ of basal area of the stands, respectively. The smaller trees were removed in favor of desirable shade-tolerant trees by the shelterwood cut, while the selective cut removed dominant and co-dominant trees to stimulate the growth of the trees in the lower crown classes. The diameter limit cut removed all trees larger than 12 inches DBH. Taking stumpage price into consideration, a crop tree release cut was simulated to remove $80 \%$ of the basal area and release valuable species, such as black cherry, red oak, and hard maple. The size, species, and location of the tree were also considered during crop tree selection.

\subsection{Data Analysis}

A three-factor, full factorial design $(5 \times 5 \times 3)$ was implemented for the felling simulation (Table 4.2). The three factors were stand, harvest, and machine. There were a total of 75 treatment combinations. Each combination was replicated three times for a total of 225 felling simulation experiments. Extraction simulations were conducted based on felling results. Each extraction was examined with five skidding patterns or one forwarding pattern. A total of 825 skidding and forwarding simulation experiments were conducted.

Data were analyzed using analysis of variance (ANOVA). The general linear model (GLM) for analyzing the felling operation is:

$$
\begin{aligned}
& Y_{i j k n}=\mu+S_{i}+H_{j}+M_{k}+S_{i} * H_{j}+S_{i} * M_{k}+H_{j} * M_{k}+\varepsilon_{i j k n} \\
& i=\text { set of stands }\{1,2,3\} \\
& j=\text { set of harvest methods }\{1,2,3,4,5\}
\end{aligned}
$$


$k=$ set of felling machines $\{1,2,3\}$

$n=$ set of replications $\{1,2,3\}$

$Y_{i j k n}$ represents the response variables - cycle time, productivity, and cost.

$S_{i}, H_{j}, M_{k}$ are the effects for stand factors, harvest factors, and felling machine

factors, respectively. $\mu$ is the overall mean of the response variable and $\varepsilon_{i j k n}$ is an error component that represents all uncontrolled variability.

Table 4.2. Variables included in the simulation experiment.

\begin{tabular}{llc}
\hline \hline Factor & Levels & No. of experiments \\
\hline Stands & Stand 1 (30 years) & 5 \\
& Stand 2 (40 years) & \\
& Stand 3 (50 years) & 5 \\
& Stand 4 (60 years) & \\
Stand 5 (70 years) & \\
Harvests & Clearcut (CC) & \\
& Shelterwood cut (SW) & \\
& Crop tree release cut (CT) \\
& Diameter-limit cut (DL) \\
& Selective cut (SC) \\
Machines & Chainsaw (CS) and cable skidder (CD) \\
& Feller-buncher (FB) and grapple skidder (GD) \\
& Harvester (HV) and forwarder (FW) \\
Extraction & Skidding pattern 1 (SP1) \\
patterns & Skidding pattern 2 (SP2) \\
& Skidding pattern 3 (SP3) \\
& Skidding pattern 4 (SP4) \\
& Skidding pattern 5 (SP5) \\
\hline \hline
\end{tabular}

The GLM for analyzing the extraction operation is:

$$
\begin{aligned}
& Y_{i j k m n}=\mu+S_{i}+H_{j}+M_{k}+S P_{m}+S_{i} * H_{j}+S_{i} * M_{k}+H_{j} * M_{k}+\varepsilon_{i j k m n} \\
& i=\text { set of stands }\{1,2,3\}
\end{aligned}
$$


$j=$ set of harvest methods $\{1,2,3,4,5\}$

$k=$ set of extraction machines $\{1,2,3\}$

$m=$ set of extraction patterns $\{1,2,3,4,5,6\}$

$n=$ set of replications $\{1,2,3\}$

$Y_{i j k m n}$ represents the response variables including extraction cycle time,

productivity, and cost. $S_{i}, H_{j}, M_{k}, S P_{m}$ are the effects for stand factors, harvest factors, extraction machine factors, and extraction pattern factors, respectively. $\mu$ is the overall mean of the response variable and $\varepsilon_{i j k m n}$ is an error component that represents all uncontrolled variability.

Regression techniques also were used to produce prediction equations for cycle time and hourly production for felling and extraction machines.

\subsection{Results}

\subsubsection{Felling Operations}

Average DBH of felled trees varied from 8.93 to 21.50 inches while average total height was between 58.15 and 84.82 feet among stand, machine, and harvest (Table 4.3). Volume per felled tree was 5.79 to $60.77 \mathrm{ft}^{3}$, and volume removed per acre was 702.63 and $3413.68 \mathrm{ft}^{3}$. Distance traveled between harvested trees ranged from 13.94 to 44.03 feet and differed significantly among stands $(\mathrm{F}=134.57 ; \mathrm{df}=2,824 ; \mathrm{P}=0.0001)$, and between harvester and chainsaw or feller-buncher $(\mathrm{F}=219.77 ; \mathrm{df}=2,824 ; \mathrm{P}=0.0001)$. Because the harvester usually cuts and processes several trees at one stop, it consistently 
had the least ground travel distance and was about half the distance with feller-buncher or chainsaw felling.

Harvesting times were between 2.75 and 4.69 minutes per tree among stands, and varied from 1.42 minutes for feller-buncher felling to 7.04 minutes for chainsaw felling (Table 4.3). Harvesting time differed significantly among stands $(\mathrm{F}=140.26$; $\mathrm{df}=2,824$; $\mathrm{P}=0.0001)$ and felling machines $(\mathrm{F}=623.64 ; \mathrm{df}=2,824 ; \mathrm{P}=0.0001)$. However, it was not significantly different among clearcuts, shelterwood cuts, and crop tree release cuts because these three harvest methods removed trees of similar diameters. Felling cycle time varied from 1.83 to 11.41 minutes and differed significantly among felling machines $(\mathrm{F}=844.59 ; \mathrm{df}=2,824 ; \mathrm{P}=0.0001)$

Felling productivity was significantly different among stands $(\mathrm{F}=4163.79 ; \mathrm{df}=$ 2,824; $\mathrm{P}=0.0001)$ and among felling machines $(\mathrm{F}=13914.20 ; \mathrm{df}=2,824, \mathrm{P}=0.0001)$ ranging from $345.19 \mathrm{ft}^{3}$ or 2.15 thousand board feet (MBF) per productive machine hour (PMH) for chainsaw felling, to $1069.27 \mathrm{ft}^{3} / \mathrm{PMH}$ (6.65 MBF/PMH) for feller-buncher felling (Table 4.3). Felling productivity was affected by average DBH removed, removal intensity, and felling machines. Regression equations were developed to predict the felling cycle time and hourly felling production (Table 4.4). It was found that the felling productivity increased with tree $\mathrm{DBH}$ and harvester was more sensitive to the tree $\mathrm{DBH}$ than feller-buncher and chainsaw (Figure 4.1). Feller-buncher consistently yielded higher productivity than chainsaw and harvester. Hourly productions for the chainsaw and harvester were similar when trees with smaller DBH were harvested; the difference increased with tree DBH. Felling productivity was highest in clearcuts, and decreased for partial cuts (Figure 4.2). It was $1318.46 \mathrm{ft}^{3} / \mathrm{PMH}$ (8.20 MBF/PMH) for the feller- 
buncher performing clearcutting, but decreased to $535.96 \mathrm{ft}^{3} / \mathrm{PMH}$ (3.33 MBF/PMH)

with the harvester and $406.64 \mathrm{ft}^{3} / \mathrm{PMH}(2.53 \mathrm{MBF} / \mathrm{PMH})$ with the chainsaw.

Table 4.3. Means and significance levels of felling simulation variables ${ }^{1}$.

\begin{tabular}{|c|c|c|c|c|c|c|c|c|}
\hline & $\begin{array}{l}\text { DBH } \\
\text { removed } \\
\text { (in) }\end{array}$ & $\begin{array}{l}\text { Avg. } \\
\text { total } \\
\text { height } \\
(\mathrm{ft})\end{array}$ & $\begin{array}{l}\text { Volume } \\
\text { per felled } \\
\text { tree }\left(\mathrm{ft}^{3}\right)\end{array}$ & $\begin{array}{c}\text { Volume } \\
\text { removed } \\
\left(\mathrm{ft}^{3} / \mathrm{ac}\right)\end{array}$ & $\begin{array}{l}\text { Distance } \\
\text { traveled per } \\
\text { harvested } \\
\text { tree }(\mathrm{ft})\end{array}$ & $\begin{array}{c}\text { Time per } \\
\text { tree } \\
(\mathrm{min})\end{array}$ & $\begin{array}{c}\text { Cycle } \\
\text { time } \\
(\mathrm{min})\end{array}$ & $\begin{array}{l}\text { Productivity } \\
\left(\mathrm{ft}^{3} / \mathrm{PMH}\right)^{2}\end{array}$ \\
\hline \multicolumn{9}{|c|}{ Stand (years) } \\
\hline 30 & $8.93 \mathrm{e}$ & $58.15 \mathrm{e}$ & $5.79 \mathrm{e}$ & $702.63 \mathrm{e}$ & $13.94 \mathrm{e}$ & $2.75 \mathrm{e}$ & $4.96 \mathrm{~d}$ & $265.93 \mathrm{e}$ \\
\hline 40 & $10.93 \mathrm{~d}$ & $65.08 \mathrm{~d}$ & $12.63 \mathrm{~d}$ & $1324.11 \mathrm{~d}$ & $16.49 \mathrm{~d}$ & $3.16 \mathrm{~d}$ & $5.14 \mathrm{~d}$ & $443.40 \mathrm{~d}$ \\
\hline 50 & $13.60 \mathrm{c}$ & $67.87 \mathrm{c}$ & $26.09 \mathrm{c}$ & $2455.78 \mathrm{c}$ & $17.89 \mathrm{c}$ & $3.96 \mathrm{c}$ & $6.12 \mathrm{c}$ & $713.64 \mathrm{c}$ \\
\hline 60 & $16.13 b$ & $72.63 b$ & $33.70 \mathrm{~b}$ & $3209.05 b$ & $21.75 b$ & $4.13 b$ & $6.59 \mathrm{~b}$ & $860.08 b$ \\
\hline 70 & $17.26 \mathrm{a}$ & $78.36 \mathrm{a}$ & $43.67 \mathrm{a}$ & $3413.68 \mathrm{a}$ & $24.61 \mathrm{a}$ & $4.69 \mathrm{a}$ & $6.97 \mathrm{a}$ & $931.83 \mathrm{a}$ \\
\hline \multicolumn{9}{|c|}{ Machine } \\
\hline $\mathrm{CS}$ & $13.69 \mathrm{a}$ & $69.13 \mathrm{a}$ & $25.53 \mathrm{a}$ & $2187.24 b$ & $21.64 \mathrm{a}$ & $7.04 \mathrm{a}$ & $7.04 b$ & $345.19 \mathrm{c}$ \\
\hline FB & $13.68 \mathrm{a}$ & $69.11 \mathrm{a}$ & $25.47 \mathrm{a}$ & $2173.95 b$ & $21.10 \mathrm{a}$ & $1.42 \mathrm{c}$ & $1.83 \mathrm{c}$ & $1069.27 \mathrm{a}$ \\
\hline $\mathrm{HV}$ & $12.73 b$ & $67.02 b$ & $22.53 b$ & $2301.96 \mathrm{a}$ & $14.09 \mathrm{~b}$ & $2.75 b$ & $9.00 \mathrm{a}$ & $514.47 \mathrm{~b}$ \\
\hline \multicolumn{9}{|c|}{ Harvest } \\
\hline $\mathrm{CC}$ & $9.79 \mathrm{c}$ & $59.43 c$ & $11.52 \mathrm{c}$ & $2898.58 \mathrm{a}$ & $11.26 \mathrm{c}$ & $1.26 \mathrm{c}$ & $3.39 \mathrm{~d}$ & $779.65 \mathrm{a}$ \\
\hline SW & $9.04 d$ & $58.08 \mathrm{~d}$ & $8.44 d$ & $2019.55 d$ & $11.39 \mathrm{c}$ & $1.36 \mathrm{c}$ & $3.76 \mathrm{c}$ & $539.32 d$ \\
\hline CT & $9.05 \mathrm{~d}$ & $57.87 \mathrm{~d}$ & $8.83 \mathrm{~d}$ & $2100.57 \mathrm{c}$ & $11.45 \mathrm{c}$ & $1.37 \mathrm{c}$ & $3.79 \mathrm{c}$ & $553.25 \mathrm{~d}$ \\
\hline DL & $17.55 \mathrm{~b}$ & $81.93 b$ & $32.33 b$ & $2695.09 \mathrm{~b}$ & $23.64 \mathrm{~b}$ & $5.41 \mathrm{~b}$ & $7.43 b$ & $656.72 \mathrm{c}$ \\
\hline $\mathrm{SC}$ & $21.50 \mathrm{a}$ & $84.80 \mathrm{a}$ & $60.77 \mathrm{a}$ & $1391.46 \mathrm{e}$ & $44.03 \mathrm{a}$ & $9.28 \mathrm{a}$ & $11.41 \mathrm{a}$ & $685.95 b$ \\
\hline
\end{tabular}

${ }^{1}$ Means containing the same letter in a column are not significantly different at the 5 percent level with Duncan's Multiple -Range Test.

${ }^{2} \mathrm{PMH}=$ Productive machine hour. 
Table 4.4. Cycle time and hourly production models for felling machines.

\begin{tabular}{|c|c|c|c|c|c|}
\hline Machine & Model $^{1,2}$ & $\mathrm{R}^{2}$ & RMSE & F-value & P-valu \\
\hline \multicolumn{6}{|c|}{ Cycle time (min.) } \\
\hline \multicolumn{2}{|c|}{$\begin{array}{c}\text { Chainsaw (a) } 2.63-0.54 * \mathrm{DBH}+0.03 * \mathrm{DBH}^{2}+ \\
0.08 * \mathrm{DT}+0.07 * \mathrm{RI}{ }^{*} \mathrm{DT}\end{array}$} & 0.98 & 0.73 & 956.19 & 0.00 \\
\hline \multicolumn{2}{|c|}{$\begin{array}{l}\text { (b) } 1.70-0.30 * \mathrm{DBH}+0.03 * \mathrm{DBH}^{2}+ \\
0.05 * \mathrm{DT}\end{array}$} & 0.98 & 0.76 & 1180.92 & 0.00 \\
\hline \multirow[t]{2}{*}{$\begin{array}{l}\text { Feller- } \\
\text { buncher }\end{array}$} & $\begin{array}{l}\text { (a) } 0.25+0.08 * \mathrm{DBH}-0.0007 * \mathrm{DBH}^{2}+ \\
5.66 / \mathrm{DT}-0.82 * \mathrm{RI}^{2}+0.001 * \mathrm{DBH}^{*} \mathrm{DT}\end{array}$ & 0.99 & 0.09 & 1583.14 & 0.00 \\
\hline & $\begin{array}{l}\text { (b) } 0.74+0.007 * \mathrm{DBH}-0.0005 * \mathrm{DBH}^{2}- \\
0.21 / \mathrm{DT}+0.002 * \mathrm{DBH} * \mathrm{DT}\end{array}$ & 0.98 & 0.13 & 839.65 & 0.00 \\
\hline \multicolumn{2}{|c|}{$\begin{array}{c}\text { Harvester (a) }-6.33-0.07 * \mathrm{DBH}^{2}-0.02 * \mathrm{DT}^{2}+ \\
\quad 8.42 * \mathrm{RI}+0.85 * \mathrm{DBH} * \mathrm{RI}+ \\
\\
0.09 * \mathrm{DBH}{ }^{*} \mathrm{DT}\end{array}$} & 0.86 & 1.45 & 87.75 & 0.00 \\
\hline & $\begin{array}{l}\text { (b) } 2.65+0.02 * \mathrm{DBH}^{2}-0.002 * \mathrm{DT}^{2}+ \\
0.004 * \mathrm{DBH}^{*} \mathrm{DT}\end{array}$ & 0.74 & 1.96 & 69.00 & 0.00 \\
\hline
\end{tabular}

\section{Productivity $\left(\mathrm{ft}^{3} / \mathrm{PMH}\right)$}

Chainsaw (a) $40.41+31.13 * \mathrm{DBH}-0.21 * \mathrm{DBH}^{2}-\quad 0.95 \quad 31.54 \quad 241.04 \quad 0.0001$ $2540.63 / \mathrm{DT}+581.73 * \mathrm{RI}^{2}-$ $16.51 * \mathrm{RI}$ *DT

(b) $-207.88+56.35 * \mathrm{DBH}-1.17 * \mathrm{DBH}^{2}+\quad 0.58 \quad 86.79 \quad 32.43 \quad 0.0001$ 649.11/DT

Feller- $\quad$ (a) $107.26-82.35 * \mathrm{DBH}-15.19 * \mathrm{DBH}^{2}-\quad \begin{array}{lllll}0.67 & 69.38 & 28.31 & 0.0001\end{array}$ buncher $\quad 3.75 * \mathrm{DT}^{2}+207.51 * \mathrm{DBH} * \mathrm{RI}+$ $16.62 * \mathrm{DBH}^{*} \mathrm{DT}$

(b) $141.35+101.95 * \mathrm{DBH}-4.39 * \mathrm{DBH}^{2}-\quad 0.48 \quad 97.57 \quad 16.10 \quad 0.0001$ $2.00 * \mathrm{DT}^{2}+4.89 * \mathrm{DBH}^{*} \mathrm{DT}$

Harvester (a) $-579.43-12.67 * \mathrm{DBH}^{2}+2.12 * \mathrm{DT}-\quad \begin{array}{lllll}0.90 & 83.83 & 129.72 & 0.0001\end{array}$ 1.93* $\mathrm{DT}^{2}+9.35 * \mathrm{DBH} * \mathrm{DT}+$ $225.55 * \mathrm{DBH} * \mathrm{RI}$

(b) $236.84+3.63 * \mathrm{DBH}^{2}-8.43 * \mathrm{DT}+\quad 0.51 \quad 88.62 \quad 17.93 \quad 0.0001$ $0.61 * \mathrm{DT}^{2}-2.30 * \mathrm{DBH}^{*} \mathrm{DT}$

$\overline{{ }^{1} \mathrm{DBH}}=$ diameter at breast height (in.); DT $=$ distance traveled between harvested trees $(\mathrm{ft}) ; \mathrm{RI}=$ removal intensity (0.25-1.00); RMSE = root of mean square error.

${ }^{2}$ Models with (a) included the removal intensity (RI) as independent variable, models with (b) did not. 


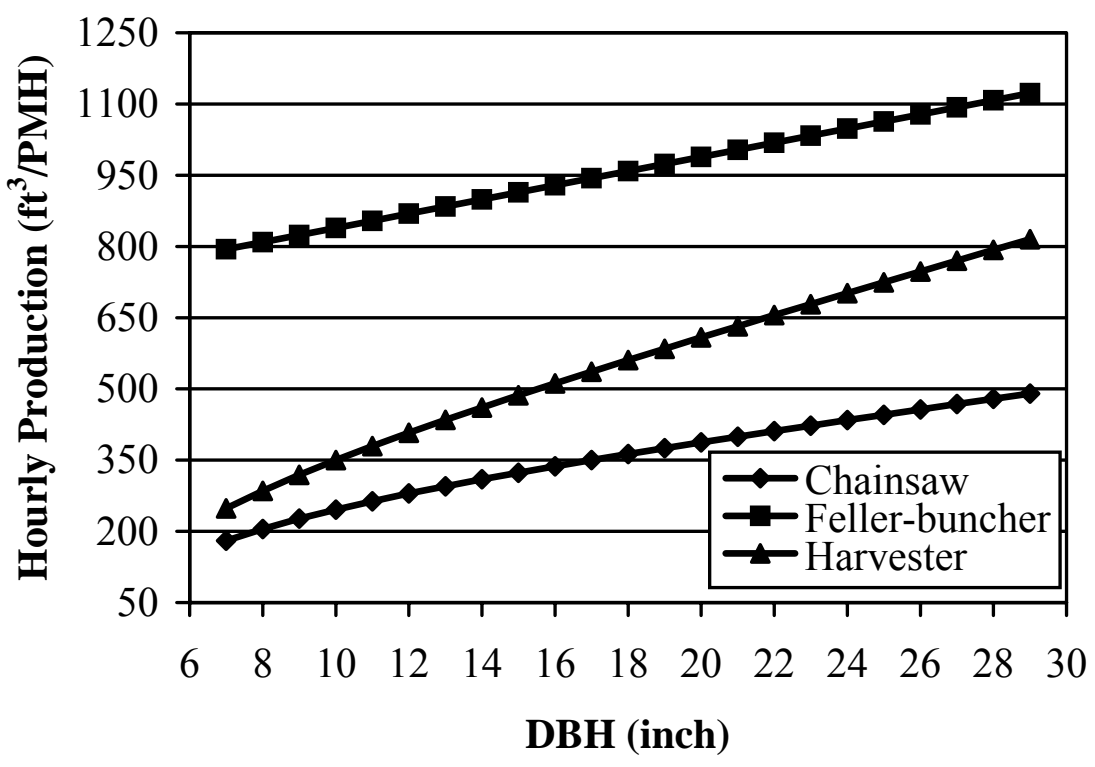

Figure 4.1. Felling hourly production.

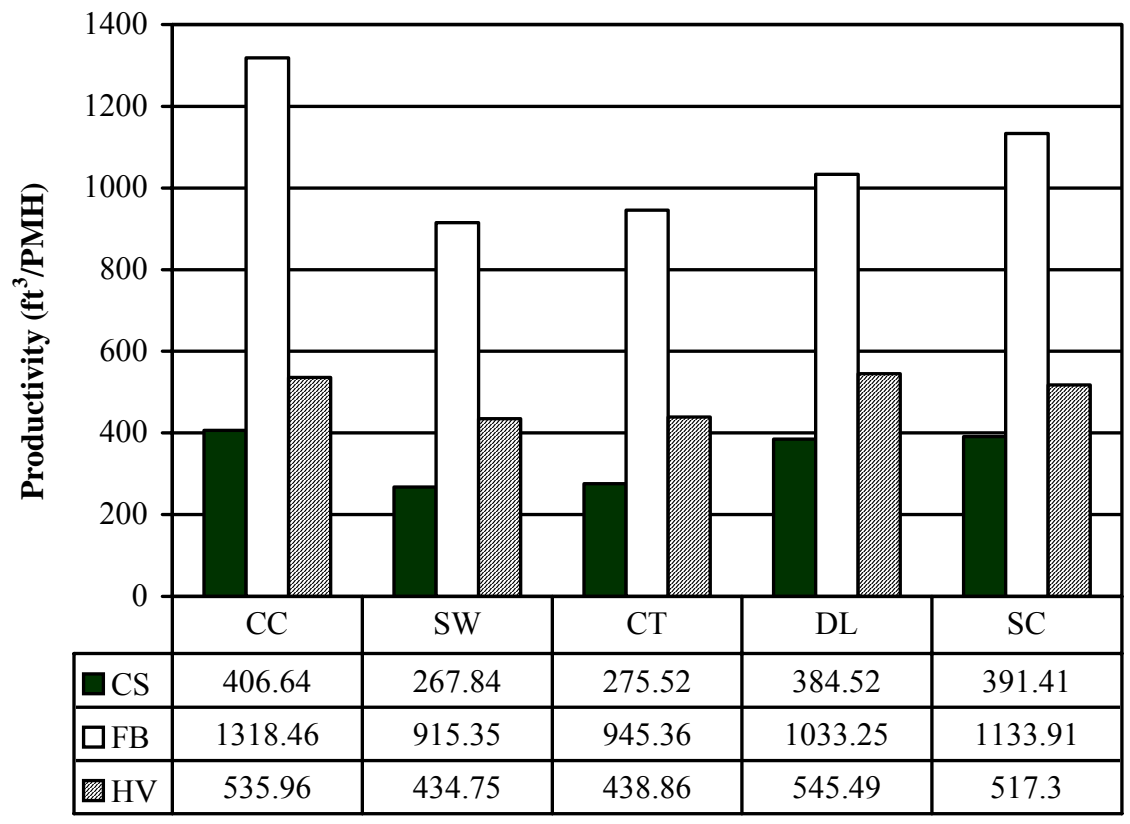

Harvests

Figure 4.2. Felling productivity vs. harvests. 


\subsubsection{Extraction Operations}

Average extraction distance (AED) varied among stands, harvests, and machines (Table 4.5). It was significantly different among extraction machines $(\mathrm{F}=$

1069.29; $\mathrm{df}=2,824 ; \mathrm{P}=0.0001)$, and among extraction patterns $(\mathrm{F}=1950.86 ; \mathrm{df}=2,824$; $\mathrm{P}=0.0001)$. The forwarder resulted in a longer forwarding distance of 1903.97 feet due to its higher payload. Average skidding distances with cable and grapple skidders ranged from 1127.19 to 1221.57 feet. The highest average skidding distance of 1371.11 feet was associated with skidding pattern 3 (SP3) in which only one diagonal primary skid trail was followed. The lowest average skidding distance occurred for skidding pattern 1 (SP1), for which there was no designated skid trail. The grapple skidder always had longer average extraction distance than cable skidder no matter which extraction pattern was followed (Figure 4.3). Average extraction distance decreased in the following extraction pattern order: FP1 -> SP3 -> SP5 -> SP2 -> SP4 -> SP1. 
Table 4.5. Means and significance levels of extraction simulation variables. ${ }^{1}$

\begin{tabular}{|c|c|c|c|c|c|c|c|c|c|}
\hline & $\begin{array}{c}\text { Average } \\
\text { extraction } \\
\text { distance } \\
(\mathrm{ft})\end{array}$ & $\begin{array}{c}\text { Bunch size } \\
\left(\mathrm{ft}^{3}\right)\end{array}$ & $\begin{array}{l}\text { Turn } \\
\text { payload }\left(\mathrm{ft}^{3}\right)\end{array}$ & $\begin{array}{l}\text { Cycle } \\
\text { time } \\
\text { (min.) }\end{array}$ & $\begin{array}{c}\text { Productivity } \\
\left(\mathrm{ft}^{3} / \mathrm{PMH}\right)\end{array}$ & $\begin{array}{l}\text { TI1 } \\
(\%)\end{array}$ & $\begin{array}{l}\text { TI2 } \\
(\%)\end{array}$ & $\begin{array}{l}\text { TI3 } \\
(\%)\end{array}$ & $\begin{array}{l}\text { TI4 } \\
(\%)\end{array}$ \\
\hline \multicolumn{10}{|c|}{ Stand (years) } \\
\hline 30 & $1227.32 \mathrm{c}$ & $39.13 \mathrm{e}$ & $118.84 \mathrm{e}$ & $17.79 \mathrm{~d}$ & $268.38 \mathrm{e}$ & $56.98 \mathrm{a}$ & $22.05 \mathrm{a}$ & $16.47 \mathrm{~b}$ & $4.50 \mathrm{c}$ \\
\hline 40 & $1231.06 \mathrm{c}$ & $83.36 \mathrm{~d}$ & 145. & & & $50.36 \mathrm{c}$ & & $21.65 \mathrm{a}$ & $8.36 \mathrm{~b}$ \\
\hline 50 & $1241.74 b$ & $173.56 \mathrm{c}$ & $219.26 c$ & $19.34 \mathrm{c}$ & & $53.31 \mathrm{~b}$ & $14.68 \mathrm{c}$ & $19.67 \mathrm{a}$ & $12.85 \mathrm{a}$ \\
\hline 60 & $1247.31 b$ & $215.99 b$ & $258.95 b$ & 20.2 & $43 \mathrm{~b}$ & $48.83 \mathrm{c}$ & $16.08 \mathrm{c}$ & $22.66 a$ & $12.44 \mathrm{a}$ \\
\hline 70 & $1256.09 \mathrm{a}$ & $305.68 \mathrm{a}$ & 316.3 & $21.95 \mathrm{a}$ & & $51.08 \mathrm{c}$ & & $20.91 \mathrm{a}$ & $12.41 \mathrm{a}$ \\
\hline \multicolumn{10}{|c|}{ Machine } \\
\hline $\mathrm{CD}$ & $1127.19 \mathrm{c}$ & $169.47 \mathrm{a}$ & $196.72 b$ & $20.26 b$ & & $70.14 \mathrm{a}$ & $6.87 \mathrm{~b}$ & $14.43 b$ & $8.56 b$ \\
\hline GD & $1221.57 b$ & $169.48 \mathrm{a}$ & 187.3 & & & $24.26 \mathrm{~b}$ & $31.24 \mathrm{a}$ & $33.15 \mathrm{a}$ & $11.35 \mathrm{a}$ \\
\hline FW & $1903.97 \mathrm{a}$ & $104.39 b$ & $409.17 \mathrm{a}$ & $33.34 \mathrm{a}$ & $805.73 a$ & $76.21 \mathrm{a}$ & $3.13 \mathrm{c}$ & $8.99 b$ & $11.67 \mathrm{a}$ \\
\hline \multicolumn{10}{|c|}{ Harvest } \\
\hline $\mathrm{CC}$ & $982.30 \mathrm{~d}$ & & & & & & & & $14.27 \mathrm{a}$ \\
\hline SW & $1193.97 \mathrm{c}$ & $52.27 \mathrm{~d}$ & $140.64 d$ & $16.83 \mathrm{c}$ & & 48. & $61 \mathrm{a}$ & $22.41 \mathrm{a}$ & $10.97 \mathrm{~b}$ \\
\hline $\mathrm{CT}$ & $1132.92 \mathrm{c}$ & $50.61 d$ & $147.62 d$ & $16.99 \mathrm{c}$ & & 47.0 & $18.77 \mathrm{a}$ & $22.90 \mathrm{a}$ & $11.32 \mathrm{~b}$ \\
\hline DL & $1367.46 b$ & $202.64 b$ & $217.52 b$ & $20.85 b$ & $439.93 b$ & $51.73 b$ & $17.79 a$ & $21.39 b$ & $9.09 \mathrm{c}$ \\
\hline $\mathrm{SC}$ & $1466.89 a$ & $443.56 \mathrm{a}$ & $389.64 a$ & $28.27 \mathrm{a}$ & $492.09 b$ & $67.73 \mathrm{a}$ & $17.06 \mathrm{a}$ & $10.31 \mathrm{c}$ & $4.90 \mathrm{~d}$ \\
\hline \multicolumn{10}{|c|}{ Extraction pattern ${ }^{2}$} \\
\hline SP1 & $1002.29 f$ & & & & & & & $30.93 a$ & $17.99 \mathrm{a}$ \\
\hline SP2 & $1173.98 \mathrm{~d}$ & $169.47 \mathrm{a}$ & $202.09 b$ & $18.24 \mathrm{c}$ & & $55.27 \mathrm{c}$ & $16.27 \mathrm{c}$ & $22.24 b$ & $6.21 \mathrm{c}$ \\
\hline SP3 & $1371.11 \mathrm{~b}$ & $169.47 \mathrm{a}$ & $201.86 b$ & $21.76 \mathrm{~b}$ & $345.21 \mathrm{~d}$ & $52.81 \mathrm{c}$ & $13.08 \mathrm{~d}$ & $21.19 b$ & $12.92 \mathrm{~b}$ \\
\hline SP4 & $1082.79 \mathrm{e}$ & $169.47 \mathrm{a}$ & $202.31 b$ & $17.92 \mathrm{c}$ & & $57.06 \mathrm{~b}$ & $19.81 b$ & $17.19 \mathrm{c}$ & $5.95 \mathrm{c}$ \\
\hline SP5 & $1241.73 c$ & $169.47 \mathrm{a}$ & $200.93 b$ & $16.49 \mathrm{~d}$ & & $57.60 \mathrm{~b}$ & $20.82 b$ & $14.89 \mathrm{~d}$ & $6.69 \mathrm{c}$ \\
\hline FP1 & $1903.97 \mathrm{a}$ & $104.39 b$ & $409.17 \mathrm{a}$ & $33.39 \mathrm{a}$ & $905.73 a$ & $76.21 \mathrm{a}$ & $3.13 \mathrm{e}$ & $8.99 \mathrm{e}$ & $11.67 \mathrm{~b}$ \\
\hline
\end{tabular}

${ }^{1}$ Means containing the same letter in a column are not significantly different at the 5 percent level with Duncan's Multiple -Range Test.

${ }^{2}$ Skidding patterns $1,2,3,4,5$ and forwarding pattern 1. 


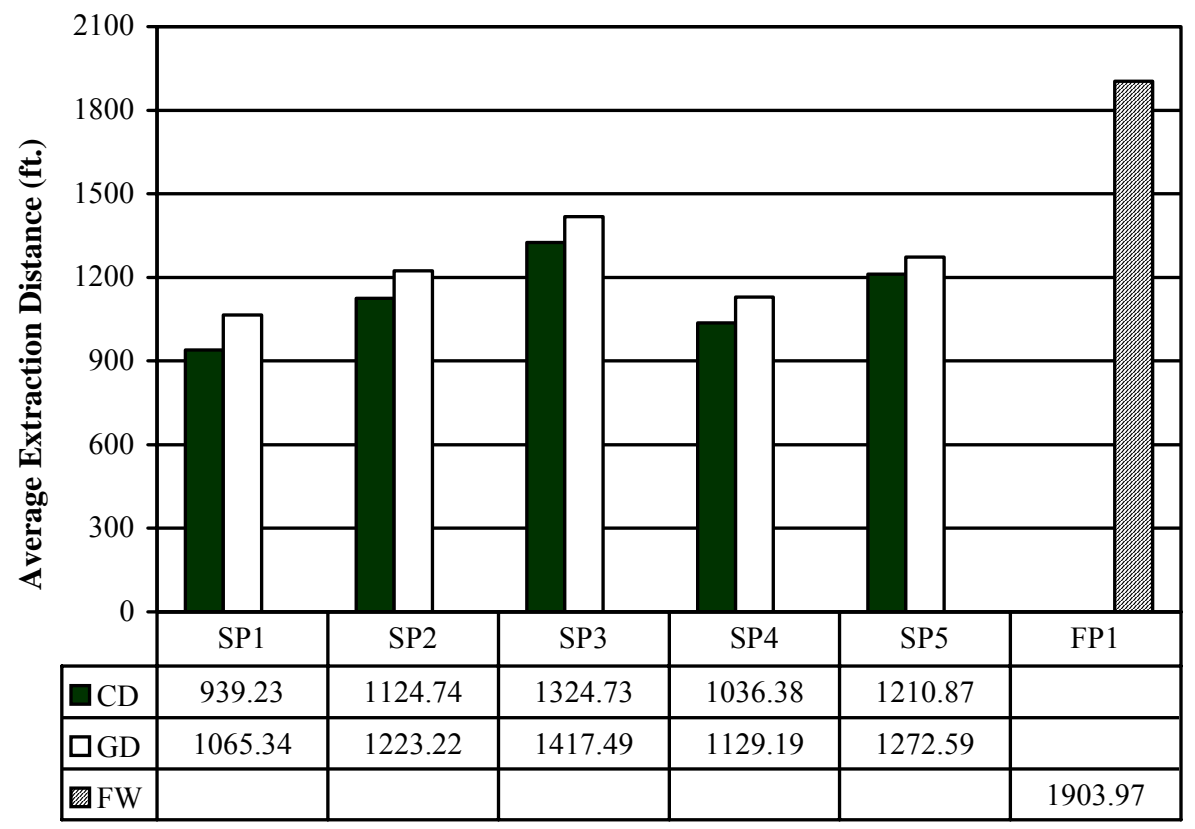

Extraction Patterns

Figure 4.3. Average extraction distance vs. extraction patterns.

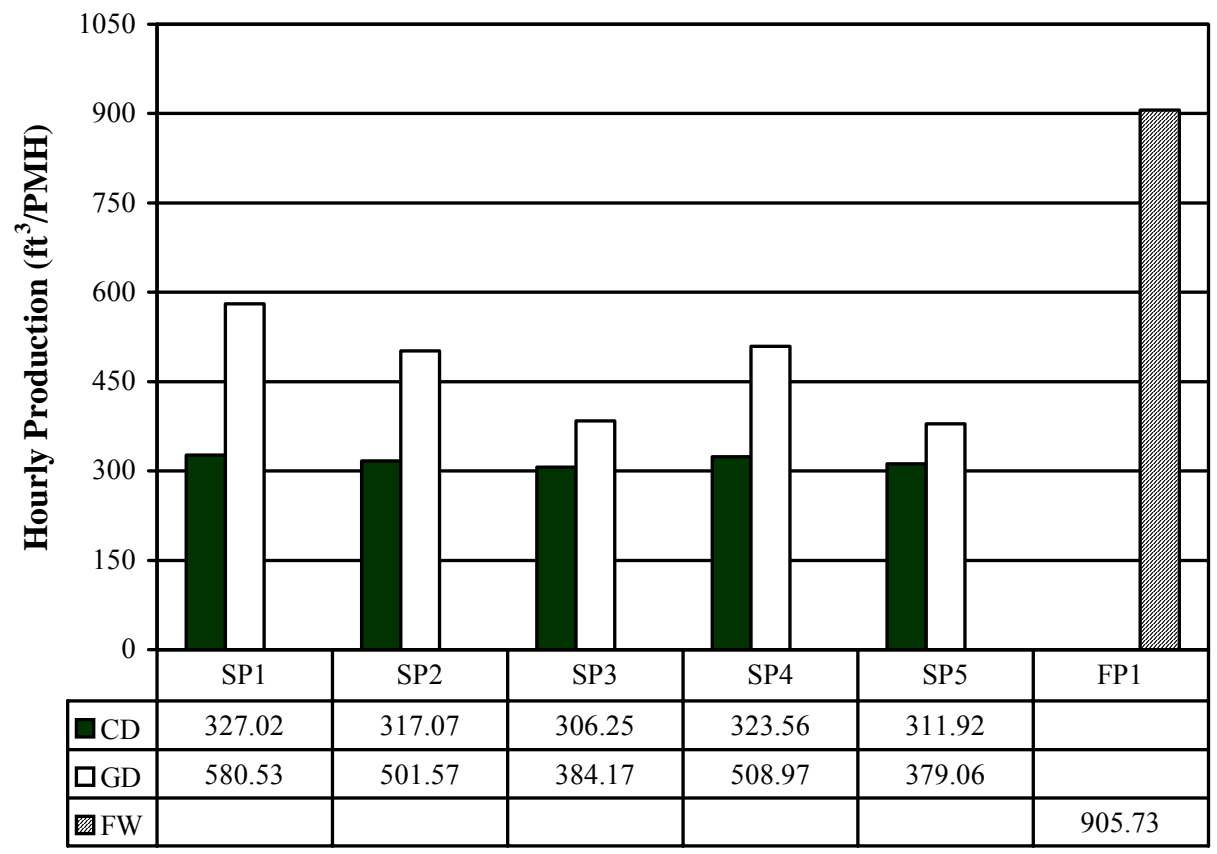

Extraction Patterns

Figure 4.4. Extraction productivity vs. extraction patterns. 
Bunch size averaged 39.13, 83.36, 173.56, 215.99, and $305.68 \mathrm{ft}^{3}$ for $30-, 40-, 50-$, 60-, and 70-year-old stands, respectively (Table 4.5). Bunch size differed significantly among stands $(\mathrm{F}=108276 ; \mathrm{df}=2,824 ; \mathrm{P}=0.0001)$, but not among cable and grapple skidders. Turn payload varied from 196.72 for the cable skidder, to 187.30 for the grapple skidder, to $409.17 \mathrm{ft}^{3}$ for the forwarder. It was significantly different from stands $(\mathrm{F}=388.91 ; \mathrm{df}=2,824 ; \mathrm{P}=0.0001)$ and extraction machines $(\mathrm{F}=14.29 ; \mathrm{df}=2,824 ; \mathrm{P}=$ 0.0002), but not among skidding patterns $\mathrm{SP} 1$ to $\mathrm{SP} 5(\mathrm{~F}=0.04$; $\mathrm{df}=2,824 ; \mathrm{P}=0.99)$.

Average extraction cycle time ranged from 15.92 minutes for the grapple skidder to 33.34 minutes for the forwarder (Table 4.5). It differed significantly among extraction machines $(\mathrm{F}=582.47 ; \mathrm{df}=2,824 ; \mathrm{P}=0.0001)$ and among diameter limit cuts, selective cuts and clearcuts $(\mathrm{F}=796.08 ; \mathrm{df}=2,824 ; \mathrm{P}=0.0001)$, but it was not significantly different from shelterwood and crop tree release cuts due to the similar DBH of trees processed.

Extraction productivity averaged 467.16 (2.91 MBF), 570.86 (3.55 MBF), and $805.73 \mathrm{ft}^{3}$ (5.01 MBF) per PMH for the cable skidder, grapple skidder, and forwarder, respectively (Table 4.5), varying with harvest and extraction patterns. It also differed significantly among stands $(\mathrm{F}=788.94 ; \mathrm{df}=2,824 ; \mathrm{P}=0.0001)$, and extraction machines $(\mathrm{F}=1674.76 ; \mathrm{df}=2,824 ; \mathrm{P}=0.0001)$. Skidding pattern $1(\mathrm{SP} 1)$ had the higher productivity of $453.77 \mathrm{ft}^{3} / \mathrm{PMH}$ (2.82 MBF/PMH), then SP4 and SP2 with 416.26 (2.59 MBF) and 409.32 $\mathrm{ft}^{3}$ (2.55 MBF) per PMH, respectively. It was lower in skidding pattern 3 (SP3) and skidding pattern 5 (SP5) of 345.21 (2.15 MBF/PMH) and 345.49 $\mathrm{ft}^{3} / \mathrm{PMH}$ (2.15 MBF/PMH), respectively. Extraction productivity for SP3 and SP5 were the lowest and nearly equal, 345.21 (2.15 MBF/PMH) and $345.49 \mathrm{ft}^{3} / \mathrm{PMH}(2.15$ 
MBF/PMH), respectively. Extraction productivity was sensitive to both machines and extraction patterns. The productivity of cable skidding was about $20 \%$ lower than grapple skidding in SP3 and SP5 while the difference between the two types of skidders was more than doubled in SP1, SP2, and SP4 (Figure 4.4). The productivity was much higher in forwarding pattern 1 (FP1) than skidding patterns SP1 to SP5. Using a stepwise selection procedure, regression equations were developed to predict extraction productivity in terms of average extraction distance (AED), payload size (PL), and bunch size (BZ) (Table 4.6). This analysis showed that extraction productivity decreased as the average extraction distance increased, and the forwarder consistently yielded higher productivity than grapple or cable skidding (Figure 4.5).

TI3 and TI4 were the major concerns since they caused the most soil compaction. TI3 was $9.43 \%$ (3.39 acres) of the total area affected by cable skidding and 33.15\% (11.93 acres) by grapple skidding, and TI4 ranged from 4.90\% (1.76 acres) for selective cuts to $14.27 \%$ (5.14 acres) in clearcuts (Table 4.5). Selective cuts had the lowest TI4 level of the total area affected due to the large piece sizes that were processed and with less volume removed. Clearcuts had the highest TI4 level. The total effect of TI3 and TI4 levels varied from $15.21 \%$ (5.48 acres) to $48.92 \%$ (17.61 acres) among stands, machines, harvests, and extraction patterns. A total of $48.92 \%$ (17.61 acres) of the extraction site was recorded as TI3 and TI4 levels for SP1. It was almost two times higher than $21.58 \%$ (7.77 acres). The TI3 and TI4 levels also were higher in SP3, $34.11 \%$ (12.28 acres). The TI3 and TI4 levels were always higher with the grapple skidder than the cable skidder and forwarder (Figure 4.6). TI3 and TI4 levels with the 
grapple skidder were highest in SP1, about 60\% (21.6 acres) compared to about $40 \%$ (14.4 acres) with the cable skidder and 20\% (7.2 acres) with the forwarder.

Table 4.6. Cycle time and hourly production models for extraction machines ${ }^{1}$.

\begin{tabular}{|c|c|c|c|c|c|}
\hline Machine & Model & $\mathrm{R}^{2}$ & RMSE & F-value & P-value \\
\hline \multicolumn{6}{|c|}{ Cycle time (min.) } \\
\hline $\begin{array}{l}\text { Cable } \\
\text { skidder }\end{array}$ & $\begin{array}{l}8.87+0.003 \mathrm{AED}+0.03 \mathrm{PL}+250.77 / \mathrm{PL}- \\
0.00001 \mathrm{PL}^{2}+0.01 \mathrm{BZ}-2.28 / \mathrm{BZ}\end{array}$ & 0.79 & 0.29 & 17315.60 & 0.0001 \\
\hline $\begin{array}{l}\text { Grapple } \\
\text { skidder }\end{array}$ & $\begin{array}{l}-5.19+0.003 \mathrm{AED}+0.000001 \mathrm{AED}^{2}+ \\
0.07 \mathrm{PL}-0.00003 \mathrm{PL}^{2}-0.03 \mathrm{BZ}+ \\
22.86 / \mathrm{BZ}+0.00001 \mathrm{BZ}^{2}\end{array}$ & 0.76 & 0.96 & 4293.93 & 0.0001 \\
\hline Forwarder & $\begin{array}{l}57.09+0.29 \mathrm{AED}-0.00008 \mathrm{AED}^{2}- \\
1.42 \mathrm{PL}+0.002 \mathrm{PL}^{2}+0.07 \mathrm{BZ}+116 / \mathrm{BZ}- \\
0.0001 \mathrm{BZ}^{2}\end{array}$ & 0.69 & 1.73 & 134.65 & 0.0001 \\
\hline \multicolumn{6}{|c|}{ Productivity $\left(\mathrm{ft}^{3} / \mathrm{PMH}\right)$} \\
\hline $\begin{array}{l}\text { Cable } \\
\text { skidder }\end{array}$ & $\begin{array}{l}426.93-0.06 \mathrm{AED}+2890 / \mathrm{AED}+0.64 \mathrm{PL} \\
-0.0004 \mathrm{PL}^{2}+0.73 \mathrm{BZ}-0.003 \mathrm{BZ}^{2}\end{array}$ & 0.71 & 14.19 & 6299.05 & 0.0001 \\
\hline $\begin{array}{l}\text { Grapple } \\
\text { skidder }\end{array}$ & $\begin{array}{l}466.49-0.13 \mathrm{AED}+3.76 \mathrm{PL}-0.003 \mathrm{PL}^{2}- \\
0.36 \mathrm{BZ}+0.0003 \mathrm{BZ}^{2}\end{array}$ & 0.63 & 60.03 & 626.01 & 0.0001 \\
\hline Forwarder & $\begin{array}{l}615.24-0.21 \mathrm{AED}+0.00003 \mathrm{AED}^{2}- \\
36500 / \mathrm{AED}+4.53 \mathrm{PL}-0.001 \mathrm{PL}^{2}- \\
0.11 \mathrm{BZ}+0.005 \mathrm{BZ}^{2}\end{array}$ & 0.67 & 38.73 & 349.75 & 0.0001 \\
\hline
\end{tabular}

$\overline{{ }^{1} \mathrm{AED}}=$ average extraction distance, $\mathrm{ft}$; $\mathrm{PL}=$ payload size, $\mathrm{ft}^{3} ; \mathrm{BZ}=$ bunch size, $\mathrm{ft}^{3}$. 


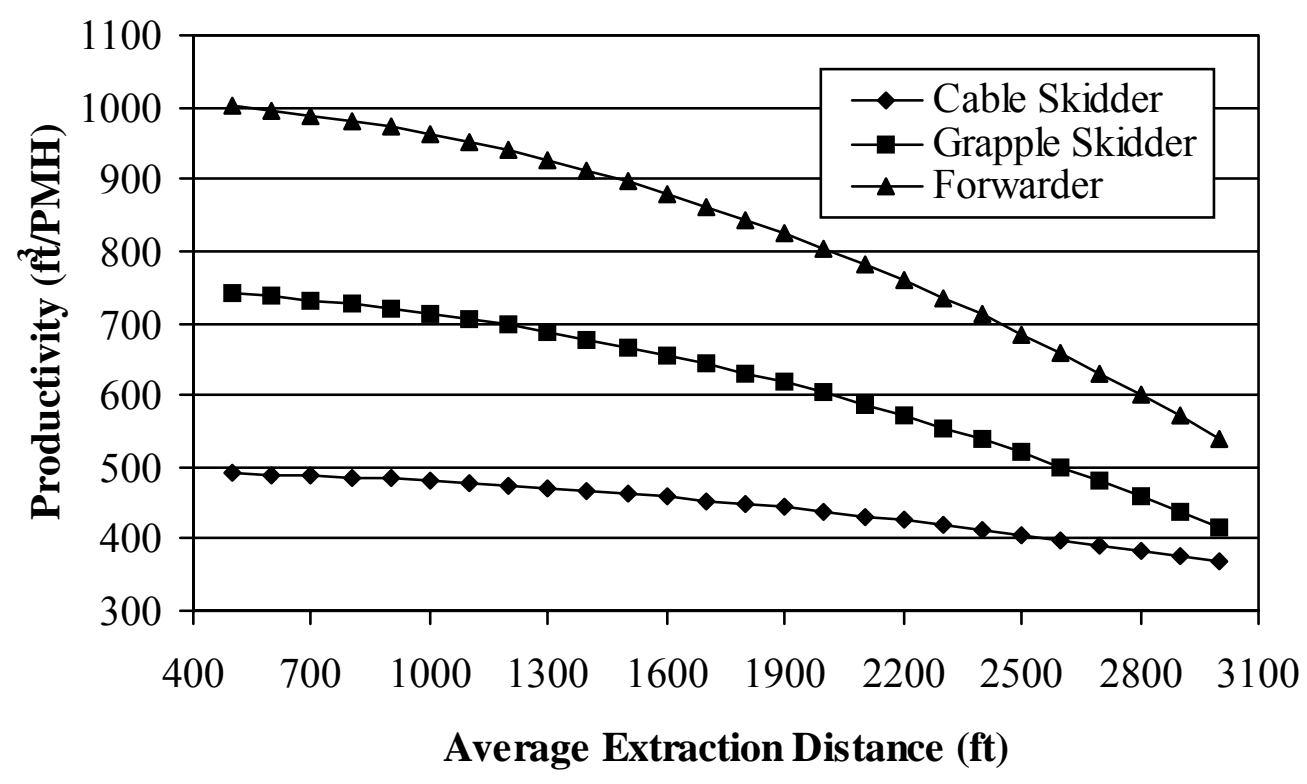

Figure 4.5. Productivity of extraction operations.

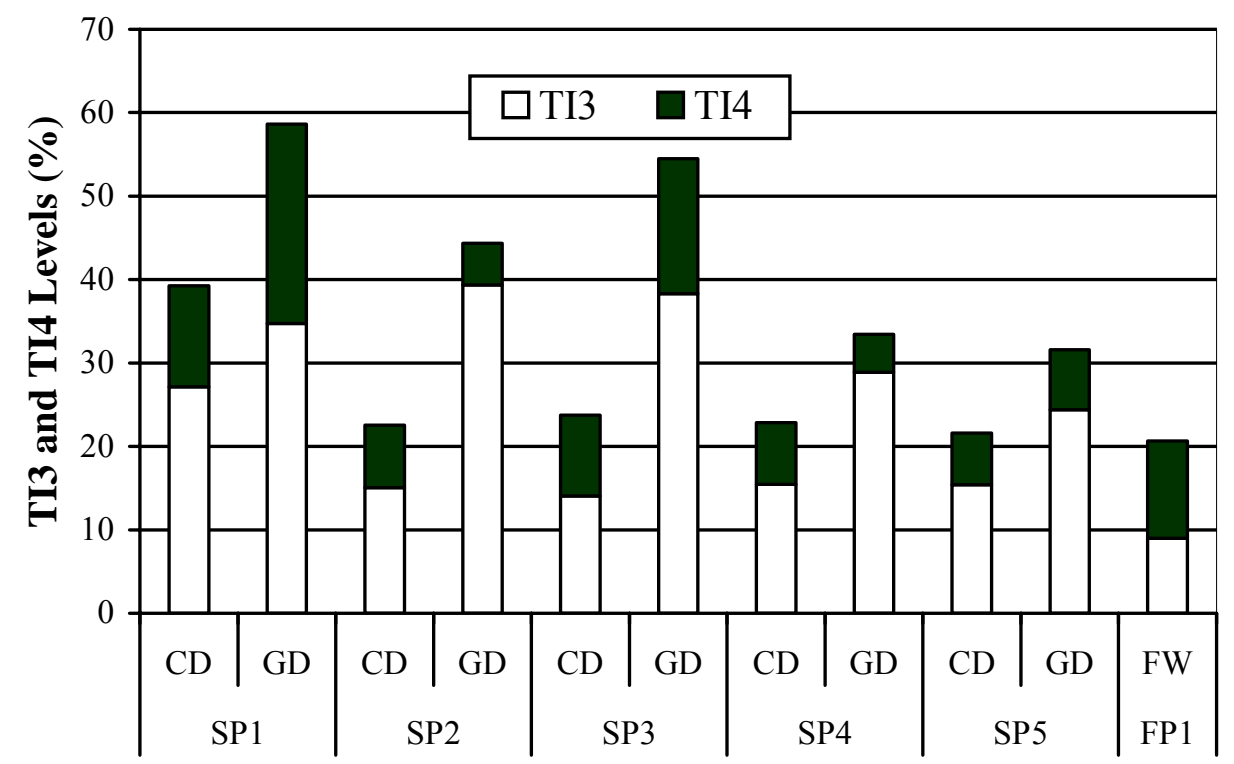

Extraction Machines and Patterns

Figure 4.6. TI3 and TI4 levels vs. extraction machines and patterns. 


\subsubsection{Cost and System Analysis}

Cost estimates of the harvesting machines were calculated by using the machine rate method (Miyata 1980). Hourly cost of a representative chainsaw was $\$ 29.00 / \mathrm{PMH}$ in the region with a mechanical availability of 50\% (Long 2003). Unit costs for other machines were calculated based on the assumptions listed in Table 4.7. Feller-buncher had an hourly cost of $\$ 99.51$ with a fixed cost of $\$ 37.17$, variable cost of $\$ 43.05$, and labor cost of $\$ 19.29$ per PMH (Table 4.8). Hourly costs were estimated at $\$ 80.18$ and $\$ 82.17$ for cable and grapple skidders. Operating harvester and forwarder costs were estimated as $\$ 144.71$ and $\$ 112.90$ per hour. Combined with the hourly production rate of $345.19,1069.27$, and $514.47 \mathrm{ft}^{3} / \mathrm{PMH}$ for each individual felling machine, the unit cost was estimated as $\$ 8.40$ per 100 cubic feet (cunit) or $\$ 13.50 / \mathrm{MBF}, \$ 9.31 /$ cunit (\$14.96/MBF), and \$28.13/cunit (\$46.22/MBF) for operating chainsaw, feller-buncher and harvester, respectively. The unit costs for the cable skidder, grapple skidder, and forwarder were $\$ 25.28 /$ cunit (\$40.64/MBF), \$17.45/cunit $(\$ 28.05 / \mathrm{MBF}$ ), and $\$ 19.19 /$ cunit (\$30.85/MBF) and their average hourly rates were 467.16, 570.86, and $805.73 \mathrm{ft}^{3} / \mathrm{PMH}$, respectively.

The felling unit cost was reversely related to DBH of the tree removed (Figure 4.7). The difference among machines was getting less with increasing DBF of the tree processed. The harvester consistently resulted in higher unit costs than the feller-buncher and chainsaw. When tree DBH was less than 10 inches, the harvester was about 57\% more expensive than the feller-buncher and three times more expensive than chainsaw felling. Extraction unit costs were related closely to average extraction distance, payload size, and bunch size. Unit costs increased with increasing average extraction distances 
(Figure 4.8). Cable skidding always had the highest unit costs, while the forwarder was about $8.17 \%$ more expensive than grapple skidding when average extraction distance was less than 900 feet.

Table 4.7. Cost assumptions for the harvesting systems.

\begin{tabular}{lccccccc}
\hline Machine & $\begin{array}{l}\text { Purchase } \\
\text { price }(\$)\end{array}$ & Economice (year) & $\begin{array}{c}\text { Scheduled } \\
\text { Hours/year }\end{array}$ & $\begin{array}{c}\text { Fuel } \\
\text { (gal/PMH) }\end{array}$ & $\begin{array}{c}\text { Lube } \\
(\mathrm{gal} / \mathrm{PMH})\end{array}$ & $\begin{array}{c}\mathrm{M} / \mathrm{R}^{1} \\
(\% \text { of D) }\end{array}$ & $\begin{array}{c}\mathrm{MA}^{2} \\
(\%)\end{array}$ \\
\hline Cable skidder & 130,000 & 5 & 2000 & 2.0 & 1.2 & 90 & 65 \\
Feller-buncher & 180,000 & 4 & 2000 & 3.5 & 1.5 & 100 & 70 \\
Grapple skidder & 130,000 & 5 & 2000 & 3.2 & 1.2 & 90 & 65 \\
Harvester & 252,000 & 4 & 2000 & 2.5 & 1.5 & 100 & 65 \\
Forwarder & 200,000 & 5 & 2000 & 2.0 & 1.5 & 100 & 65 \\
\hline \hline
\end{tabular}

${ }^{1}$ Maintenance and repairs as a percent of depreciation.

${ }^{2}$ Mechanical availability of machine.

Table 4.8. Machine rate calculations. ${ }^{1}$

\begin{tabular}{lllllll}
\hline \hline & Chainsaw & $\begin{array}{l}\text { Cable } \\
\text { skidder }\end{array}$ & $\begin{array}{l}\text { Feller- } \\
\text { buncher }\end{array}$ & $\begin{array}{l}\text { Grapple } \\
\text { skidder }\end{array}$ & Harvester & Forwarder \\
\hline $\begin{array}{l}\text { Fixed cost } \\
(\$ / P M H)\end{array}$ & 0.60 & 29.60 & 37.17 & 29.60 & 65.91 & 47.85 \\
Variable cost & 1.40 & 29.81 & 43.05 & 31.79 & 58.03 & 44.28 \\
$(\$ / P M H)$ & $(0.70)$ & $(19.38)$ & $(30.14)$ & $(20.66)$ & $(37.72)$ & $(28.78)$ \\
& 27.00 & 20.77 & 19.29 & 20.77 & 20.77 & 20.77 \\
$\begin{array}{l}\text { Labor cost } \\
(\$ / P M H)\end{array}$ & $(14.50)$ & $(13.50)$ & $(13.50)$ & $(13.50)$ & $(13.50)$ & $(13.50)$ \\
$\begin{array}{l}\text { Total cost } \\
\text { \$/PMH) }\end{array}$ & 29.00 & 80.18 & 99.51 & 82.17 & 144.71 & 112.90 \\
$\begin{array}{l}\text { Hourly production } \\
\left(\mathrm{ft}^{3} / \mathrm{PMH}\right)\end{array}$ & $(14.50)$ & $(52.1)$ & $(69.52)$ & $(53.41)$ & $(94.06)$ & $(73.39)$ \\
& $(172.60)$ & $(206.15)$ & $(748.49)$ & $(306.06)$ & $(334.41)$ & $(588.72)$ \\
$\begin{array}{l}\text { Unit cost } \\
(\$ / \text { cunit })\end{array}$ & 8.40 & 25.28 & 9.31 & 17.45 & 28.13 & 19.19 \\
\hline \hline
\end{tabular}

${ }^{\mathrm{T}}$ Parenthesis indicates the values per scheduled machine hour (SMH). 


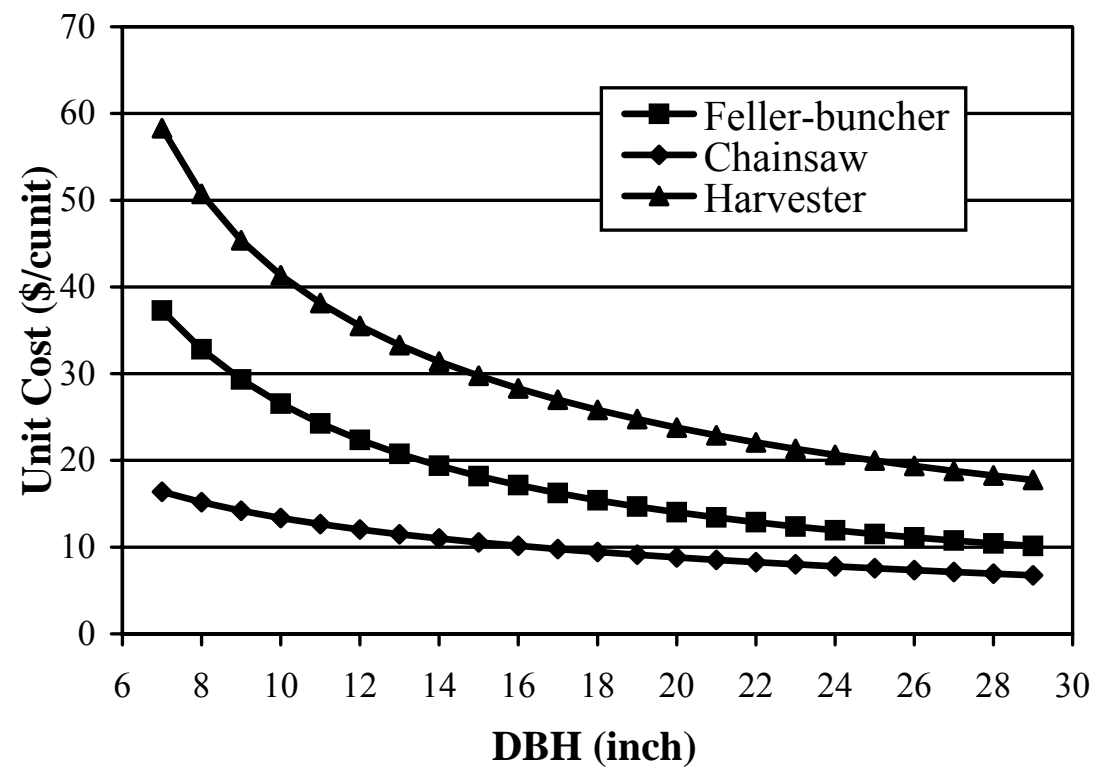

Figure 4.7. Unit costs of felling operations.

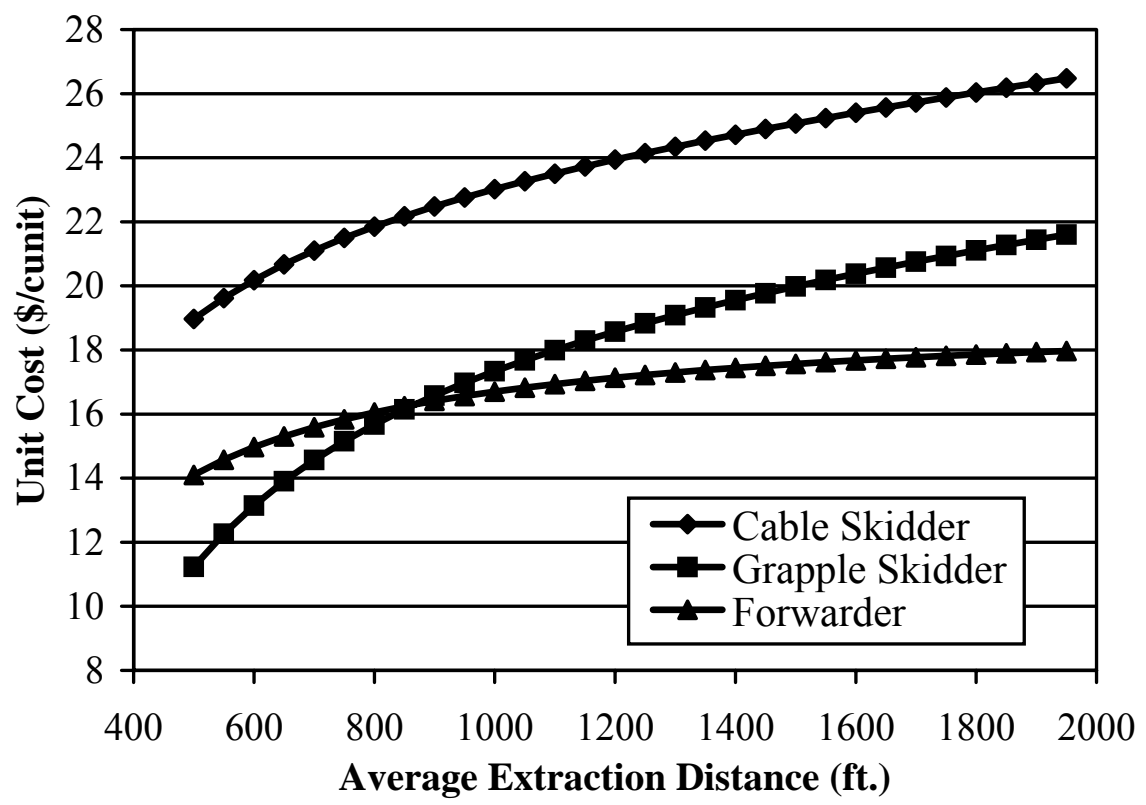

Figure 4.8. Unit costs of extraction operations.

Three harvesting systems were balanced and compared in terms of the system production rate and unit cost. Two chainsaws and one cable skidder were used for the 
chainsaw/cable skidder system (CS/CD), one feller-buncher and two grapple skidders were used for the feller-buncher/grapple skidder system (FB/GD), and one harvester and one forwarder were used for the harvester/forwarder system (HV/FW).

System productivity increased in the following ways: chainsaw/cable skidder system $<$ harvester/forwarder system $<$ feller-buncher/grapple skidder system (Figure 4.9). The weekly production rate for chainsaw/cable skidder system was about 12146.16 $\mathrm{ft}^{3}$ or $75.56 \mathrm{MBF}$ with a unit cost of $\$ 35.28 /$ cunit or $\$ 56.71 / \mathrm{MBF}$. For the fellerbuncher/grapple skidder and harvester/forwarder system, the weekly production rates were $28484.62 \mathrm{ft}^{3}$ (177.20 MBF) and $16714.27 \mathrm{ft}^{3}$ (103.98 MBF), respectively, with unit costs of $\$ 27.41 /$ cunit (\$44.07/MBF), and \$43.80/cunit (\$70.41/MBF), respectively. Compared to chainsaw/cable skidder and harvester/forwarder systems, the fellerbuncher/grapple skidder was the most productive and least expensive system. Since the harvester/forwarder system requires higher initial investment and more maintenance, it was the most expensive system.

System productivity decreased and unit cost increased from clearcut to selective and diameter limit cuts, and to crop tree release and shelterwood cuts. The productivity of chainsaw/cable skidder system was $16770.52 \mathrm{ft}^{3} /$ week (104.33 MBF/week) with the unit cost of $\$ 26.33 /$ cunit $(\$ 42.33 / \mathrm{MBF})$ in clearcuts compared to $9936.68 \mathrm{ft}^{3} /$ week $(61.81$ $\mathrm{MBF} /$ week) with the unit cost of $\$ 42.37 /$ cunit $(\$ 68.11 / \mathrm{MBF}$ ) in shelterwood cuts (Figure 4.9, Figure 4.10). Unit costs for the harvester/forwarder system were much higher than the other two systems in shelterwood and crop tree release cuts (Figure 4.10). 


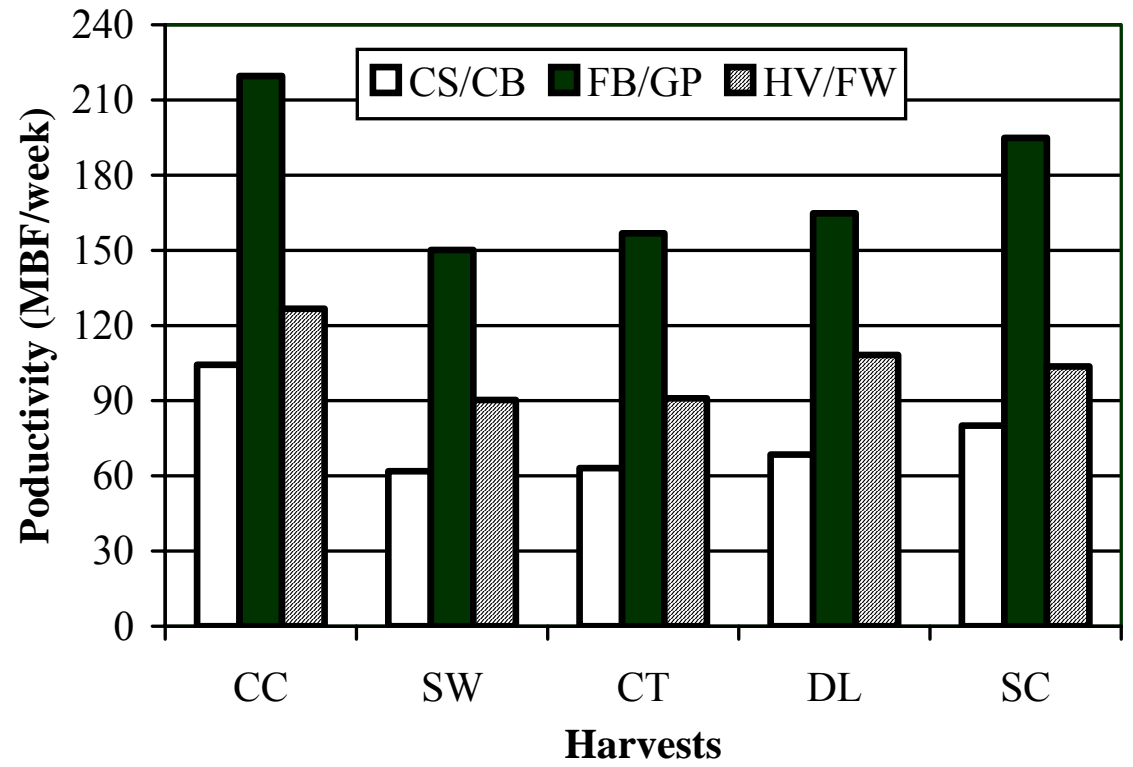

Figure 4.9. Harvesting system productivity.

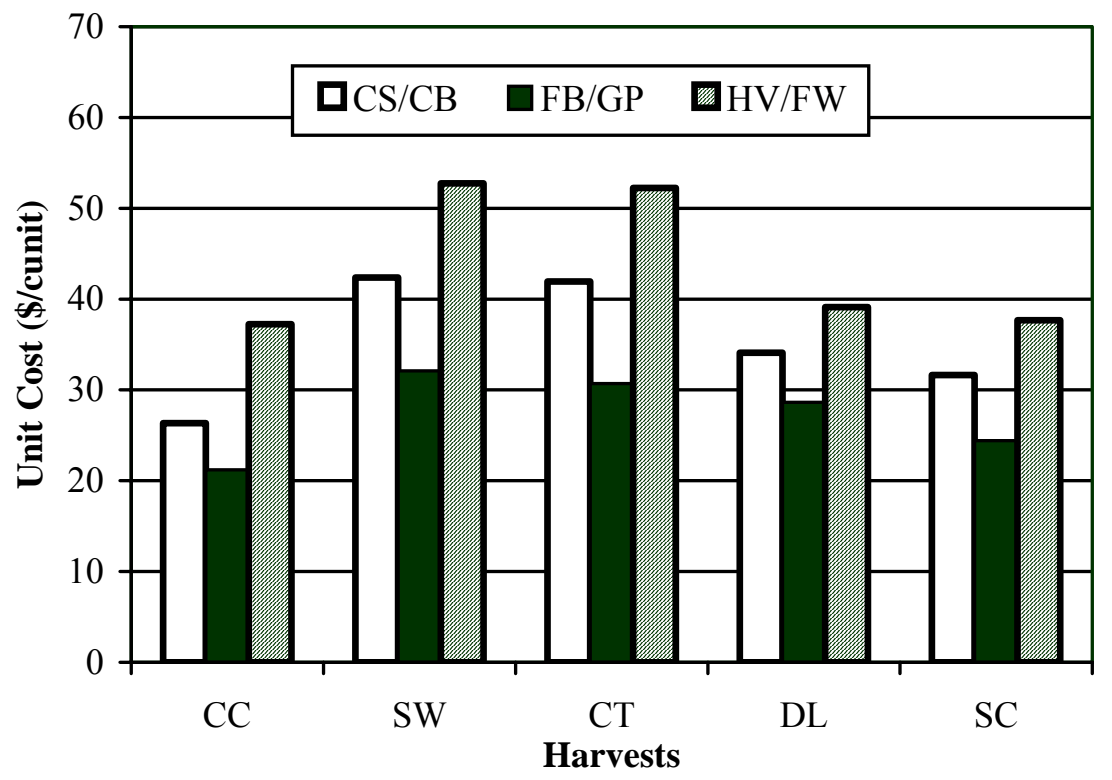

Figure 4.10. Harvesting system unit cost. 


\section{CHAPTER 5: CONCLUSIONS AND DISCUSSION}

The harvesting simulation system was developed to evaluate harvesting operations in central Appalachia. Specifically, the system can be used to examine the interactions of stands, harvests, and machines, and the traffic intensity of skidding/forwarding operations across the site.

Object oriented programming (OOP) with three unique features of encapsulation, inheritance, and polymorphism was employed to enhance the reusability of the program through Microsoft Visual Basic (MS VB) and Microsoft Visual C++ (MS VC++). MS $\mathrm{VB}$ is well known for the interface design while MS $\mathrm{VC}++$ is well suited for implementing the business functions. The graphical user interface (GUI) allows the user easy access to any modules or components in the system.

There are four components in the system: stand generator, felling/extraction simulation, analysis, and report. The Microsoft Component Object Model (MS COM) was used to communicate among the components in the simulation system. Traditionally, applications were distributed in single, large executable files, which are now known as procedural programming or monolithic applications. These had many inherent problems, the largest of which was that if one line of code needed to be modified, then the entire application needed to be rebuilt. MS COM with object-oriented design technique overcomes these problems and enhances the application's modularity and modifiability. The COM objects make it possible to implement components with both MS VB and MS $\mathrm{VC}++$ languages.

A Microsoft Foundation Class (MFC) based Open Graphics Library (OpenGL) programming, a powerful tool for 3 dimensional graphics, was adopted for the modeling 
and projection transformation of the generated stands. Generated stand can be displayed either in 2-dimension or 3-dimension format accompanied with DBH distribution and stand information. The stand generator was validated by comparing tree characteristics of control stands with treated stands. The stand generator developed is a powerful tool to facilitate forest management planning, such as harvesting simulation and layout. It can be used to aid other research projects and analyze forest stand structure and dynamics. This stand generator can be applied to other regions by slightly modifying species and some other related equations used in the system.

Three felling machines of chainsaw, feller-buncher, and harvester, and three extraction machines of cable skidder, grapple skidder, and forwarder were modeled and simulated on five generated stands of different ages in the study. Elemental functions were modeled for each individual machine. An "obstacle checking" procedure was implemented for the felling and extraction machines to avoid residual tree damage or felled tree bunches, making the simulation results more realistic and accurate. Five harvest methods of clearcut, shelterwood cut, crop tree release cut, diameter limit cut, and selective cut were examined.

A relational database was implemented via an entity-relationship (ER) model, which was used to enhance the data accessibility and utility. The ER model that views the real world as entities and relationships, and makes the data more easily transformed into relational tables and more easily understood by the end user. By using the Structured Query Language (SQL), stand summary, felling operation summary, and extraction operation summary reports can be generated from the simulation results. Variables 
included in the report was predefined, but could be modified according to users' requirements.

The results showed that felling production and cost were primarily affected by DBH of the trees removed, removal intensity, distance traveled between harvested trees, and felling machines. Compared with chainsaw and feller-buncher, harvester was more sensitive to individual tree size. The feller-buncher was the most cost-effective and productive felling machine. Clearcutting always presented the highest productivity while the shelterwood cut was the least productive method. The crop tree release cut removed smaller trees, which had the similar silvicultural effects as shelterwood cut but without sacrificing the stumpage price. Unit costs were higher with the harvester than the fellerbuncher and chainsaw.

Extraction operation was affected primarily by payload size, average extraction distance, and bunch size. The forwarder resulted in a longer forwarding distance than cable skidding and grapple skidding due to its higher payload. The longest average skidding distance was associated with skidding pattern 3 (SP3) while the lowest distance was presented in skidding pattern 1 (SP1). The grapple skidding always resulted in relatively longer average extraction distances than the cable skidding no matter what extraction pattern was followed. Average extraction distance also varied among extraction patterns.

Extraction productivity decreased while unit cost increased as the average extraction distance increases. Extraction unit costs also increased with average extraction distance. The forwarder was the most productive machine and cable skidding is the least productive method. The relatively lower productivity of the cable skidder was partly due 
to the time consumed for choking, which accounted for about 25 percent of the total cycle time of the cable skidder. The productivity was much higher in forwarding pattern 1 (FP1) than skidding patterns 1 to 5 .

Because of the smaller payload and more machine passes, the TI3 and TI4 levels for both cable skidding and grapple skidding were up to 40 percent across clearcuts and more than 20 percent for the four less intensive harvest methods. However, TI3 and TI4 levels were consistently less than 20 percent across the site with the forwarder regardless harvest method was used. The highest TI3 and TI4 levels were in clearcuts while the lowest were in the selective cuts. Grapple skidding always resulted in the higher TI3 and TI4 levels than cable skidding and forwarding.

System productivity increased from the chainsaw/cable skidder system to the harvester/forwarder system, and to the feller-buncher/grapple skidder system. Among the three harvesting systems simulated in this study, the feller-buncher/grapple skidder was the most productive and least expensive system. Since the harvester/forwarder system requires higher initial investments and more maintenance, it was the most expensive system. System productivity also varied among harvest methods. The weekly production rates decreased and unit costs increased from clearcut to selective and diameter limit cut, and to crop tree release and shelterwood cut.

This harvesting simulation system successfully modeled the typical harvesting operations in central Appalachian hardwoods and evaluated the interactions among machines, harvests, and stands. It is a useful tool in forest management and provides lots of valuable information for loggers, landowners, forest managers, and researchers. Some improvements to the simulation, however, should be considered in future related studies. 
The current model of stand generation does not contain mortality or growth functions. These modules and components can be added to the system to enhance the functionality and flexibility. By adding these modules, we can project the stand development and predict the species composition transition dynamically. The tree design module should be improved to provide the user with more capabilities to design trees by species and make them look more realistic. Modules also can be added to evaluate impacts of related environmental and landscape conditions.

Drive-to-tree feller-buncher was modeled in this simulation. Swing-to-tree fellerbuncher could be modeled on the basis of drive-to-tree feller-buncher and swing-to-tree harvester. No delays were assumed for the machines modeled in the system while delay time can be significant in real work operations due to weather, terrain, or other conditions. In addition, machine interaction delays also happen and affect system production rates. Therefore, to model machine delays, random distribution can be assumed to generate some random delay times and added to the machine production rate.

Because of the varied operating environment and multiple variables involved, soil compaction/disturbance caused by harvesting operations is not easily quantified in the simulation study. Traffic intensity level is a useful index for evaluating soil compaction/disturbance, but it could be further improved particularly if combined with machine payload size.

Operating costs for marking trees, which were affected primarily by basal area marked per acre (Sydor et al. 2004), should be included in the model since tree marking costs is substantial in shelterwood and crop tree release cuts. Additionally, a new module could be incorporated into the simulation model to evaluate potential residual stand 
damage during harvesting. Other harvesting systems used in the region, such as shovel logging, helicopter logging, and cable yarding, also could be incorporated into the simulation system.

Topography factors, which are closely related to the performance of harvesting machines, should be considered in the model to improve estimates of production economics of harvesting hardwood stands in central Appalachia. In this simulation, the logging sites were assumed to be square and the major skid trails were predefined in specific skidding patterns. Topography and other geographic features must be taken into consideration when laying out skid trails and locating landings. In order to handle irregular polygons and consider the terrain and geographic features into the model, MapObjects application can be integrated into the simulation program. The MapObjects is an ActiveX mapping component created by Environmental Systems Research Institute, Inc. (ESRI). Once it is added into the system, the dynamic mapping and geographic information system (GIS) capabilities can be enhanced to build custom mapping and GIS solutions for the harvesting simulation system. 


\section{REFERENCES}

Aedo-Ortiz, D.M., E.D. Olsen, and L.D. Kellogg. 1997. Simulation a harvester-forwarder softwood thinning: A software evaluation. Forest Prod. J. 47(5): 36-41.

Aust, W.M., M.D. Tippett, J.A. Burger, and W.H. McKee. 1995. Compaction and rutting during harvesting affect better drained soils more than poorly drained soils on wet pine flats. South. J. Appl. For. 18(2): 72-77.

Bailey, R.L. and T.R. Dell. 1973. Quantifying diameter distributions with the Weibull function. For. Sci.19: 97-104.

Bare, B.B., B.A. Jayne, and B.F. Anholt. 1976. A simulation-based approach for evaluating logging residue handling systems. USDA Forest Service GTR PNW- 45.

Barrett, S.M. 2001. A computer simulation model for predicting the impacts of log truck turn-time on timber harvesting system productivity. M.S. Thesis. Virginia Ploytechnic Institute and State University. Blacksburg, VA.

Bass, C.M., J.L. Fridley, and F.E. Lee. 1991. Methods of interactive control and simulation of forestry machinery. Presented at the 1991 International Winter Meeting. Hyatt Regency Chicao, Chicago, IL. December 17-20, 1991.

Baumgras, J.E., C.C. Hassler, and C.B. LeDoux. 1993. Estimating and validating harvesting system production through computer simulation. Forest Prod. J. 43(11): 65-71.

Bechtold, W.A., S.J. Zarnoch, and W.G. Burkman. 1998. Comparisons of modeled height predictions to ocular height estimates. South. J. Appl. For. 22 (4): 216-221.

Biller, C.J. and L.R. Johnson. 1973. Comparing logging systems through simulation. Transactions of the ASAE. 16 (6): 1060-1063.

Bliss, C.I. and K.A. Reinker. 1964. A log-normal approach to diameter distribution in even-aged stands. For. Sci. 10: 350-360.

Block, W.A. and J.L. Fridley. 1990. Simulation of forest harvesting using computer animation. Transactions of the ASAE. 33(3): 967-974.

Borders, B.E., W.M. Harrison, D.E. Adams, R.L. Bailey, and L.V. Pienaar. 1990. Yield prediction and growth projection for site-prepared loblolly pine plantations in the Carolinas, Georgia, Florida, and Alabama. Univ. of Georgia PMRC Tech. Rep. 1990-2.

Bradley, D.P., R.E. Biltonen, and S.A.Winsaure. 1976. A computer simulation of full-tree field chipping and trucking. USDA Forest Service Research Paper NC-129. North Central Forest Experiment Station, St. Paul, Minnesota. 
Brand, G.J., M.R. Holdaway, and S.R. Shifley. 1987. A description of the TWIGS and STEMS individual-tree-based growth models and their applications. In: Proceedings of the IUFRO Forest Growth Modeling and Prediction Conference. Minneapolis, MN, August 24-28.

Burkhart, H.E. and P.T. Sprinz. 1984. A model for assessing hardwood competition effects on yields of loblolly pine plantations. School of Forestry and Wildlife Resources, Virginia Tech, Blacksburg. Pub. FWS-3-84.

Campbell, R.G. 1974. The impact of timber harvesting and site preparation on selected soil conditions and plant growth. Ph.D. dissertation, University of Georgia, Athens, GA.

Cao, Q.V. and H.E. Burkhart. 1984. A segmented distribution approach for modeling diameter frequency data. For. Sci. 30:129-137.

Carruth, J.S. and J.C. Brown. 1996. Predicting the operability of South Carolina coastal plain soils for alternative harvesting systems. USDA For. Serv. Gen. Tech. Rep. NC-186. 8 p.

Carter, E.A., T.P. McDonald, and J.L. Torbert. 1999. Application of GPS technology to monitor traffic intensity and soil impacts in a forest harvest operation. In: J.D. Haywood (ed.), Proc. 10th Bienn. South. Silv. Res. Conf. Shreneport, LA. 16-18 February 1999. Gen. Tech. Rpt. SRS-30, USDA-FS, SRS, Asheville, NC.

Choudhury, D.Z. 1999. Interactive Web Tutorial for Object Oriented Programming. South Bank University. http://homepages.unl.ac.uk/ chalkp/proj/ootutor/index.html

Clutter, J.L. and F.A. Bennett. 1965. Diameter distribution in old-field slash pine plantations. Can. For. Res. Counc. Rep. 13, 9 p.

Clutter, J.L., J.C. Fortson, L.V. Pienaar, G.H. Brister, and R.L. Bailey. 1983. Timber mangement: a quantitative approach. Krieger Publishing Company. Malabar, FL. 333p.

Cohen, A.C. and B.J. Whitten. 1983. Modified maximum likelihood and modified moment estimators for the three parameter Weibull distribution. Commun. Stat. - Theory and Methods 11:2631-2656.

Corns, I.G.W. 1988. Compaction by forestry equipment and effects on coniferous seedlings growth on four soils in the Alberta foothills. Can. J. For. Res.18: 75-84.

Cottam, G., J. T. Curtis, and B. W. Hale. 1953. Some sampling characteristics of a population of randomly dispersed individuals. Ecology. 34: 741-757.

Cox, B.J. 1987. Object Oriented Programming - An Evolutionary Approach. Reading, Mass.: Addison-Wesley. 
Curtis, R.O. 1967. Height-diameter and height-diameter-age equations for secondgrowth Douglas-fir. For. Sci. 13: 365-375.

Da Silva, J.A.A. 1986. Dynamics of stand structure in fertilized slash pine plantations. Ph.D. dissertation. University of Georgia, Athens, GA.

Ek, A.R., E.T. Birdsall, and R.J. Spears. 1984. A simple model for estimating total and merchantable tree heights. USDA Forest Service, North Central Forest Experiment Station. Research Note, NC-309.

Eliasson, L. 1999. Simulation of thinning with a single-grip harvester. For. Sci. 45(1): 2634.

Ergun, S. 1956. Application of the principle of least squares to families of straight lines. Industry and Engineering Chemistry. 48(11): 2060-2068.

Farrar, K.D. 1981. In situ stand generator for use in harvesting machine simulations. M.S. Thesis, Virginia Polytech. Ins. and State Univ., Blacksburg,VA. 211p.

Fisher, L.E. and D.L. Gochenour, Jr. 1980. Improved timber harvesting through better planning. A GASP IV simulation analysis. Transactions of the ASAE. 23 (3): 553-557.

Fridley, J.L., J.L. Garbini, and J.E. Jorgensen. 1982. Interactive simulation of forest thinning system concepts. ASAE Paper No. 82-1603.

Fridley, J.L, J.L. Garbini, J.E. Jorgensen, and P.A. Peters. 1985. An interactive simulation for studying the design of feller-bunchers for forest thinning. Transactions of the ASAE. 28(3): 680-686.

Froehlich, H.A., D.E. Aulerich, and R. Curtis. 1981. Designing skid trail systems to reduce soil impacts from tractive logging machines. Oregon State Univ. Res. Rap. 44. Garbini, J.L., M.R. Lembersky, U.H. Chi, and M.T. Hehnen. 1984. Merchandiser design using simulation with graphical animation. Forest Prod. J. 34 (4): 61-68.

Goulet, D.V., .R.H. Iff, and D.L. Sirois. 1979. Tree-to-mill forest harvesting simulation models: Where are we? Forest Prod. J. 29(10): 50-55.

Gove, J.H. 2000. Some observations on fitting assumed diameter distributions to horizontal point sampling data. Can. J. For. Res. 30: 521-533.

Greacen, E.L. and R. Sands. 1980. Compaction of forest soils: A review. Aust. J. Soil Res. 18:163-189.

Greene, W.D. and B.L. Lanford. 1986. An interactive simulation program to model feller-buncers. Alabama Agricultural Experiment Station, Bulletin No. 576. 
Greene, W.D., B.L. Lanford, and E.F. Mykytka. 1987. Stand and operating effects on feller-buncher productivity in second thinnings of southern pine. Forest Prod. J. 37(3): 27-34.

Hassler, C.C., J.F. MeNeel, and D.P. Bradley. 1985. A comparison of cutting patterns for a track-type feller-buncher. Forest Prod. J. 35(3): 31-38.

Hatchell, G.E., C.W. Ralston, and R.R. Foil. 1970. Effects on soil characteristics and growth of loblolly pine in the Atlantic Coastal Plain. J. For. 68.772-776.

Hilt, D.E. 1985. OAKSIM: An individual-tree growth and yield simulator for managed, even-aged, upland oak stands. USDA Forest Service, Northeastern Forest Experiment Station. Research Paper NE-562.

Huang, S., S.J. Titus, and D.P. Wiens. 1992. Comparison of nonlinear height-diameter functions for major Alberta tree species. Can. J. For. Res. 22: 1297-1304.

Johnson, L.R., D.L. Gochenour, and C.J. Biller. 1972. Simulation analysis of timberharvesting systems. Technical Paper. 23rd Annual conference and Convention of the American Institute of Industrial Engineers. Anaheim, CA., May 30- June 3: 353-365.

Jackson, G.A. 1988. Relational Database Design with Microcomputer Applications. Prentice Hall, Englewood Cliffs, New Jersey 07632.

Kenefic, L.S. and R.D. Nyland. 1999. Sugar maple height-diameter and age-diameter relationships in an uneven-aged Northern hardwood stand. North. J. Appl. For. 16(1): 43-47.

Killham, J.R. 1975. The development of a forest harvesting simulation model. M.S. Thesis. Auburn Universtiy. Auburn, Alabama.

King, T. and S. Haines. 1979. Soil compaction absent in plantation thinning. USDA For. Serv. Res. Note S0-251. 4p.

Knowe, S.A., T.B. Harrington, and R.G. Shula. 1992. Incorporating the effects of interspecific competition and vegetation management treatments in diameter distribution models for Douglas-fir saplings. Can. J. For. Res. 22: 1255-1262.

Koger, J.L., E.C. Burt, and A.C. Trouse. Jr. 1984. Skidder tire size vs. soil compaction in soil bins. Trans. ASAE. 27: 665-669.

Lanford, B.L. and B.J. Stokes. 1995a. Comparison of two thinning systems. Part 1. Stand and site impacts. Forest Prod. J. 45(5): 74-79.

Lanford, B.L. and B.J. Stokes. 1995b. Comparison of two thinning systems. Part 2. Stand and site impacts. Forest Prod. J. 46(11/12): 47-53. 
Law, A.M. and S. Vincent. 1999. ExpertFit - User's Guide. Averill M. Law \& Associates, Tucson, AZ. 172p.

LeDoux, C. B., J. E. Baumgras, and J. Sherar. 1994. Comparison of temporary cable harvesting pratices for eastern hardwoods on steep slopes. In: Proc. Meeting on advanced technology in forest operations: Applied ecology in action, Corvallis, Oregon. Forest Engineering Dept., Oregon State Univ., Corvallis, OR. Pp.155-166.

Lewis, T. 1999. VB COM: A Visual Basic programmer's introduction to COM. Wrox Press Ltd., Birmingham, UK.

Long, C.R. 2003. Production and cost analysis of two harvesting systems in central Appalachia. M.S. Thesis. West Virginia University, Morgantown, WV.

Maltamo, M., J. Puumalainen, and R. Paivinen. 1995. Comparison of beta and Weibull functions for modeling basal area diameter distribution in stands of pinus sylvestris and picea abies. Scand. J. For. Res. 10: 284-295.

Marquis, D.A. and R.L. Ernst. 1992. User's guide to SILVAH: Stand analysis, prescription, and management simulator program for hardwood stands of Alleghenies. USDA Forest Service, Northeastern Forest Experiment Station. GTR NE-162.

McDonagh, K.D. 2002. Systems dynamics simulation to improve timber harvesting system management. M.S. Thesis. Virginia Ploytechnic Institute and State University. Blacksburg, VA.

McDonald, T., E. Carter, S. Taylor, and J. Torbert. 1998a. Relationship between site disturbance and forest harvesting equipment traffic. In: Whiffen, H. J-H;Hubbard, W.C.,eds. Proceedings of the second southern forestry GIS conference; 1998 October 2829; Athens, GA.: 85-92.

McDonald, T., E. Carter, S. Taylor, and J. Torbert. 1998b. Traffic patterns and site disturbance. In: Harvesting logistics: from woods to markets: Proceedings of the 21st annual meeting of the council on forest engineering (COFE); 1998 July 20-23; Portland. OR.

McGaughey, R. J. 1997. Visualizing forest stand dynamics using the stand visualization system. In Proceedings: 1997 ACSM/ASPRS Annual Convention \& Exposition; April710; Seattle, WA. Bethesda, MD: American Society of Photogrammetry and Remote Sensing. Vol. 4: 248-257.

McMahon, S.D. 1997. Unearthing soil compaction: The hidden effects of logging machines. GPS World. March: 40-45.

Meerschaert, W.J. 1988. An overview of CACTOS: The California Conifer Timber Output Simulator. USDA Forest Service, GTR NC-120. 
Miller, R.E., W. Scott, and J.W. Hazard. 1996. Soil compaction and conifer growth after tractor yarding at three coastal Washington locations. Can. J. For. Res. 26: 225-236.

Miyata, E.S. 1980. Determining fixed and operating costs of logging equipment. USDA For. Serv. Gen. Tech. Rep. NC-55. 20 p.

Nelson, T.C. 1964. Diameter distribution and growth of loblolly pine. For. Sci. 10:105115 .

Newberry, J.D. 1993. Evaluation of simple quantile estimation functions for modeling forest diameter distribution in even-aged stands of interior Douglas-fir. Can. J. For. Res. 23: $2376-2382$.

Newnham, R.M. 1968. Generation of artificial population of points (spatial patterns) on a plane. For Manage Res and Serv Inst., Ottaewa, Canada. Inf Rep FMR-X0101, 28 p.

Newnham, R.M. and G.T. Maloley. 1970. The generation of hypothetical forest stands for use in simulation studies. Forest Management Insitute: Ottawa, Ontario. Information Report FMR-X-26. Project FM-27. 72p.

O'Hearn, S.E., W.B. Stuart, and T.A. Walbridge. 1976. Using computer simulation for comparing performance criteria between harvesting systems. 1976 Winter meeting, American Society of Agricultural Engineers, Paper No. 76-1567.

Oinas S. and L. Sikanen. 2000. Discrete event simulation model for purchasing of marked stands, timber harvesting and transportation. Forestry, 73 (3): 283-301.

Pelkki, M. and D. Rose. 1988. DTREES - An automated stand prescription writer and harvest simulator. USDA Forest Service, GTR NC-120.

Perry, T.O. 1964. Soil compaction and loblolly pine growth. U.S. For. Serv. Tree Plant. Notes, 67: 9p.

Pielou, E. C. 1957. The effect of quadrat size on the estimation of the parameters of Neyman's and Thomas's distributions. J. Ecol. 45: 31-47.

Randhawa, S.U. and E.D. Olsen. 1990a: LOGSIM: A tool for mechanized harvesting systems design and analysis. Applied Engineering in Agriculture. 6(2): 231-237.

Randhawa, S.U. and E.D. Olsen. 1990b. Timber harvesting analyses and design using simulation. Pakistan J. of Forestry. 7: 210-214.

Randhawa, S.U., T.M. Scott, and E.D. Olsen. 1992. Timber harvester: A microcomputerbased system for automatic selection of timber harvesting equipment. Applied Engineering in Agriculture. 8(1): 121-127. 
Randhawa, S.U. and T.M. Scott. 1996. Model generation for simulation analysis: an application to timber harvesting. Computers ind. Engng. 30 (1): 51-60.

Rennie, J.C. 1996. Formulas for Mesavage's cubic-foot volume table. North. J. Appl. For. 13(3): 147.

Reutebuch, S. E., S. D. Bergen, and J. L. Fridley. 1997. Collecting and using sitespecific vegetation and terrain data for varying accuracy for use in landscape visualizations of harvest operations. In the Proceedings of 20th Annual Council on Forest Engineering. July 28 - July 31, 1997, Rapid City, South Dakota.

Shetron, S.G., J.A. Sturos, E. Padley, and C. Trettin. 1988. Forest soil compaction: Effect of multiple passes and loadings on wheel track surface soil bulk density. North. J. Appl. For. 5: 120-123.

Shiver B.D. 1988. Sample sizes and estimation methods for the Weibull distribution for unthinned Slash Pine plantation diameter distributions. For. Sci. 34 (3): 809-814.

Stampfer, K. and J. Henoch. 1999. Process simulation to evaluate steep terrain harvesting systems. Landwards, The Institution of Agriculture Engineers. 54(3):1-11.

Stewart, R., H. Froehlich, and E. Olsen. 1988. Soil compaction: An economic model. West. J. Appl. For. 3 (1):20-22.

Stuart, W.B. 1981. Harvesting analysis Technique: a computer simulation system for timber harvesting. Forest Prod. J. 31(11): 45-53.

Sydor, T., R.A. Kluender, R.L. Busby, and M. Pelkki. 2004. Productivity and cost of marking activities for single-tree selection and thinning treatments in Arkansas. Forest Prod. J. 54 (3): 59-96.

Taylor, S.E., T.P. McDonald, M.W. Veal, and T.E. Grift. 2001. Using GPS to evaluate productivity and performance of forest machine systems. In: Proceedings of First International Precision Forestry Symposium. June 17-19, 2001. Seattle, Washington, USA.

Turcotte, D.E. , C.T. Smith and C.A. Federer. 1991. Soil disturbance following wholetree harvesting in north-central Maine. North. J. Appl. For. 8(2): 68-72.

Valentine, H.T., D.A. Herman, J.H. Gove, D.Y. Hollinger, and D.S. Solomon. 2000. Initializing a model stand for process-based projection. Tree Physiology. 20:393-398.

Van Deusen, P.C. 1986. Fitting assumed distributions to horizontal point sample diameters. For. Sci. 32: 146-148. 
Wang J., and C.B. LeDoux, 2003. Estimating and validating ground-based timber harvesting production through computer simulation. For. Sci. 49 (1): 64-76.

Wang, J., C.B. LeDoux, and Y. Li. 2003. Modeling and simulating two cut-to-length harvesting systems in central Appalachian hardwoods. In: Proceedings of the 26th Annual Meeting of Council on Forest Engineering. September 7-10, 2003, Bar Harbor, Maine. 5 p.

Wang, J., Y. Li, and G. Miller. 2002. Development of a 3D stand generator for central Appalachian hardwood forests. In: Proceedings of the IUFRO Conference on Symposium on Statistics and Information Technology in Forestry. September 8-12. 2002. Blacksburg, VA. 5 p.

Wang, J. and W. D. Greene. 1999. An interactive simulation system for modeling stands, harvests, and machines. Journal of Forest Engineering 10(1): 81-99.

Wang, J., W. D. Greene, and B. Stokes. 1998. Stand, harvest, and equipment interactions in simulated harvesting prescriptions. Forest Prod. J. 48 (9): 81-86.

Webster, D.B. 1975. Development of a flexible timber harvesting simulation model.

Forest Prod. J. 25 (1): 40-45.

Wert, S. and B.R. Thomas. 1981. Effects of skid roads on diameter, height, and volume growth in Douglas-fir. Soil Sci. Soc. Am. J. 45: 629-632.

Wiant, H.V., Jr. 1986. Formulas for Mesavage and Girard's volume tables. North. J. Appl. For. 3: 124.

Wiant, H.V., Jr. 1978. Shortcuts for Mesavage and Girard volume tables. The Consultant $23: 72$.

Winsauer, S.A. 1980. A program and documentation for simulation of a tracked feller/buncher. USDA Forest Service Research Paper NC - 192: 26p.

Winsauer, S.A. and P.D. Kofman. 1986. Simulation of the KOCKUMS 81-11 feller/buncher. Presented at the 1986 Winter Meeting American Society of Agriculture Engineers. Hyatt Regency, Chicago, IL. Decemer 16-19, 1986.

Woo, M., J. Neider, T. Davis, and D. Shreiner. 2000. OpenGL Programming Guide: The Official Guide to Learning OpenGL, Version 1.2. Addison-Wesley, Reading, MA. 


\section{APPENDIX A: USER'S MANUAL FOR THE HARVESTING SIMULATOR}

\section{A.1 System Requirements}

The recommended system configuration for this harvesting simulation system is Microsoft Windows ${ }^{\circledR}$ 2000, or Microsoft Windows XP with a Pentium III processor and 128 megabytes $(\mathrm{MB})$ of RAM. The minimum requirements for the computer are given in Table A.1.

Table A.1. System requirements.

\begin{tabular}{ll}
\hline \hline Item & Requirements \\
\hline $\begin{array}{l}\text { Processor } \\
\text { Operating System }\end{array}$ & $\begin{array}{l}\text { Intel Pentium III processor or later } \\
\text { Memory }\end{array}$ \\
64 MB of memory (RAM) minimum \\
Hard disk & $80 \mathrm{MB}$ of available hard-disk space \\
Drive & A CD-ROM drive \\
Display & Super VGA (800 x 600) or higher-resolution monitor with 256 colors \\
Peripherals & Microsoft Mouse or compatible pointing device \\
\hline \hline
\end{tabular}

\section{A.2 System Setup}

The simulator is compiled in distribution format with a setup program. The setup program installs the simulator to your computer. Files cannot be simply copied from the distribution files to the hard disk to run the simulator. 
When the setup program is run, directories are created. Files from the simulator will be put under "C:IFHSimuldirectory". Another directory

"C:|FHSimulapplications $\mid$ " will be created for the simulation application files. To setup from CD-ROM drive:

- Insert CD in the CD-ROM drive;

- Use appropriate commands in your operating environment to run the setup program, and

- Follow the setup instructions on the screen

\section{A.3 Performing Simulations}

The simulation system can be started by clicking the FHSimulator icon or from the start menu under Microsoft Windows environment. After starting the system, a login window pops out and asks the user to input the appropriate user ID and password (Figure A.1). The user can change the password by clicking the "Change Password..." button. Neither user ID nor password are case sensitive.

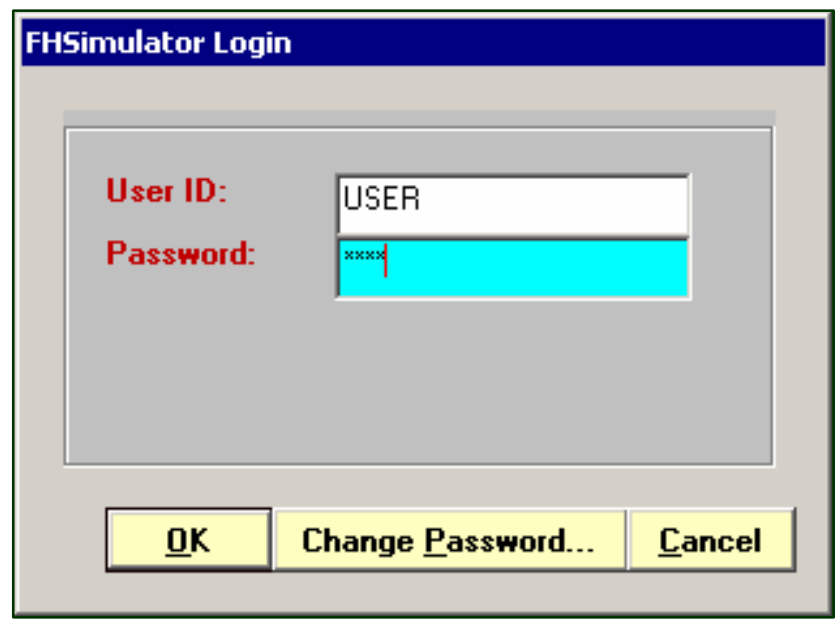

Figure A.1. Login box. 
After the correct information is entered and the "OK" button is clicked, the main window of the simulator is displayed (Figure A.2).

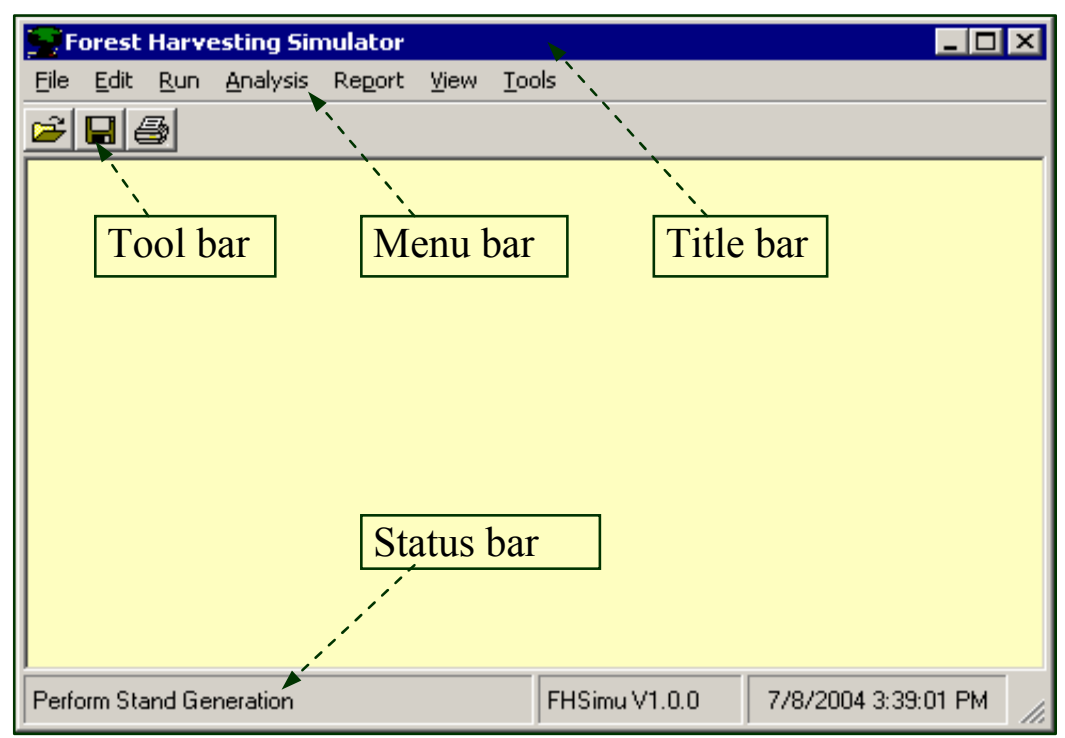

Figure A.2. MDI window of the harvesting simulator.

This multiple document interface (MDI) was used to display the simulation processes. The title bar appears at the top of the window and the menu bar appears just below the title bar. The menu bar includes File, Edit, Run, Analysis, View, and Tools event procedures and serves as the command center of the harvesting simulator. Each option on the menu bar calls up a drop-down menu of commands that you can use to link to other event procedures in this simulator. The tool bar, displayed below the menu bar, that provides the major functions for running the simulator, such as, printing and exiting the system. 


\section{A.3.1 Stand Generation}

By clicking Run, Stand Generation, and Natural Stand sequentially from the menu bar, an input form is displayed for generating a natural stand (Figure A.3). Inputs consist of species composition, stand density, age, DBH class, and spatial pattern.

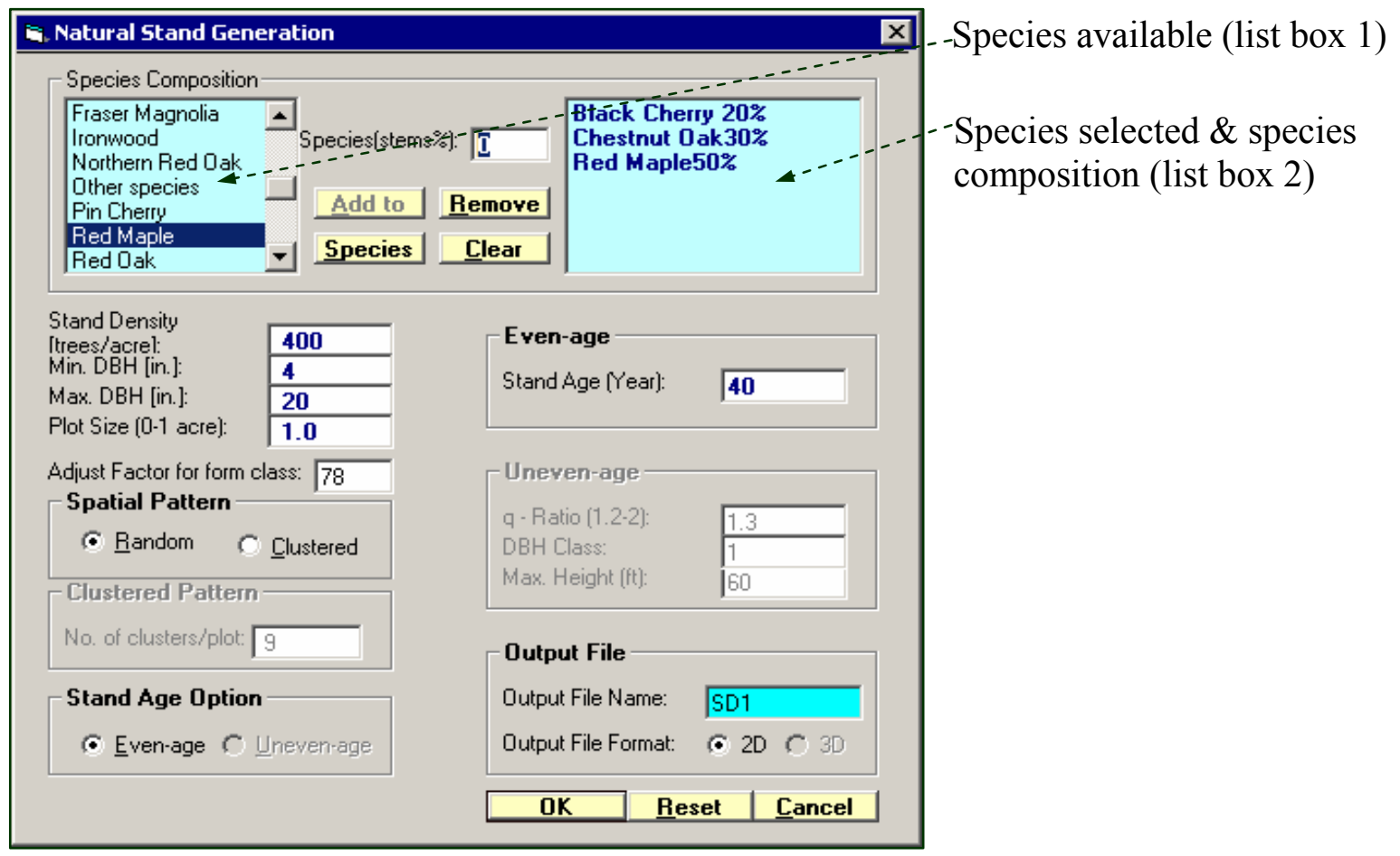

(1) Species Composition: More than thirty tree species available in central Appalachia are listed for selection. Species percentage can be entered by the user or the default values can be used. The default percentage is always the percentage available (100 minus the selected percentage). The species composition can be entered in the following ways:

Input species composition:

- Select the species in list box 1 (the selected item will be highlighted) 
- Enter the species percentage

- Hit "Add to" button (disabled when the selected percentage is 100)

Or just double click the tree species in list box 1 (default species percentage will be used), and then the selected tree species together with the species percentage will appear in list box 2 .

$\underline{\text { Remove selection: }}$

- Select the item in list box 2 (the selected item will be highlighted)

- Hit "Remove" button (disabled when list box 2 is empty)

$\underline{\text { Clear all selections: }}$

- Hit "Clear" button (disabled when list box 2 is empty)

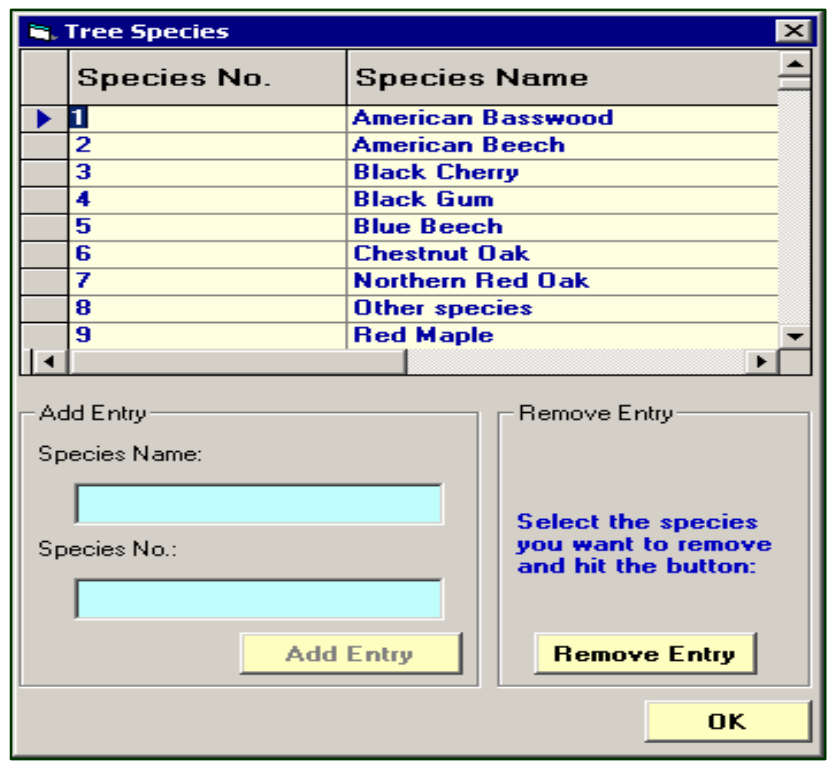

Figure A.4. Edit species.

Edit species:

- Hit "Species" button (Figure A.4) 
- Enter species name and number and hit "Add Entry" button to add species

- Select species and hit "Remove Entry" button to delete species

(2) Stand Density

(3) Min. DBH

(4) Max. DBH

(5) Plot Size

(6) Spatial Pattern

(7) Stand Age

(8) Output File Name
Number of trees per acre.

Minimum DBH class in inches.

Maximum DBH class in inches.

Area of plot in acre, default 0.4 acre.

Spatial generation pattern of stand.

Age of stand in year.

A standard file name.

Default values for these data fields are provided in Figure A.3.

\section{Outputs}

The stand map generated is displayed on the computer screen and saved to an ASCII data file that includes $\mathrm{x}-\mathrm{y}$ coordinates, $\mathrm{DBH}$, height, and volume of each tree in the plot. The distribution of DBH also is displayed on the screen. The output example is shown in Figure A.5 (a). The default stand map is in 2-dimensional format. A 3dimensional format (Figure A.5 (b)) is enabled by clicking Tools|Convert to 3D.

The default DBH distribution in Figure A.5 (a) is for the entire stand. DBH distribution for other species in the stand, however, could be displayed by selecting the species name and hitting the "OK" button. Additionally, the chart type can be changed from bar to line by selecting the desired chart type and hitting the "OK" button. 


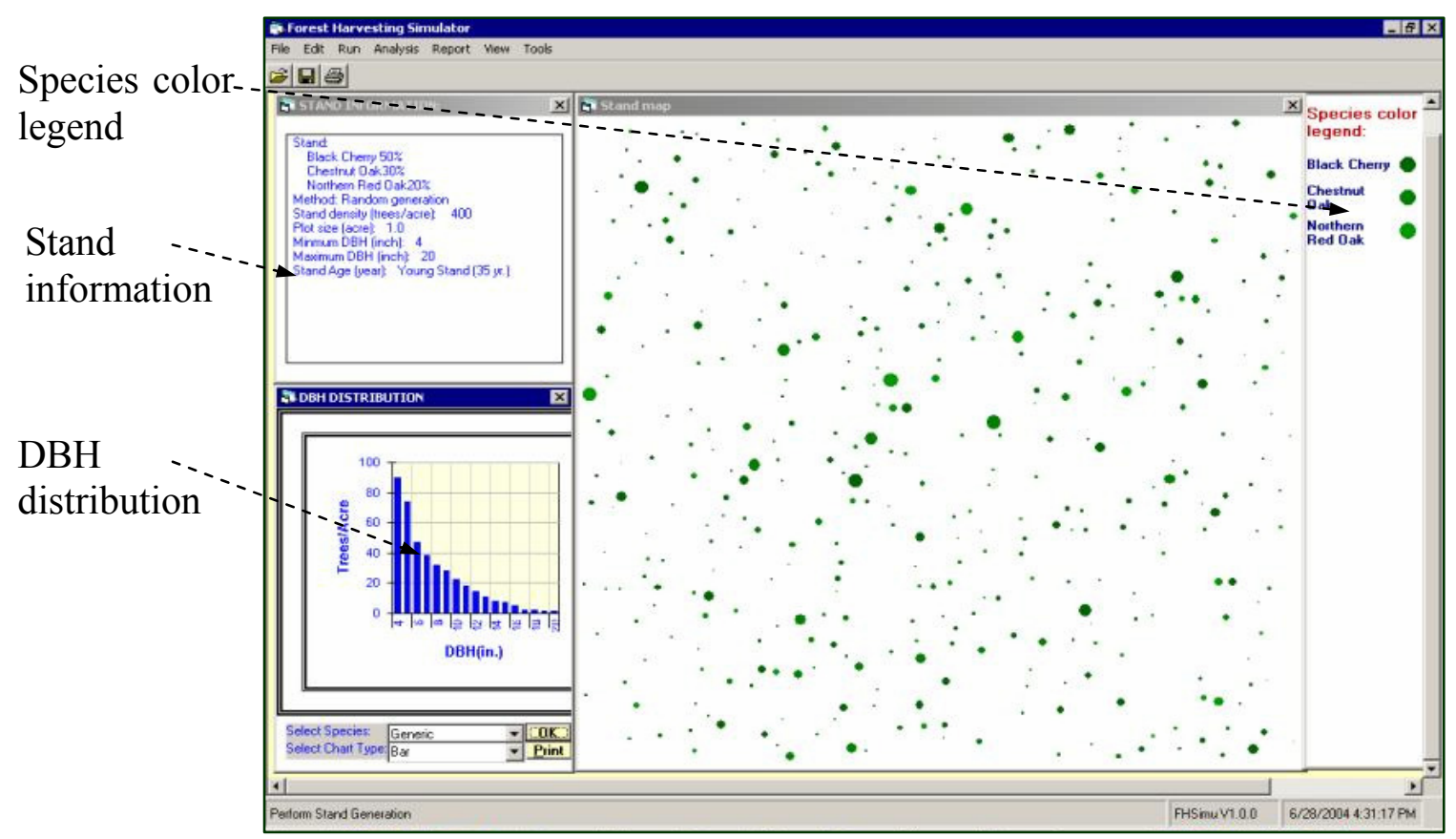

(a)

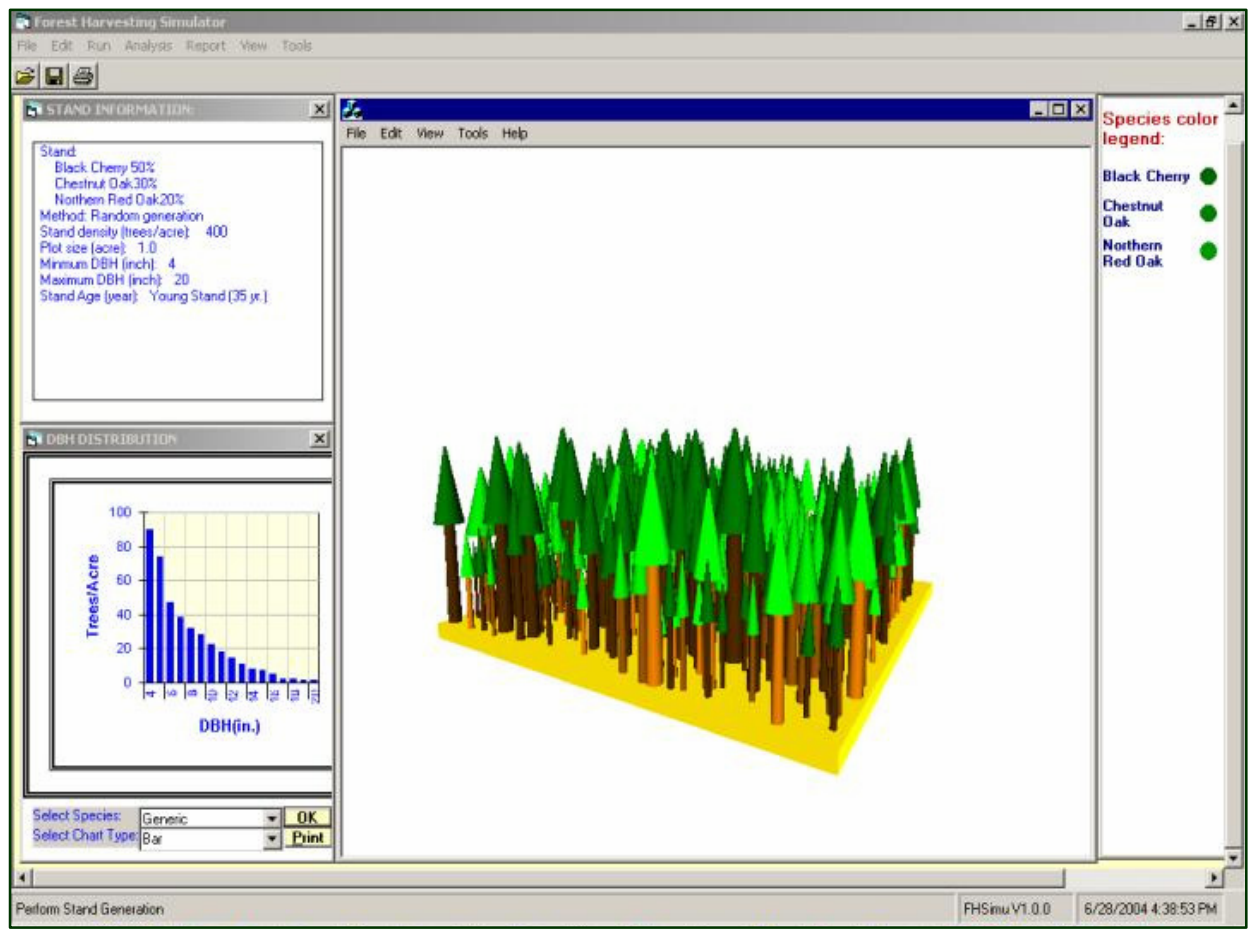

(b)

Figure A.5. Output of a generated stand. 


\section{A.3.2 Felling Simulation}

By clicking "Run|Perform Fell", an input form for felling simulation is displayed on the top of MDI window (Figure A.6).

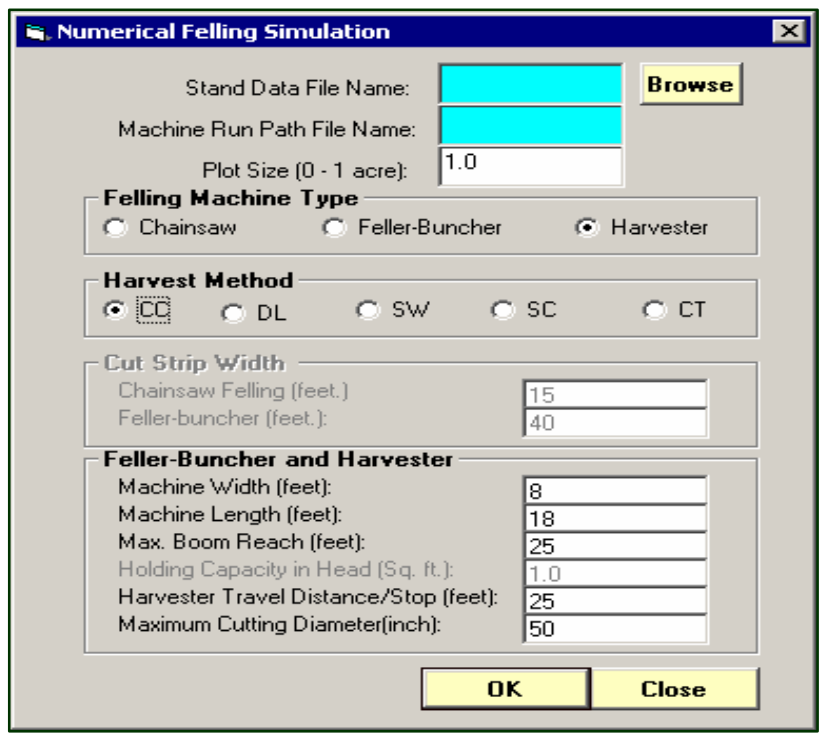

Figure A.6. Inputs for felling simulation.

\section{Input Data Fields}

(1) Stand Data File Name

(2) Machine Run Path File Name

(3) Plot Size

(4) Felling Machine Type

(5) Harvest Method
A generated or mapped stand map file.

A consistent file name for storing machine activities.

$>0$ and $<=1.0$ acre, default 0.4 acre.

Choose one of three options: chainsaw (CS), feller-buncher (FB), or harvester (HV).

Select one of the five options: clear cut (CC), diameter limit cut (DL), shelterwood cut 
(SW), selective cut (SC), or crop tree release $\operatorname{cut}(\mathrm{CT})$.

(6) Cut Strip Width

(7) Machine Width

(8) Machine Length

(9) Max. Boom Reach

(10) Holding Capacity in Head
Width of a swath in feet that a logger with chainsaw and feller-buncher can manage.

Width of machine in feet.

Length of machine in feet.

Maximum boom reach of harvester in feet.

Holding capacity of felling head in $\mathrm{ft}^{2}$.

(11) Harvester Travel Distance/Stop Distance harvester traveled from one stop to another in feet.

Regarding the stand data file name field, the user can either type the stand file name directly in the text box or use the "Browse" button to select the stand file (Figure A.7). A stand file browse window will automatically pop out upon clicking the "Browse"

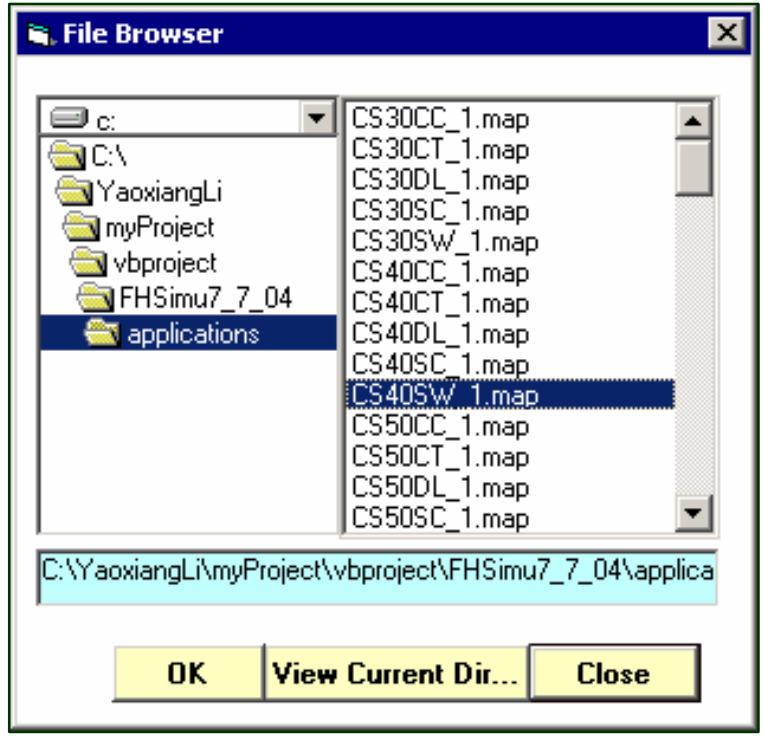

Figure A.7. Stand file browse window. 
button. The user can select the stand file by either single clicking the stand file name and then clicking the "OK" button or double clicking on the stand file name. The user also can view the current working directory by hitting the "View Current Dir..." button.

After inputs, three windows are displayed. The bigger one shows the stand map and the felling simulation. The two smaller windows display machine summaries and machine action commands.

When ending a felling simulation run, two ASCII data files are saved by the system. One is the thinned stand file whose data structure is the same as that used by the stand generator. Another file is the felling machine running path file that records $x-y$ coordinates of machine path, machine action, DBH of the felled tree, number of trees or logs per dump, and cubic feet per dump. These files together with the original stand file are used for later analysis. The felling machine running path file also is used as the input for skidding or forwarding simulation.

\section{Chainsaw Felling}

When chainsaw is selected, the stand map, machine summary, and action window are displayed (Figure A.8). If one of the partial cuts is selected, the "Mark Tree" button is enabled. By clicking on it, the marking tree window is displayed and allows the user to mark the trees to be cut and define the partial cut prescriptions (Figure A.9). Trees can be marked by DBH, height, species, or a user-defined parameter. Click the "Apply" button after selecting the marking rule or rules. If the "Mark" box is selected, another window pops up and allows the user to change the values for tree mark ( 1 for mark, and 0 for unmark) (Figure A.10). by clicking the "Basal area marked" at the bottom of the 
window, basal area marked as a percentage of total basal area and number of trees marked is displayed. Trees selected are marked with yellow circles (Figure A.11). A confirmation message box also is displayed to remind the user to locate a starting point for the logger. Figure A.12 shows the output for chainsaw felling in a diameter limit cut.

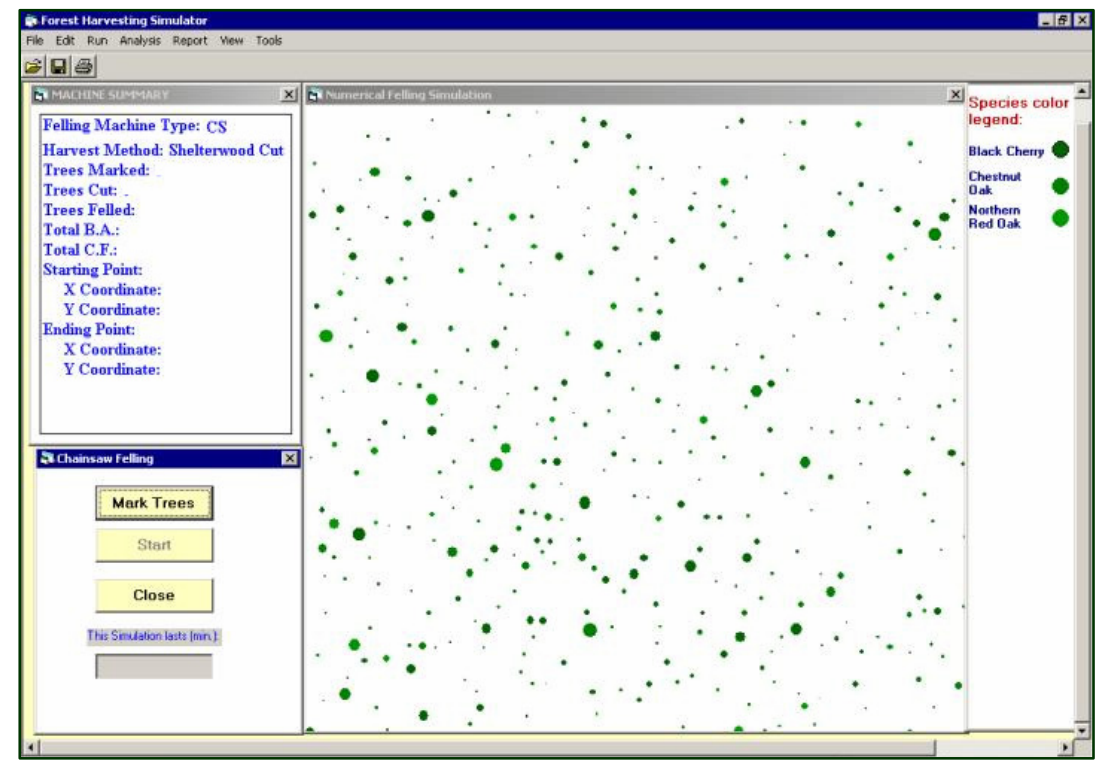

Figure A.8. Chainsaw felling.

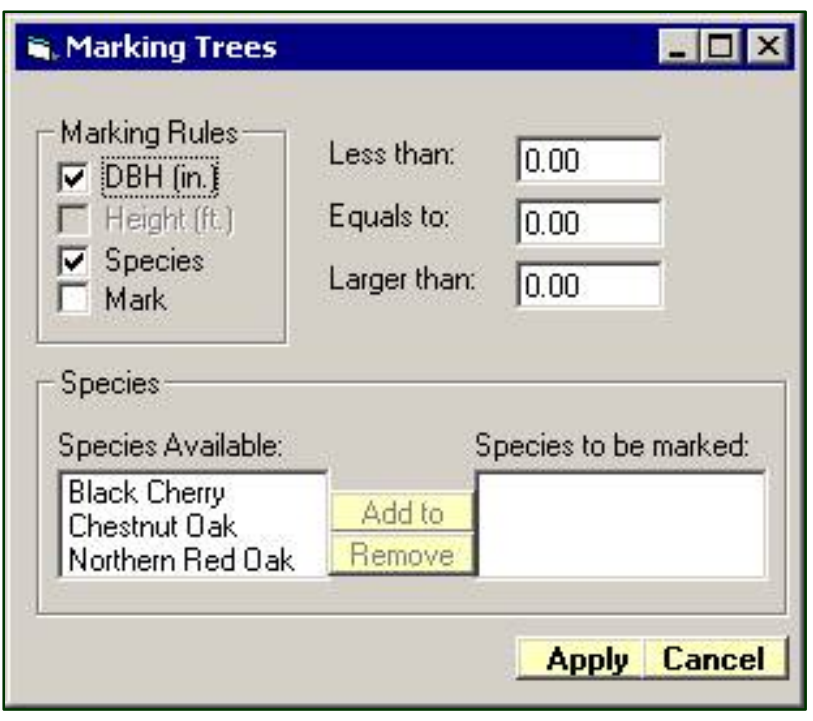

Figure A.9. Select marking rules. 


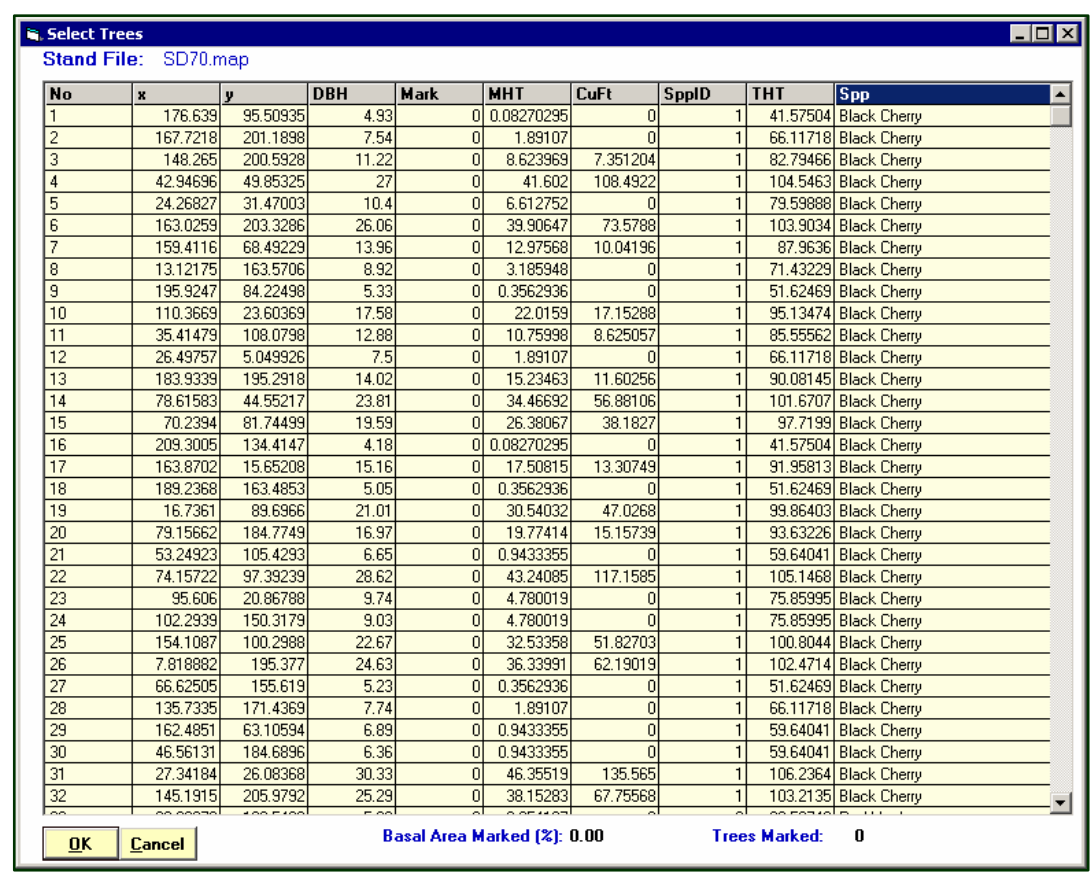

Figure A.10. Mark trees by mark.

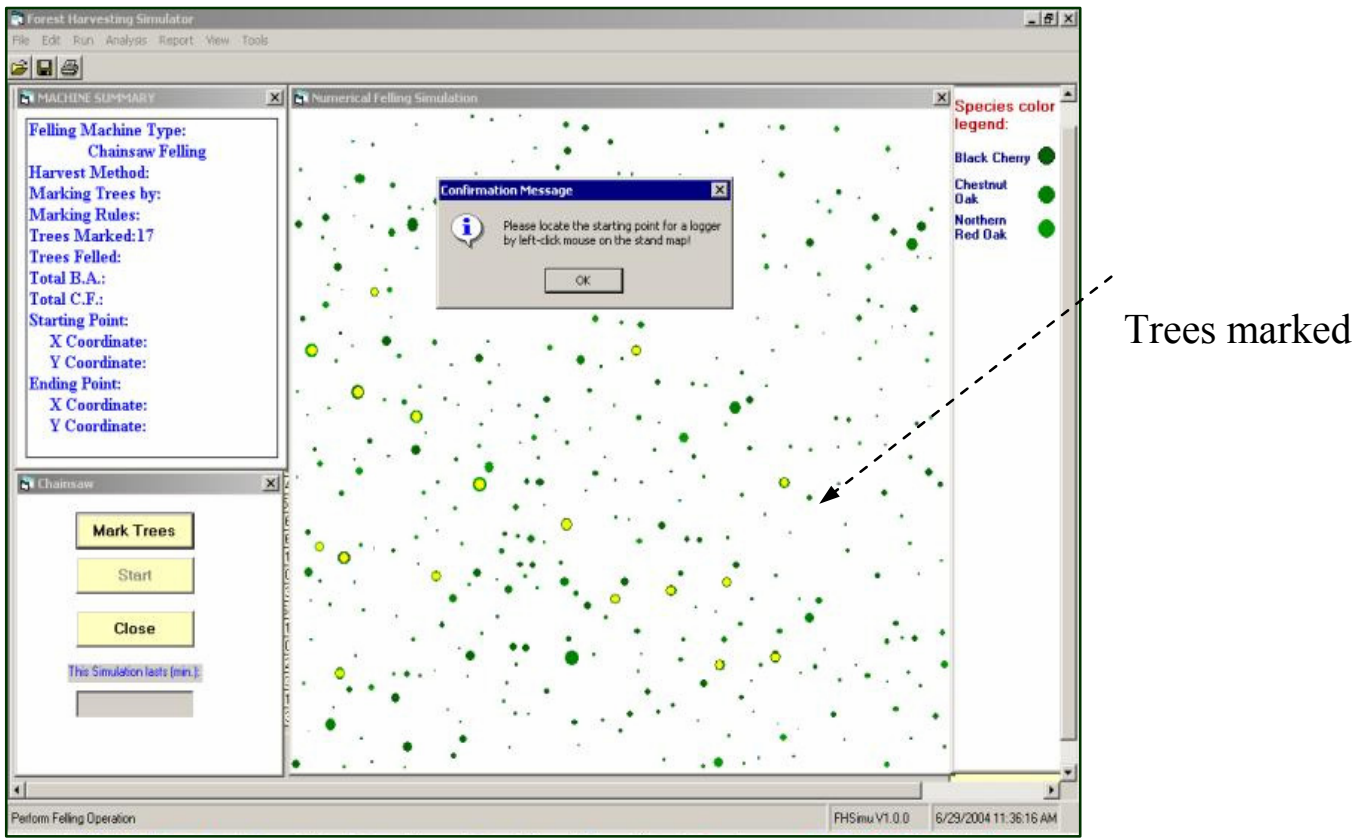

Figure A.11. Trees marked for felling. 


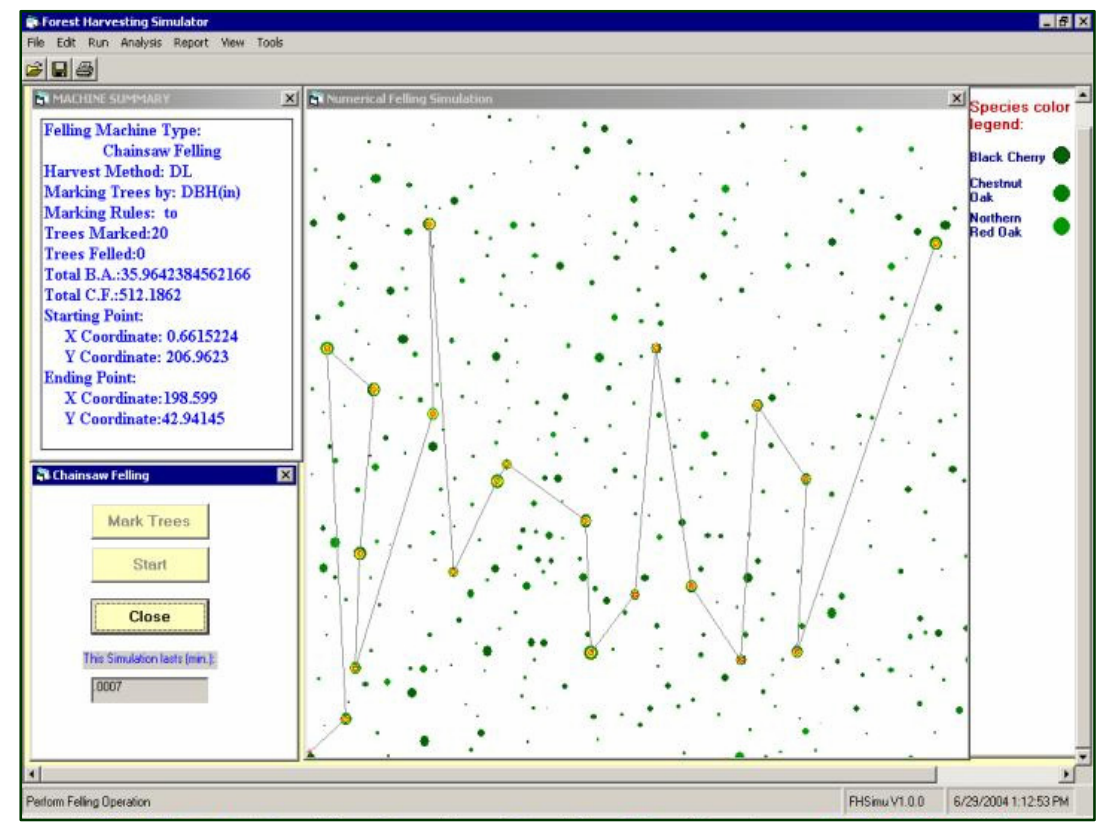

Figure A.12. Chainsaw felling output in diameter limit cut.

Simulation Procedures:

- Input data

- Mark trees to be cut if DL, SW, SC, or CT is selected

- Locate starting position for a logger with a chainsaw

- Press 'Start' button

\section{Feller-Buncher and Harvester Felling}

Similar to chainsaw felling, after locating the starting point for feller-buncher or harvester and pressing 'Start' button, the simulation results are displayed (Figure A.13, A.14). During the simulation process, the rated holding capacity of the felling head of the feller-buncher is examined in terms of butt areas of trees. If the accumulated area of felled trees is over the rated capacity, the tree bunches will be dumped at an appropriate 
location. The smaller blue "+" signs represent the felled tree or log bunches. The maximum felling diameter of the harvester is also checked. If the butt diameter of the tree is larger than the maximum cutting diameter of the harvester, the tree will be left and be felled later by chainsaw.

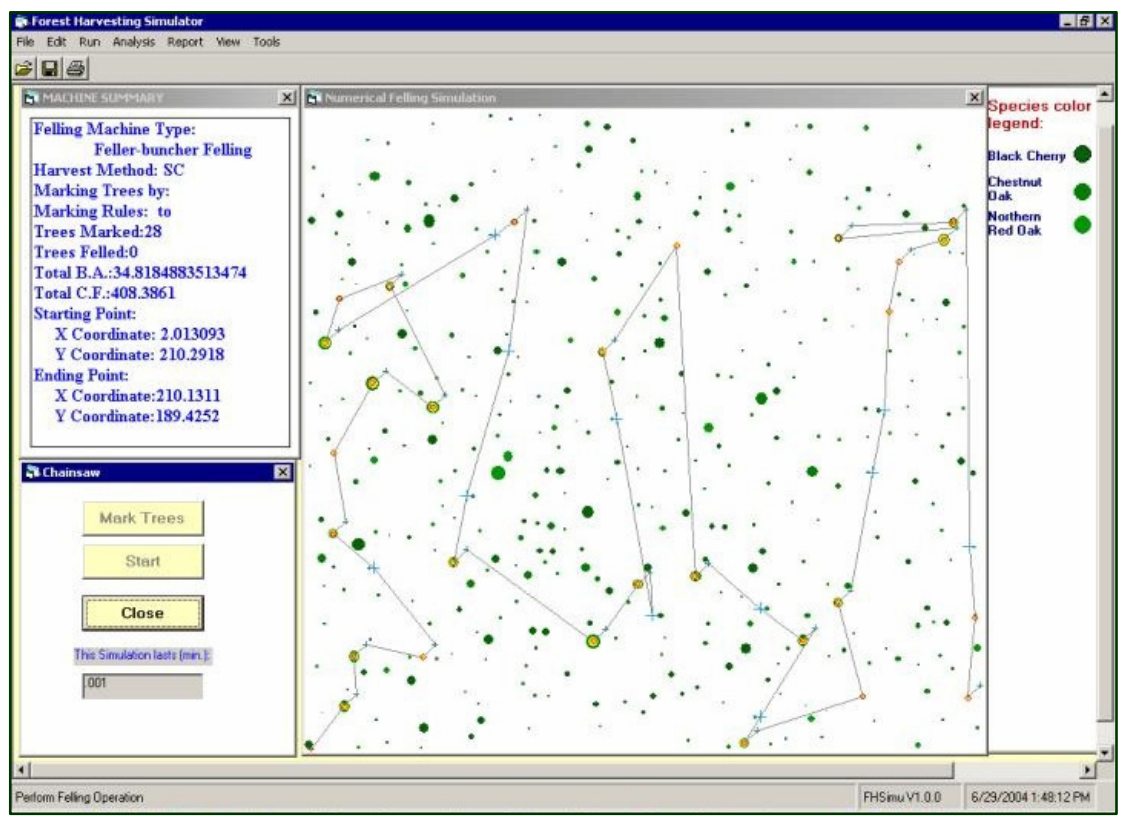

Figure A.13. Feller-buncher felling output in selective cut.

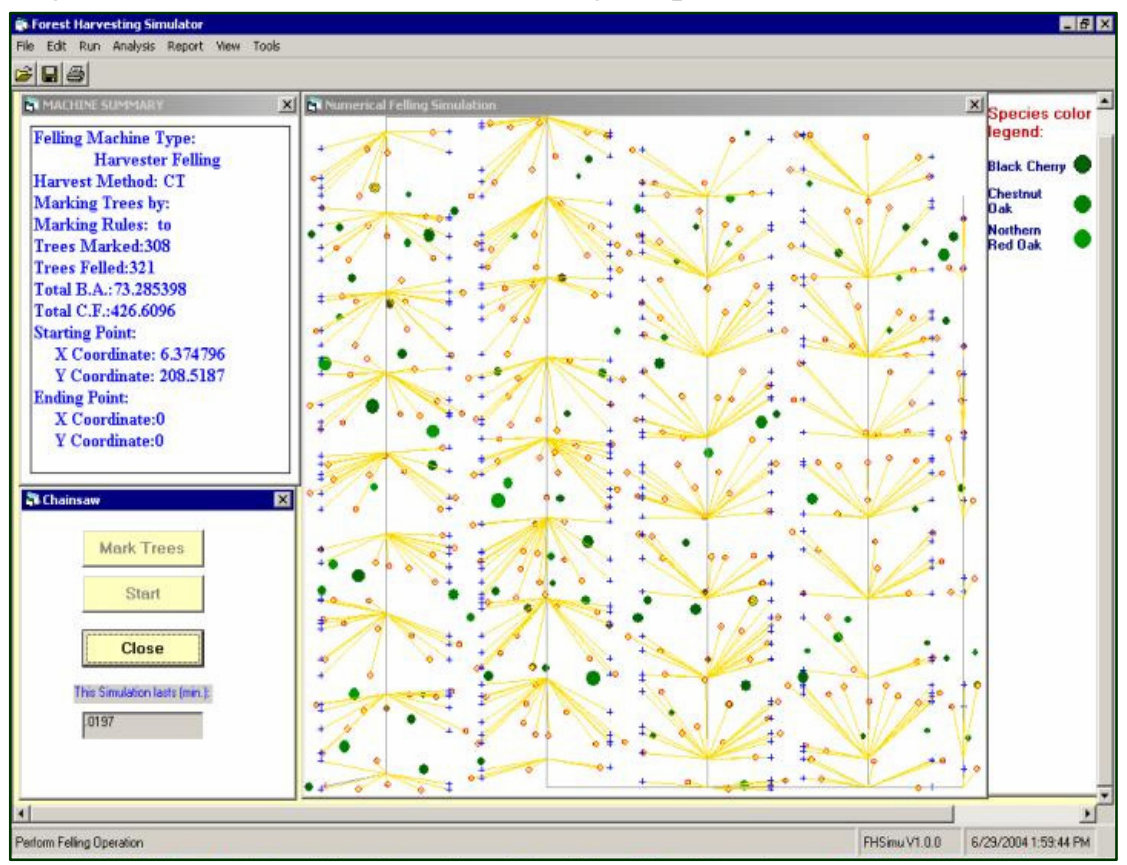

Figure A.14. Harvester felling in a crop tree release cut. 


\section{$\underline{\text { Simulation Procedure: }}$}

- Input data

- Mark trees or define partial cut prescription if applicable

- Locate starting point of the feller-buncher or harvester

- Press "Start" button

\section{A.3.3 Extraction Simulation}

By invoking "Run|Perform Skid/Forward", the input form for extraction simulation is displayed (Figure A.15).

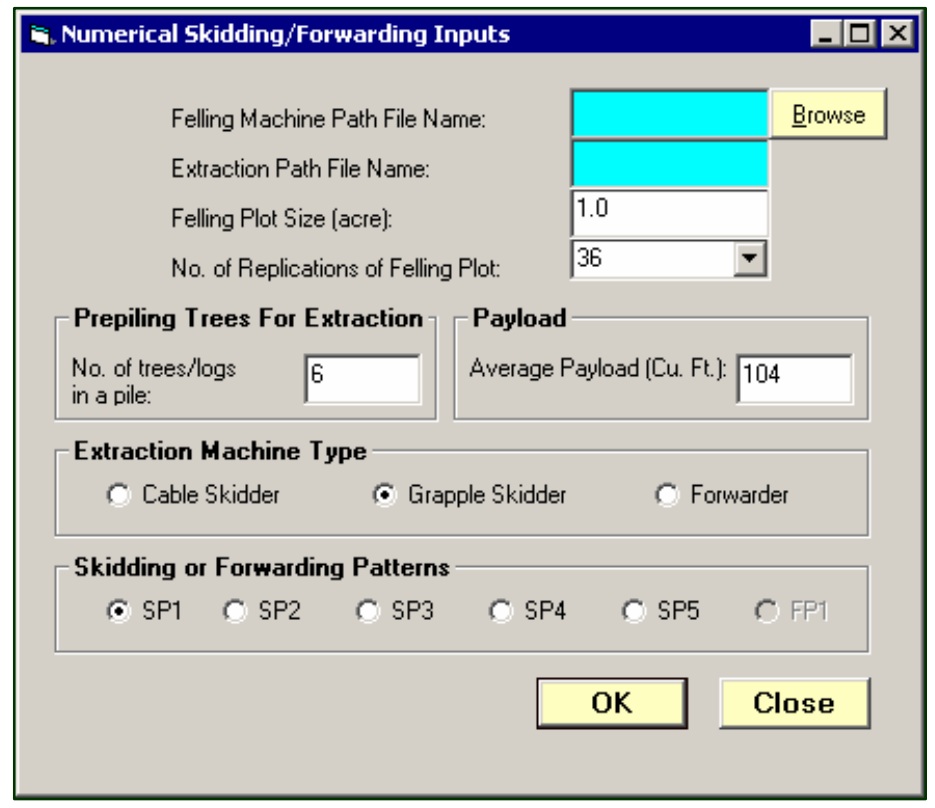

Figure A.15. Inputs for extraction simulation.

The program also allows the user to select the landing location and change the payload size. When ending a skidding or forwarding simulation, two ASCII data file are saved for analysis. One is the skidder or forwarder running path file that records $x-y$ 
coordinates of the machine running path, machine action, trees or logs per turn, and cubic feet per turn. The other file is the skidder or forwarder travel-load intensity that contains a felling grid array plot $(i, j)$, number of passes with the machine loaded, and travel intensity category of each grid (16.5 feet by 16.5 feet).

\section{Input Data Fields}

Inputs consist of felling machine running path file, extraction path file name, felling plot size, number of replications of the felling plot, extraction machine type, number of prebunched trees, extraction pattern, and payload size.

(1) Felling Machine Path File Name

A file created in felling simulation. As with the felling simulation, the file name can be typed or selected by browsing the files.

(2) Extraction Path File Name

A consistent file name used for storing extraction machine activities.

(3) Felling Plot Size Size of felling plot, same as used in the corresponding felling operation.

(4) No. of replications of felling plot

Default 49 . The system allows the user to use 36 , $49,64,81,100$ replications of a felling plot.

(5) Extraction Machine Three extraction machines, cable skidder (CD), grapple skidder (SD) and forwarder (FW) are modeled in the simulation.

(6) No. of Trees Prebunched/Pile Default 6 trees for chainsaw and harvester felling and 3 trees for feller-buncher felling. (7) Payload Payload size of extraction in cubic feet. 
(8) Extraction Pattern

\section{Simulation Procedures}

After inputs, three windows are displayed on the computer screen (Figure A.16).

The bigger one displays the logging site for extraction and the other two smaller windows show the machine summaries and machine actions.

- First locate the position of the landing in the bigger simulation window using the left mouse button. A large red "+" will be drawn to indicate the center point of the landing.

- Click the "Start" button in the action window and all the felled trees or log piles will be extracted to the landing (Figure A.16).

The skidding pattern shown in Figure A.16 is SP4 of the cable skidder. Similar simulation can be performed with the grapple skidder and forwarder with other extraction patterns. 


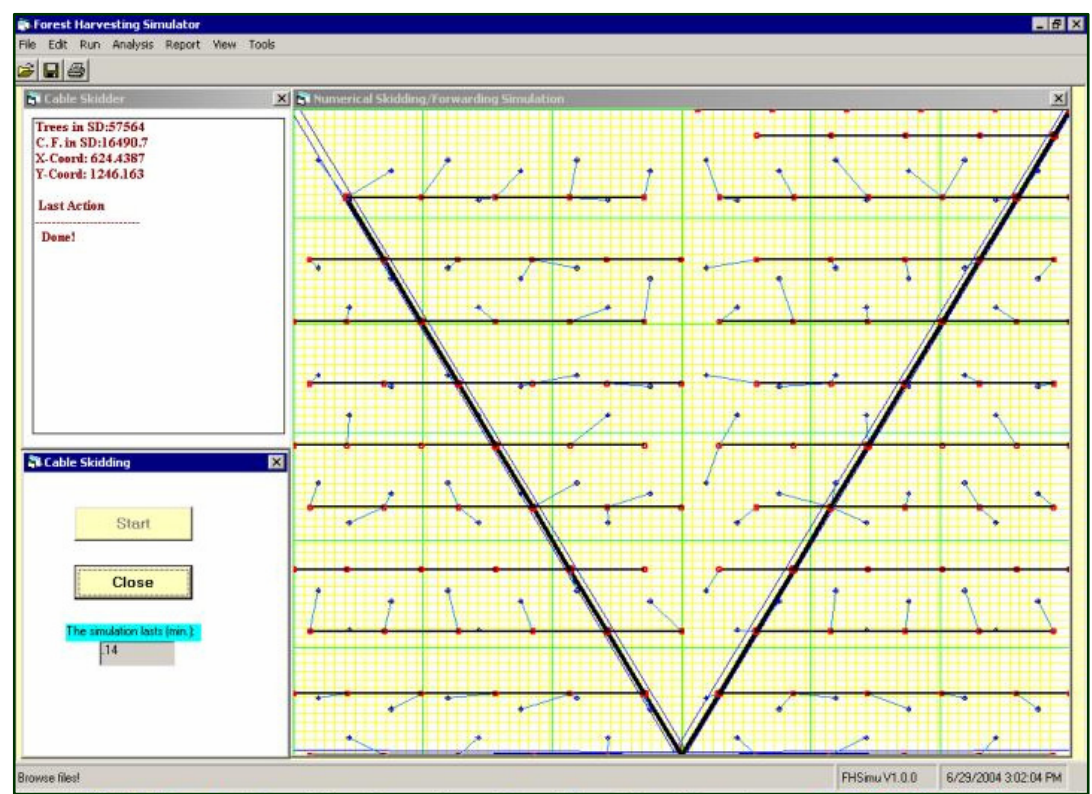

Figure A.16. Cable skidding output with skidding pattern 4 (SP4).

\section{A.4 Simulation Results Analysis}

\section{A.4.1 Stand Data}

The summary of stand data compares the original stand to the residual stand and computes the trees, basal area, and volume removed per acre in partial cuts. This is

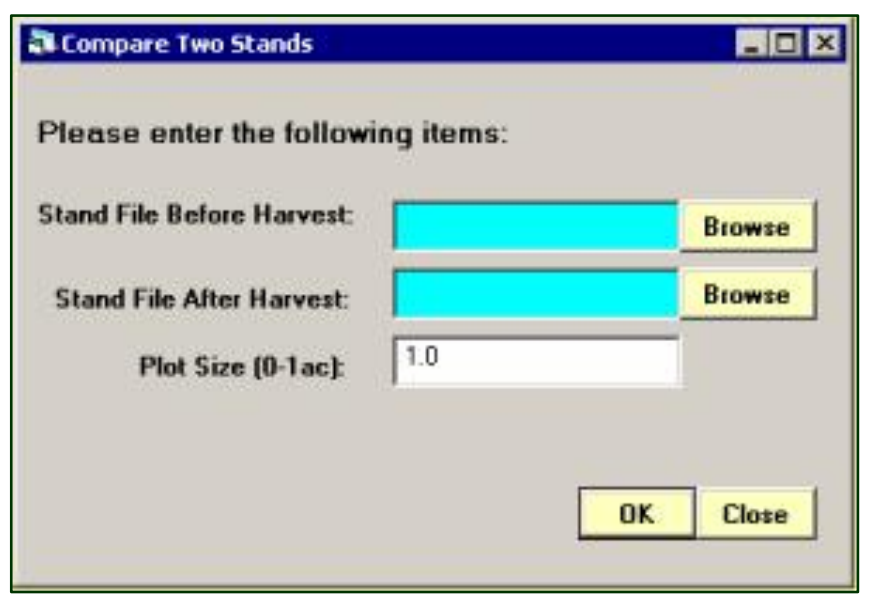

Figure A.17. Inputs for stand summary. 
provided in the stand and stock table format that is used commonly by foresters to report stand information. DBH distribution is provided in a histogram.

By clicking “Analysis|Stand Data|Two Stands Comparison”, the input form is shown (Figure A.17).

After selecting the stands to be compared and hitting the "OK" button, a summary window is displayed, which contains the stand and stock tables and DBH distributions for the two stands (Table A.18). The results can be exported to Microsoft Excel spreadsheet by clicking the "Export" button or saved to Microsoft Access and displayed as a report by clicking the "Report" button. When the "Close" button is selected, a dialog box pops up reminding the user to save the results to a database. By selecting "OK", the results are saved to Microsoft Access for later use.

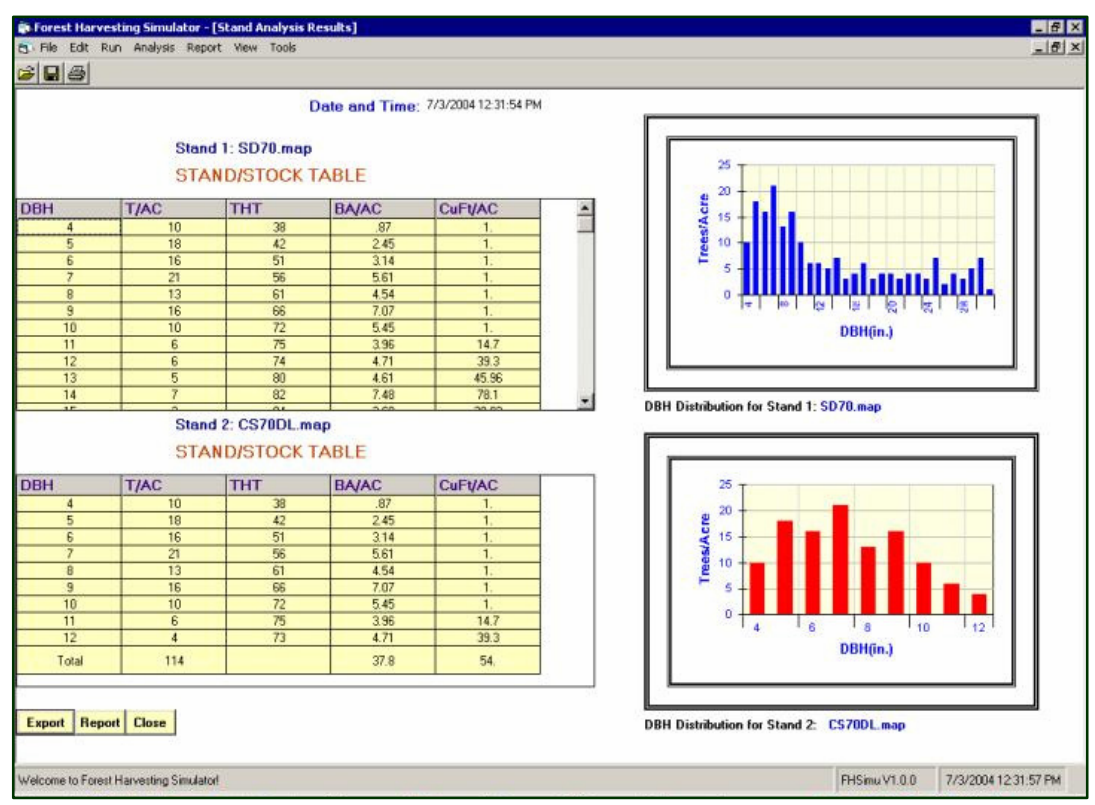

Figure A.18. Output of stand comparison. 


\section{A.4.2 Felling Operations}

By clicking "Analysis|Felling Operations" from the menu bar, the input form is shown (Figure A.19).

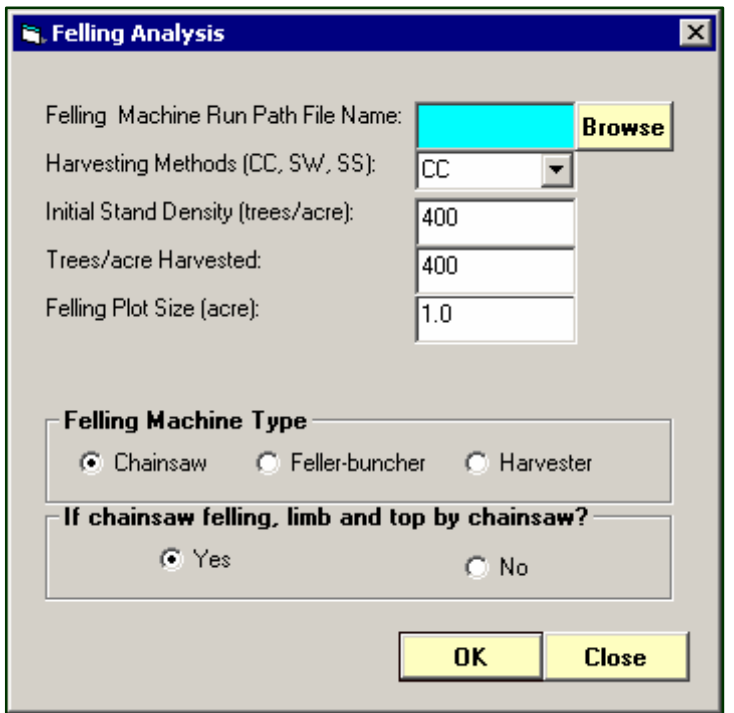

Figure A.19. Inputs for felling operation analysis.

\section{Input Data Fields}

(1) Felling Machine Run

Path Name

(2) Harvesting Method

(3) Initial Stand Density

(4) Tree/acre Harvested

(5) Felling Plot Size

(6) Felling Machine Type
A file created in felling simulation

CC - Clearcut: $\mathrm{CT}$ - crop tree release cut;

DL - diameter limit cut; SC - selective cut ;

SW - Shelterwood cut

Trees per acre of a stand before harvest.

Harvest intensity.

Same as used in felling simulation, default 0.4 acre.

Chainsaw (CS), Feller-buncher (FB), and Harvester 
(7) Limb and Top by Chainsaw Only used for chainsaw felling.

\section{Machine Rate Calculation}

After finishing the inputs in Figure A.19, most parts of analysis are done. The next question asked is whether the cost of this machine is to be calculated. This calculation is based on the machine rate method. If the answer is "yes", the input form for cost calculation will be shown (Figure A.20).

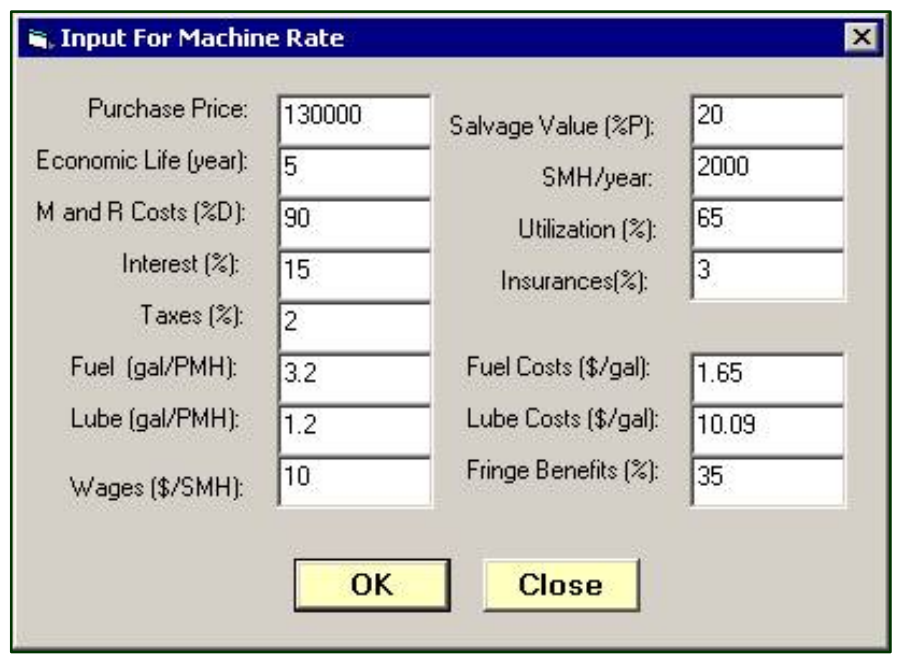

Figure A.20. Machine rate calculation.

The following data fields are required for machine rate calculations:

Purchase Price Purchase price of the machine in dollars.

Economic Life Usually 3 to 5 years.

Salvage Value $\quad$ Percentage of purchase price.

SMH/year Scheduled machine hours a year, 2000 for default.

$\mathrm{M}$ and $\mathrm{R}$ Cost $\quad$ Maintenance and repair cost, percentage of depreciation.

Utilization Ratio of productive machine hour (PMH) over scheduled machine hour. 
Interest

Insurance

Tax

Fuel

Fuel Costs

Lube

Lube Costs

Wages

Fringe Benefits
Assumed percentage of AVI (annual value of investment).

Assumed percentage of AVI.

Assumed percentage of AVI.

Fuel consumption, gal/PMH.

Dollars per gallon.

Lubricant consumption, gal/PMH.

Dollars per gallon.

Wages per SMH.

Percentage of wages/SMH.

\section{Analysis Results}

After completing all the inputs, a summary are provided (Figure A.21), which includes:

- An elemental time summary;

- A summary by work cycle;

- A summary of harvested stand or logging site; and

- A production summary. 


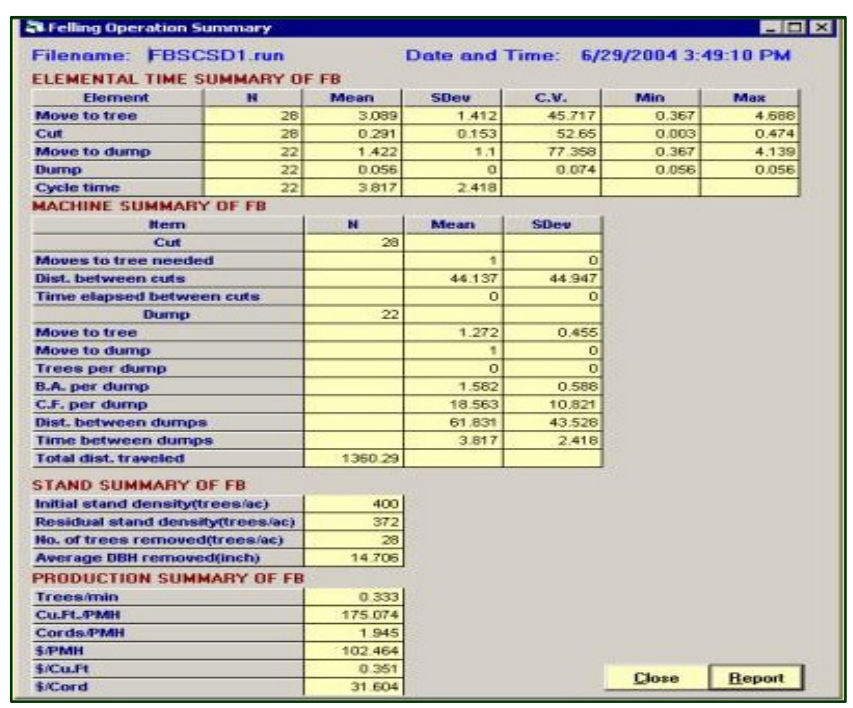

Figure A.21. Results of felling operations.

The results can be exported to Microsoft Excel, saved to Microsoft Access database, or displayed in report format.

\section{A.4.3 Extraction Operations}

Extraction operations can be analyzed by clicking "Analysis|Extraction Operations". The input form is as shown in Figure A.22.

Input data fields include:

(1) Skidding Machine Path File Name

(2) Skidder/Forwarder

(3) No. of Replication of Felling Plot

(4) No. of Bunches in a Pile
A file created in skidding or forwarding simulation.

$\mathrm{SD}$ - skidder, FW - forwarder.

For creating a larger extraction area, default 49.

Six trees for chainsaw and harvester felling, three trees for feller-buncher felling. 


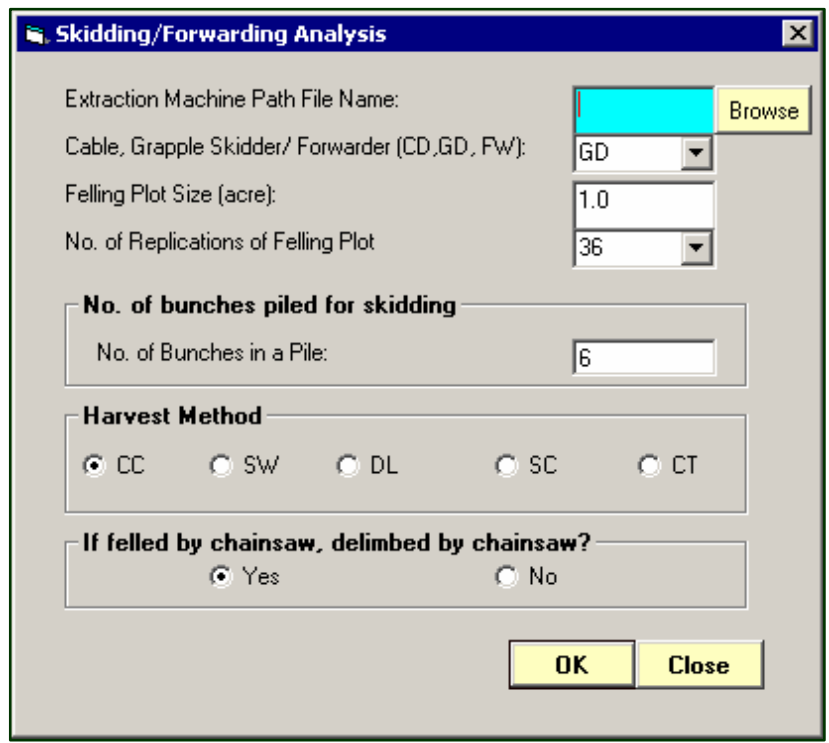

Figure A.22. Inputs for extraction operation analysis.

(5) Harvest Method

(6) Delimbed by Chainsaw
CC - Clearcut: CT - crop tree release cut;

$\mathrm{DL}$ - diameter limit cut; SC - selective cut ;

SW - Shelterwood cut

Only used for chainsaw felling.

The same input form of Figure A.20 is displayed if cost calculations are needed.

After inputs, the summary for an extraction machine is shown (Figure A.23).

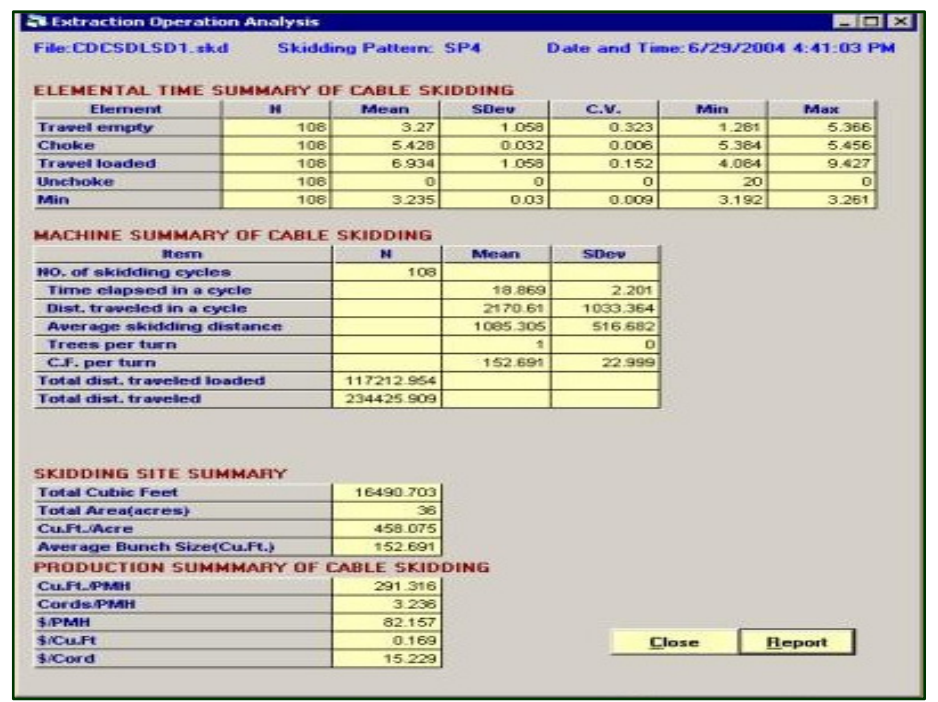

Figure A.23. Analysis results for extraction operations. 


\section{A.4.4 Travel Intensity}

By clicking the "Skid/Forward TI" under "Analysis", the travel intensity summary provides the proportion and area of each travel intensity category in the logging site (Figure A.24). The travel intensity categories are summarized on a grid level (16.5 feet by 16.5 feet). The traffic intensity level also can be viewed by clicking the "View|Skid/Forward TI" (Figure A.25).

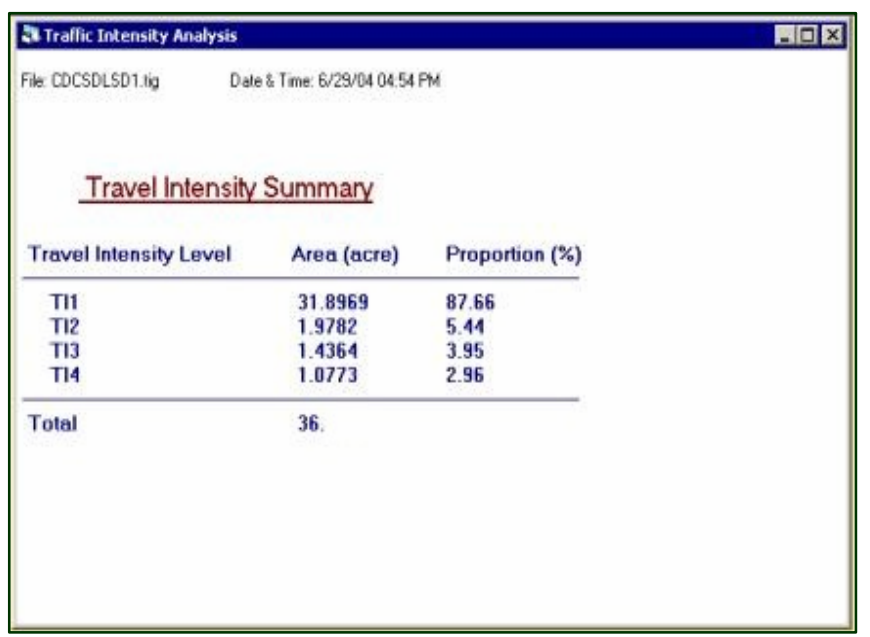

Figure A.24. Summary of travel intensity in a logging area of 36 acres after felling and extraction operations. 


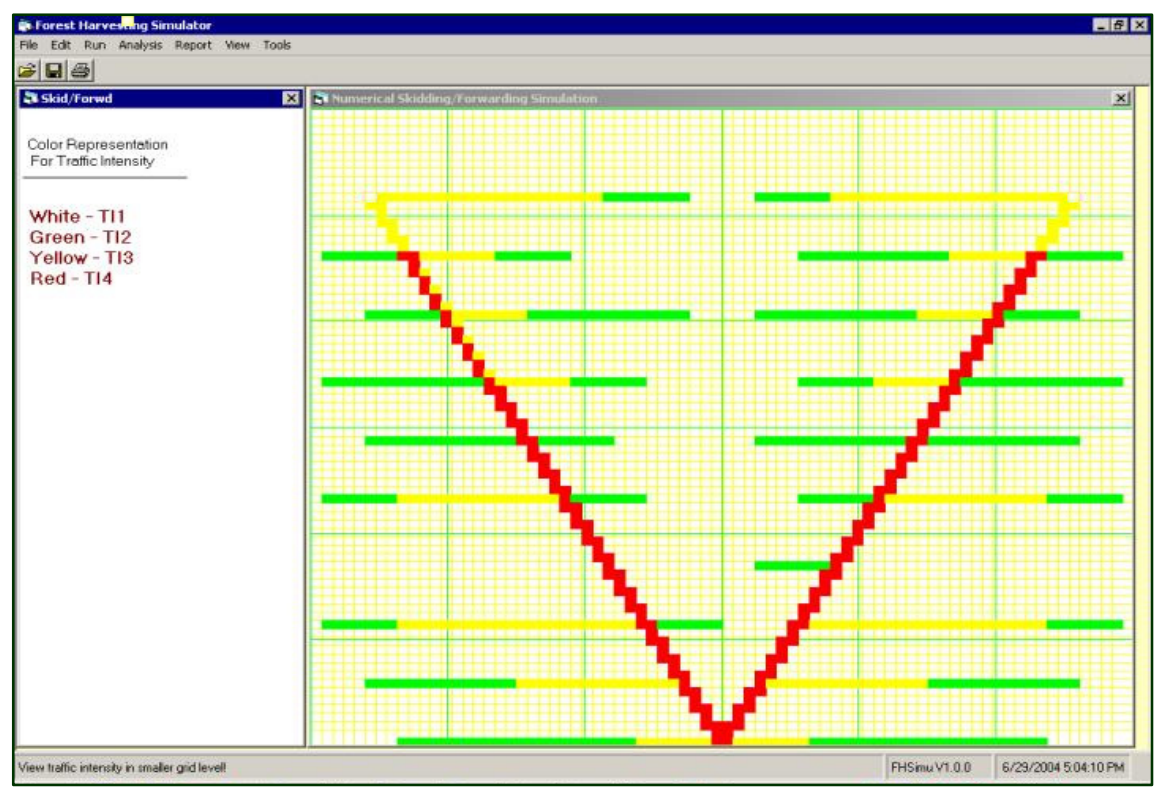

Figure A.25. Traffic intensity levels.

\section{A.5 Generate Report}

A report can be generated by clicking "Report|Stand Summary" (Figure A.26).

Similarly, the felling and extraction operation summary reports can be generated by clicking "Felling Summary" or "Extraction Summary" under "Report".

\section{Data Field}

\section{Data Field for Stand Summary}

(1) Name Stand file name

(2) TP

Stand density (trees per acre)

(3) $\mathrm{MeanDBH}$

Average DBH of the stand summarized

(4) $\mathrm{MinDBH}$

Minimum DBH in the stand summarized

(5) $\mathrm{MaxDBH}$

Maximum DBH in the stand summarized

(6) MeanTHT

Average total height of the stand summarized 


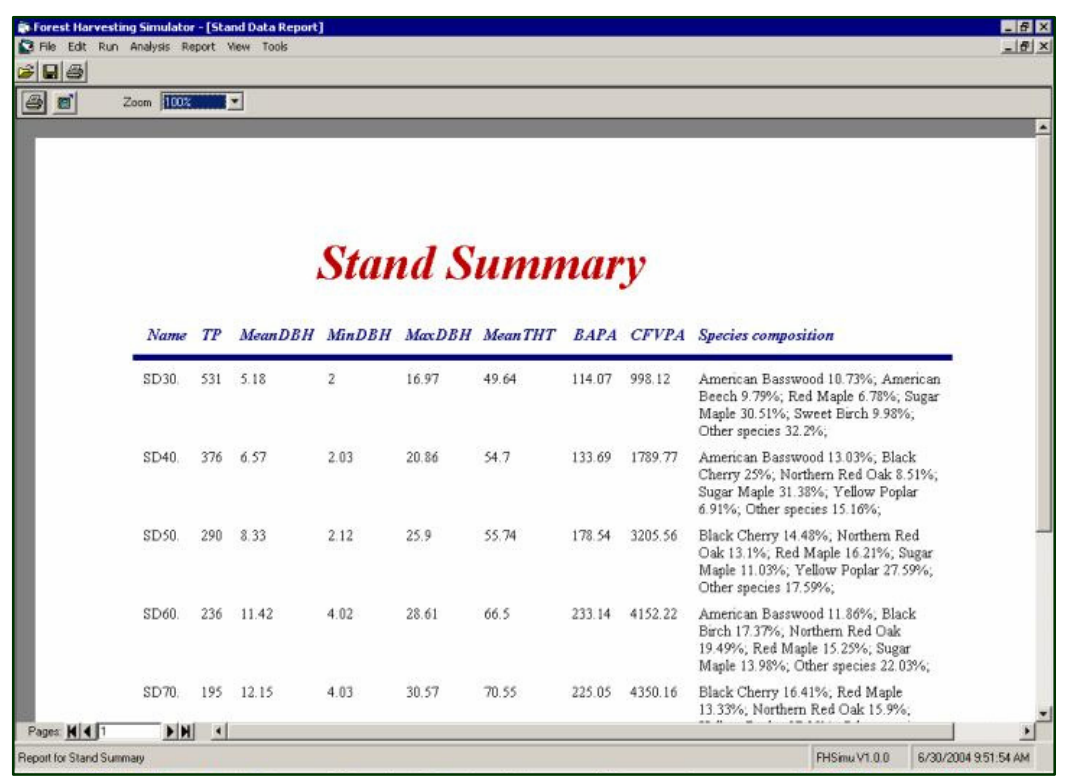

Figure A.26. Report for stand summary.

(7) BAPA Basal area per acre $\left(\mathrm{ft}^{2} /\right.$ acre $)$

(8) CFVPA Volume per acre $\left(\mathrm{ft}^{3} / \mathrm{acre}\right)$

(9) Species Composition Stem percentage (\%) of each individual species in the stand summary

\section{Data Field for Felling Operation Summary}

(1) Stand Stand file used for the felling operation simulation

(2) Felling Felling machine running path file name

(3) Machine Felling machine type

CS - chainsaw

FB - feller-buncher

HV - harvester

(4) Harvest

Harvest method (CC, CT, DL, SC, SW) used for the felling operation 
(5) Trees/min

(6) Cycletime

(7) DBHRemoved

(8) $\mathrm{CuFt} / \mathrm{PMH}$

(9) Cords/PMH

(10) $\$ / \mathrm{PMH}$

(11) $\$ / \mathrm{CuFt}$
Number of trees felled per minute

Time elapsed per felling cycle (min.)

Average DBH of the felled trees (in.)

Felling productivity, cubic feet volume processed per

productive machine hour $\left(\mathrm{ft}^{3} / \mathrm{PMH}\right)$

Volume (Cords) processed per productive machine hour

Felling machine hourly cost in U.S. dollars

Machine unit cost $\left(\$ / \mathrm{ft}^{3}\right)$

\section{Data Field for Extraction Operation Summary}

(1) Extraction

(2) Machine

(3) Pattern

(4) CycleTime

(5) AED

(6) Payload

(7) $\mathrm{CuFt} / \mathrm{PMH}$

(8) $\$ / \mathrm{PMH}$
Skidding/forwarding machine running path file name

Extraction machine

CD - cable skidder

GD - grapple skidder

$\mathrm{FW}$ - forwarder

Skidding/forwarding pattern (SP1, SP2, SP3, SP4, SP5, and FP1)

Time elapsed per skidding/forwarding cycle (min.)

Average extraction distance (ft.)

Machine turn payload $\left(\mathrm{ft}^{3}\right)$

Extraction productivity, cubic feet volume

skidded/forwarded per productive machine hour ( $\left.\mathrm{ft}^{3} / \mathrm{PMH}\right)$

Extraction machine hourly cost in U.S. dollars 


\section{Table Relationships}

Structured Query Language (SQL) is used to query the database and generate the report. The relationships among tables are shown in Figure A.27.

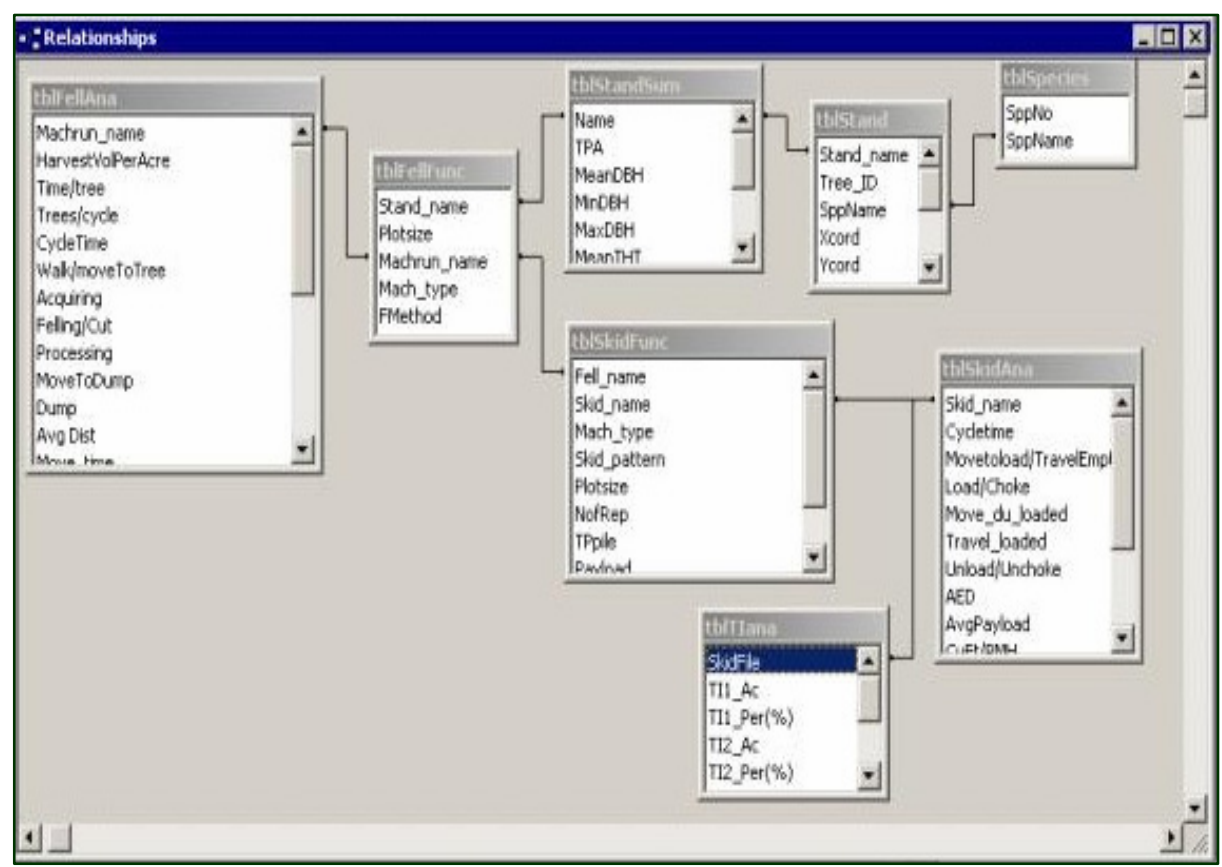

Figure A.27. Table relationships in the database.

\section{Export Report}

The generated reports can be exported by clicking “Tools|Export Report”. A dialog box pops up, which allows the user to select the directory and export format either text or html (Figure A.28, A.29). 


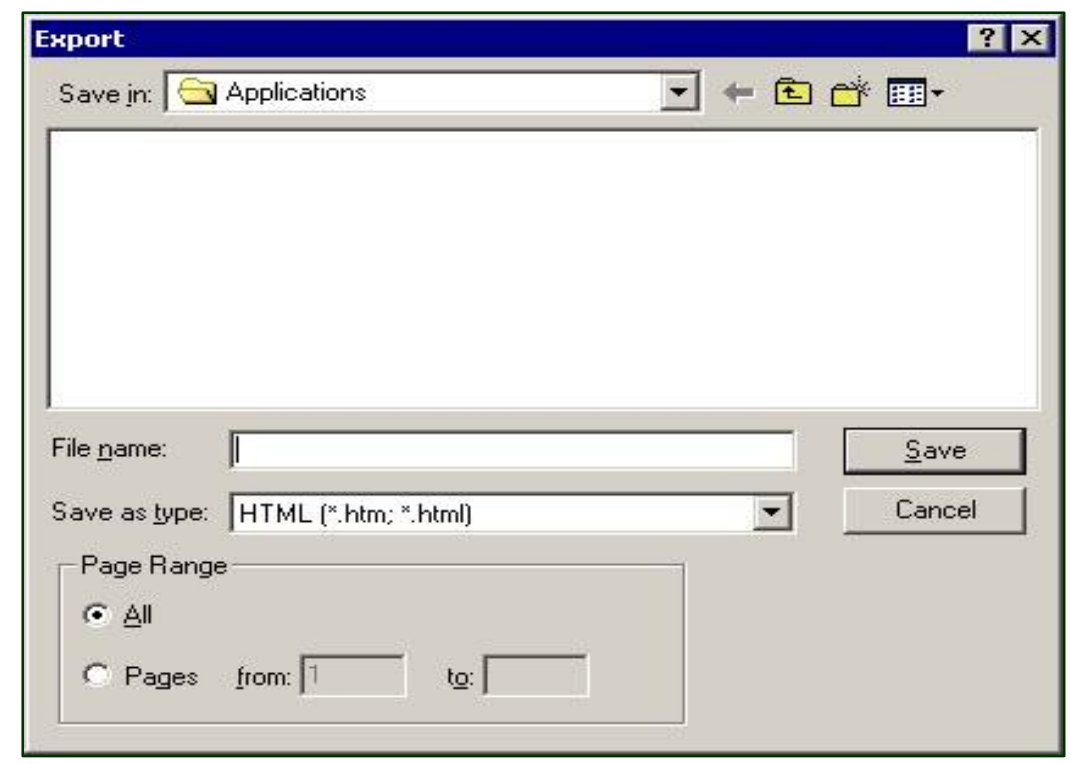

Figure A.28. Export report.

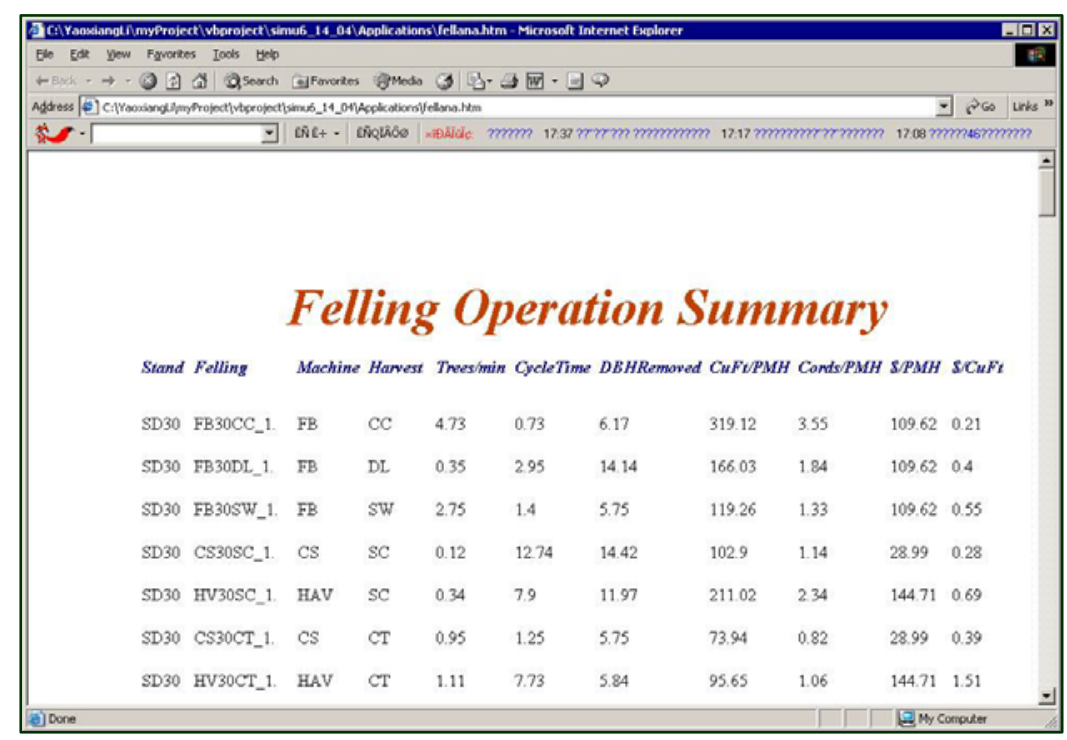

Figure A.29. Report exported in html format. 